\title{
Perspective
}

Subscriber access provided by University of East Anglia Library

\section{Thirty years of HDAC inhibitors: 2020 hindsight}

Terence Ho, Alex Chan, and A. Ganesan

J. Med. Chem., Just Accepted Manuscript • DOI: 10.1021/acs.jmedchem.0c00830 • Publication Date (Web): 01 Jul 2020

Downloaded from pubs.acs.org on July 6, 2020

\section{Just Accepted}

"Just Accepted" manuscripts have been peer-reviewed and accepted for publication. They are posted online prior to technical editing, formatting for publication and author proofing. The American Chemical Society provides "Just Accepted" as a service to the research community to expedite the dissemination of scientific material as soon as possible after acceptance. "Just Accepted" manuscripts appear in full in PDF format accompanied by an HTML abstract. "Just Accepted" manuscripts have been fully peer reviewed, but should not be considered the official version of record. They are citable by the Digital Object Identifier (DOI®). "Just Accepted" is an optional service offered to authors. Therefore, the "Just Accepted" Web site may not include all articles that will be published in the journal. After a manuscript is technically edited and formatted, it will be removed from the "Just Accepted" Web site and published as an ASAP article. Note that technical editing may introduce minor changes to the manuscript text and/or graphics which could affect content, and all legal disclaimers and ethical guidelines that apply to the journal pertain. ACS cannot be held responsible for errors or consequences arising from the use of information contained in these "Just Accepted" manuscripts. 


\section{Thirty years of HDAC inhibitors: 2020 hindsight}

Terence C. Hot, Alex H. Y. Chan", A. Ganesan*

School of Pharmacy, University of East Anglia, Norwich NR4 7TJ, United Kingdom

${ }^{*}$ Orcid ID/0000-0003-4862-7999

†Present Address: Norwich Medical School, University of East Anglia, Norwich NR4

7TJ, United Kingdom

TPresent Address: Department of Chemistry, University of Cambridge, Lensfield Road, Cambridge CB2 1EW, United Kingdom

KEYWORDS. enzyme inhibitors, metalloenzymes, amidohydrolases, epigenetics,

histone deacetylases 


\begin{abstract}
It is now thirty years since the first report of a potent zinc-dependent histone deacetylase (HDAC) inhibitor appeared. Since then, five HDAC inhibitors have received regulatory approval for cancer chemotherapy, while many others are in clinical development for oncology as well as other therapeutic indications. This perspective reviews the biological and medicinal chemistry advances over the last three decades with an emphasis on the design of selective inhibitors that discriminate between the eleven human HDAC isoforms.
\end{abstract}

\title{
Introduction
}

The human genome contains a modest number of 20,000-25,000 genes coded by only $5 \%$ of its DNA sequence. However, it is not the case that 'one gene $=$ one protein', as processes such as mRNA editing lead to a transcriptome that is several-fold higher than the number of genes. A further expansion occurs after protein synthesis through the post-translational modification (PTM) of amino acid side chains. The majority of PTMs 
are dynamic in nature, enabling a single protein to exist in multiple functional states and move from one state to another in a reversible manner. The $\varepsilon$-amino side chain of lysine, in particular, is the conduit for a plethora of PTMs (Figure 1) via alkylation or acylation reactions. ${ }^{1,2}$ Alkylation increases the size of the lysine side chain while preserving its positively charged nature at physiological $\mathrm{pH}$, whereas acylation results in neutral or even negatively charged side chains ranging from the addition of a single carbon in formylation to the conjugation of proteins such as ubiquitin. Two of these processes, acetylation and methylation, occur in the lysine-rich $\mathrm{N}$-terminal tails of histone proteins where they play a central role in the epigenetic regulation of chromatin structure and the recruitment of its binding partners to modulate gene transcription. Consequently, the enzymes involved in lysine acetylation and methylation and their removal have become important targets for small molecule drug discovery. ${ }^{3}$ At the present time, five inhibitors of lysine deacetylation, and one of lysine methylation, have received regulatory approval as anticancer agents. This year marks the 30th anniversary of the disclosure of the natural product trichostatin A as the first potent inhibitor of histone deacetylation. In this perspective, we summarize the progress since 


\begin{abstract}
then regarding the biology of lysine deacetylase enzymes, the compounds currently in clinical development against this target and the discovery of isoform selective inhibitors.

Previous reviews in this journal provide a snapshot of the state of the art at earlier time points. ${ }^{4,5}$
\end{abstract}




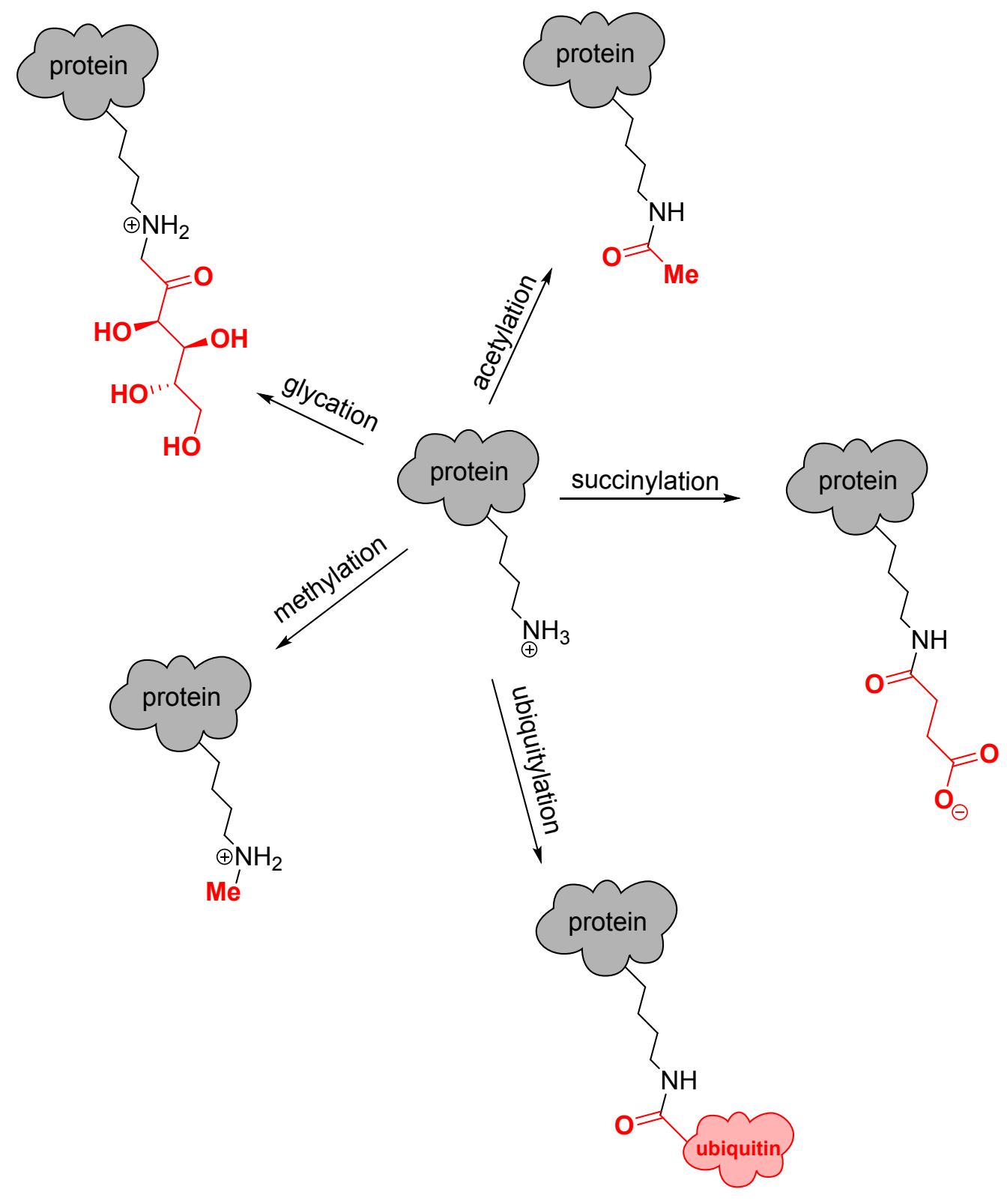

Figure 1. Examples of lysine post-translational modification in proteins.

Lysine acetylation was first observed in the early 1960s in histones due to the abundance of the PTM in these proteins. Soon thereafter, enzymes that catalyze the 
forward acetylation reaction and the reverse deacetylation reaction were discovered and logically named histone acetyltransferases (HATs) and histone deacetylases (HDACs) respectively. Unfortunately, this historical nomenclature is well entrenched despite its inaccuracy, as we now know that lysine acetylation is not restricted to histones but a widespread PTM in thousands of human proteins present in diverse cellular compartments. ${ }^{6}$ The PTM is produced via the transfer of an acetyl group from acetyl CoA to a lysine residue, either by a reaction catalyzed by HATs or through an enzymefree process. Acetylation can dramatically alter the biological properties of a protein (Table 1) as well as being the chemical signal for recognition by bromodomains, a protein-protein interaction subunit found in transcriptional activators. ${ }^{7}$ Meanwhile, a variety of other acyl CoA species undergo a similar reaction with lysine residues in vivo to create distinct PTMs. ${ }^{8}$ These include short and medium-chain saturated carboxylic acids such as formic, propionic, butyric and myristic; short-chain dicarboxylic acids such as malonic, succinic and glutaric; and carboxylic acids with additional functionality such as 2-hydroxyisobutyric, crotonic, phosphoglyceric, lipoic and biotin. Although the precise physiological roles of many of these recently discovered acyllysine PTMs are yet to be 
deciphered, the inadequacy of the nomenclature's emphasis on histone proteins and acetylation is apparent.

\begin{tabular}{|l|l|}
\hline Acetylation consequence & Examples \\
\hline Reduced nucleic acid binding & Histone-DNA, E2F-DNA \\
\hline Increased protein binding & Histone-PCAF, Histone-BRD4 \\
\hline Reduced protein binding & Hsp90-GR, Ku70-p23 \\
\hline Increased stability & p53, $\alpha$-tubulin \\
\hline Decreased stability & DNMT1, HIF1 $\alpha$ \\
\hline Reduced enzymatic activity & Aurora B kinase, RNase II \\
\hline Altered cellular localization & STAT3, c-Abl \\
\hline Altered aggregation & Tau, GRP78 \\
\hline
\end{tabular}

Table 1. Examples of the consequences of lysine acetylation in human proteins.

\section{The eleven human HDACs}

The reversal of lysine acetylation is accomplished by enzymatic cleavage catalyzed by the HDACs. In humans, there are 18 HDACs that fall into two families based on their catalytic mechanism. ${ }^{9}$ Eleven of the HDACs are zinc-dependent metalloenzymes named HDAC1-11 that hydrolyze the amide bond using water as a nucleophile. The remaining seven sirtuins 1-7 employ $\mathrm{NAD}^{+}$as a cofactor and transfer the acyl group to 
the $\mathrm{C} 2$ position of the ribose sugar. ${ }^{10}$ Although both enzyme families perform the same chemical reaction of acyllysine cleavage, the term HDAC usually refers to the zincdependent enzymes that are the focus of this perspective..$^{11}$

X-ray crystal structures are available for the majority of HDAC isoforms with the free protein, protein-inhibitor complexes as well as substrates bound to mutated proteins that do not turnover. These extensive studies have provided a detailed understanding of the catalytic mechanism, as exemplified in the model for HDAC8. ${ }^{12}$ The acetyllysine substrate sits in a narrow channel lined with hydrophobic residues, with a tyrosine residue flipping in conformation to enable hydrogen bonding with the carbonyl oxygen (Figure 2A). The hydrophobic nature of the channel, and the conformational change by the tyrosine residue, serve to provide enzyme specificity for the acyllysine side chain. A zinc cation, coordinated to aspartate and histidine residues, sits at the end of the substrate channel, bound to a water molecule activated by a charge relay mechanism with two adjacent histidine residues. Nucleophilic attack of the carbonyl by the water produces a tetrahedral oxyanion intermediate (Figure 2B), which collapses to give rise 
to the free lysine and acetate products (Figure 2C). In some HDAC isoforms, there is an additional hydrophobic internal cavity lateral to the active site also known as the 'foot pocket'. This cavity accommodates acyl side chains longer than acetyl in the case of HDAC8 and HDAC11 (see below) and may aid the entry of water and the release of acetate.

A

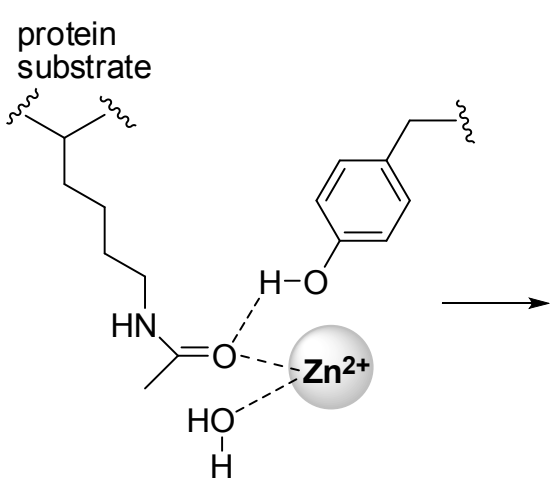

B

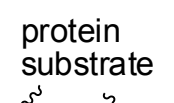

C

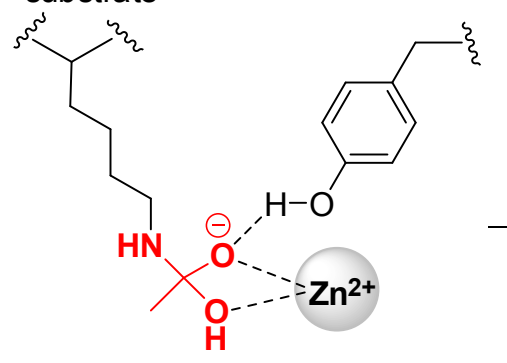

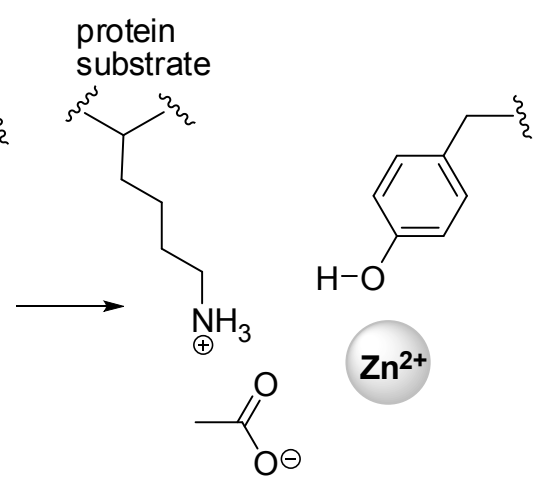

Figure 2. A simplified illustration of the catalytic mechanism of deacetylation by HDACs: A. Enzyme-substrate complex, with binding interactions between the acetyllysine bearing protein substrate and a tyrosine residue and the zinc cation in the HDAC active site. B. The tetrahedral oxyanion enzyme intermediate arising from nucleophilic attack by water. C. Enzyme-product complex, with the lysine residue and acetate prior to release from the active site.

It is worth highlighting a few key points regarding the HDAC enzymes: 
1. Substrate binding is predominantly through the acetyllysine side chain entering the hydrophobic channel rather than recognition of the protein backbone. In some cases, bonding interactions are observed between HDACs and the amino acid residues that are +1 or -1 with respect to the scissile acetylysine. However, extended contacts such as occur in peptide backbone recognizing proteases are rare in HDACs which are relatively nonspecific in their substrate sequence preferences. The compact nature of substrate binding is an advantage for medicinal chemistry, as small molecule inhibitors need only simulate acetyllysine rather than a longer peptide sequence.

2. Coordination between acetyllysine and the active site zinc cation is critical for substrate binding and catalysis. Indeed, all high affinity HDAC inhibitors barring covalent modifiers achieve their potency by zinc coordination, acting as either monodentate or bidentate ligands to mimic the tetrahedral oxyanion intermediate.

3. In broad terms, the features of the HDAC8 catalytic mechanism hold true for other isoforms. Nevertheless, there are significant variations in the geometry of the active site, the nature of the catalytic residues, the substrate channel, presence or absence of the 
internal cavity and positioning of adjacent protein loops. Selective inhibitors that discriminate between HDAC isoforms will need to take advantage of such differences.

The human histone deacetylases are further subdivided into four classes according to their sequence homology and cellular localization: Class I = HDAC1, HDAC2, HDAC3 and HDAC8; Class Ila = HDAC4, HDAC5, HDAC7 and HDAC9; Class Illb = HDAC6 and HDAC10; Class III = sirtuins 1-7; Class IV = HDAC11. However, this classification is somewhat arbitrary and masks the similarities or differences between isoforms in terms of structure and function. In cell-free biochemical assays, HDAC1, HDAC2, HDAC3 and HDAC6 have high enzymatic activity against simple acetyllysine containing peptides and will be discussed first, followed by the other isoforms that are more mysterious in their substrate preferences.

\section{HDAC1, HDAC2}

These isoforms are core HDACs that are co-expressed and are ubiquitous within and between species. ${ }^{13}$ Although they efficiently hydrolyze acetyllysine peptide substrates on their own in vitro, they predominantly exist in the nucleus as homo- and heterodimer 
constituents of the NuRD, Sin3A, CoREST, MiDAC and MIER transcriptional repressor complexes. While there is $>80 \%$ homology between HDAC1 and HDAC2, they perform independent roles in development and embryonic knockout of either isoform is lethal.

On the other hand, in conditional knockouts, there is a level of redundancy with knockout of both isoforms usually needed for a phenotypic effect. HDAC1 and HDAC2 are truly HDACs in the sense that they play a major role in histone deacetylation. In addition, they deacetylate many other nuclear proteins involved in transcriptional regulation including p53, E2F, ATM kinase and CAF1. There is crosstalk with other epigenetic processes such as methylation, as both DNMT1 and LSD1 are among their substrates.

\section{HDAC3}

HDAC3 shares $~ 50 \%$ sequence homology with HDAC1 and HDAC2. The divergence is mainly in the C-terminal region, with HDAC3 containing a domain for binding to the nuclear NCoR/SMRT complexes. ${ }^{14}$ In fact, HDAC3 is unstable without the presence of either NCoR or SMRT, and their association is also necessary for the activation of 
catalysis. Interestingly, the X-ray crystal structure of HDAC3 with the deacetylaseactivating domain of SMRT contained a molecule of inositol tetraphosphate at the interface, bringing the two proteins together. Like HDAC1/HDAC2, HDAC3 is ubiquitously expressed and involved in the deacetylation of histones, while other nuclear protein substrates include STAT3 and FOXP3. In addition to distinct roles in embryonic development, HDAC3 is implicated in a number of physiological processes including circadian rhythms, energy metabolism, neuronal function and bone remodeling.

\section{HDAC6}

If HDAC1-3 are the nuclear workhorses of lysine deacetylation, then HDAC6 is the cytoplasmic equivalent. ${ }^{15}$ HDAC6 is the largest in size among the HDACs, with a Cterminal ubiquitin-binding zinc finger domain. A nuclear localization sequence (NLS) is opposed by a nuclear export sequence (NES) and Ser-Glu-containing tetrapeptide (SE14) repeats that result in the protein mainly being in the cytoplasm. Through the deacetylation of $\alpha$-tubulin and cortactin aided by an $\mathrm{N}$-terminal microtubule-binding 
domain, HDAC6 directly impacts upon the cytoskeleton and cell mobility. Moreover, HDAC6 is involved in the repair of protein misfolding, as deacetylation of Hsp90 restores its chaperone activity while HDAC6's ubiquitin-binding domain fosters binding to misfolded proteins and their targeting for destruction by aggresomes. Additional cytoplasmic substrates include Ku70, whose deacetylation leads to a loss in binding to BAX and thereby inhibition of apoptosis, and Tau, in which deacetylation alters the propensity for aggregation. Further to these cytoplasmic roles, HDAC6 can also localize in the nucleus where it functions as a transcriptional repressor similar to HDAC1-3.

Uniquely among the HDACs, HDAC6 contains two catalytic domains CD1 and CD2. While CD2 is a robust lysine deacetylase in vitro, CD1 was considered inactive for a long time. However, recent studies reveal that CD1 is a competent deacetylase with the right substrates, expressing a preference for C-terminal acetyllysine sequences aided by the presence of a lysine residue in CD1 that forms electrostatic interactions with the carboxylate. ${ }^{16,17}$ Another unusual feature of HDAC6, unlike other isoforms, is that 
knockout mice are viable and healthy, and do not express an obviously defective phenotype.

\section{HDAC8}

HDAC8 is the only isoform for which the gene lies in the $X$ chromosome. Although it is grouped as a Class I nuclear HDAC, it is fundamentally distinct from the HDAC1-3 isoforms in this Class. ${ }^{18}$ Unlike the others, HDAC8 is smaller in size and acts independently, as it is bereft of C-terminal protein-protein interaction domains that promote incorporation into multiprotein complexes. In vitro, HDAC8 has a lower $k_{\text {cat }} / K_{m}$ value for the hydrolysis of acetyllysine containing peptides compared to HDAC1-3 or HDAC6. Nevertheless, the catalytic activity is significantly higher against tetrameric histone $\mathrm{H} 3 / \mathrm{H} 4$ proteins suggesting that histones are, to some extent, in vivo substrates for HDAC8. ${ }^{19}$ Additional nuclear substrates have been identified such as SMC3, p53, ERR $\alpha$ and ARID1a. Recently, Lin demonstrated that HDAC8 hydrolyzes acyllysine peptides with acyl chains of 2-16 carbons, and $k_{\text {cat }} / K_{m}$ for the longer acyl chains of octanoyl-, dodecanoyl-, and myristoyllysine was higher than for acetyllysine. ${ }^{20}$ These 
longer chain acyl groups are likely to be accommodated by extending beyond the active site zinc cation to occupy the hydrophobic internal cavity lateral to the substrate channel. It may be that fatty acid deacylation is a more important physiological function of HDAC8 than deacetylation, which would explain the relatively small number of known validated HDAC8 substrates. Physiologically, the incorporation of these longer acyl chains into lysine PTMs could act as a sensor of energy metabolism by reporting on the relative abundance of different acyl CoA species. Alternatively, some fatty acid acylation may occur adventitiously in which case HDAC8 and HDAC11 (see below) could be operating as proofreading repair enzymes to remove these PTMs.

\section{HDAC11}

HDAC11 was first reported only in 2002 and is the smallest of the HDAC isoforms, with its catalytic domain accounting for $>80 \%$ of the protein sequence. Primarily localized in the nucleus, it functions as a transcriptional regulator with an important role in immunomodulation. ${ }^{21}$ As an enzyme, HDAC11 has weak activity against acetyllysine substrates. Instead, like HDAC8, it efficiently hydrolyzes acyllysine residues with longer 
chain lengths such as the $C_{12}$ dodecanoyllysine and the $C_{14}$ myristoyllysine. ${ }^{22,23}$ Although an X-ray structure of HDAC11 is unavailable, homology modeling suggests long chain acyl groups are accommodated within an internal cavity in the same manner as HDAC8. Interestingly, HDAC11 is susceptible to product inhibition by free fatty acids such as myristic, palmitic, and stearic acids while palmitoyl-coenzyme A and myristoylcoenzyme A serve to enhance the fatty acid deacylase activity.

\section{HDAC4, HDAC5, HDAC7 and HDAC9}

These so-called Class Ila isoforms, unlike other HDACs, are expressed in a tissue specific manner. They are relatively large in size, with an $\mathrm{N}$-terminal domain that binds to the MEF2 family of transcriptional repressors. ${ }^{24}$ Both an NLS and NES are present, enabling the Class Ila isoforms to move between the nucleus and cytoplasm. The shuttling is regulated by the reversible phosphorylation of multiple serine residues, with the unphosphorylated form being nuclear and acting to influence transcriptional regulation. The $\mathrm{C}$-terminal region contains the active site in which the key tyrosine residue (Figure 2) is replaced by a histidine, resulting in weak catalytic activity. By using 
more electrophilic trifluoroacetyllysine containing peptides, it is possible to carry out in vitro assays and profile HDAC inhibitors against these isoforms. Whether they are truly enzymes in vivo or serve to recognize and bind acetyllysine containing proteins is unclear. The evidence suggests they act as a scaffolding protein, bringing together the acyllysine substrate and HDAC3 containing multiprotein complexes, with the actual hydrolysis carried out by HDAC3. On the other hand, it is worth noting that the archetypal zinc amidohydrolase thermolysin contains a histidine residue in a similar location within the active site that participates in catalysis. ${ }^{25}$ Thus, it is conceivable that the Class Ila isoforms are catalytically competent, and their true substrates have yet to be identified. Alternatively, these HDACs may perform dual functions of recognition of an acetyllysine signal followed by slow catalysis as a means of eventual signal termination, in a similar fashion to the binding of GTP to GTPases which then destroy the nucleotide.

\section{HDAC10}


HDAC10 is found in both the nucleus and cytoplasm, and involved in processes such as autophagy, immunoregulation and DNA repair. ${ }^{26}$ While it appears to function as a transcriptional repressor, this activity was puzzlingly independent of lysine deacetylation. Recent studies from Christianson have clarified this anomaly and convincingly demonstrated that $\mathrm{HDAC} 10$ is an acetylpolyamine hydrolase evolutionarily related to the prokaryotic homologue. ${ }^{27,28}$ In HDAC10, a unique $3_{10}$ helix defined by the $P(E, A) C E$ motif serves to narrow the hydrophobic substrate channel, leading to selectivity for acetylpolyamines over more bulky peptides or proteins containing acetyllysine residues. While the HDAC10 active site contains the conserved tyrosine and histidine residues and the zinc activated water typical in HDAC catalysis (Figure 2), an additional negatively charged glutamate residue unique to this isoform acts as a gatekeeper to favor the binding of cationic acetylpolyamine residues. In fact, the substitution of this glutamate residue by leucine was sufficient to restore acetyllysine hydrolytic activity in the mutant enzyme.

\section{Overview}


Our understanding of HDACs is continually evolving with new insights regarding their substrates. Until recently, it seemed the family could be unified under the nomenclature of protein lysine deacylases or KDACs that would encompass both deacetylation as well as the hydrolysis of other amides. However, the discovery that HDAC10 is a small molecule polyamine deacetylase means that even the KDAC terminology is no longer accurate. Meanwhile, whether HDAC4, HDAC5, HDAC7 or HDAC9 are truly enzymes is debatable. The traditional subdivision of human HDACs according to Class I-IV does not take these recent developments into account, and we prefer to group them according to their in vitro substrate tolerance (Figure 3, Table 2).

While this perspective is focused on the human HDACs, homologues in other species offer additional opportunities for drug discovery. The selective targeting of fungal HDACs as a means to create novel antifungal agents is one example. ${ }^{29}$ The combination of fluconazole and MethylGene's MGCD209, an inhibitor of the fungal Hos2 HDAC, ${ }^{30}$ reached Phase 2 clinical trials for the treatment of severe vulvovaginal candidiasis, but unfortunately did not show improved efficacy over fluconazole alone. 
Another major area of research is the HDACs present in parasites responsible for neglected tropical disease. The approved HDAC inhibitors and clinical candidates as well as novel compounds intended to selectively inhibit the parasite enzymes have shown promising results in in vivo models, as summarized in a recent review. ${ }^{31}$

\begin{tabular}{|c|c|c|c|}
\hline \multicolumn{4}{|c|}{ In vitro Acetyl-Lys peptide hydrolases } \\
\hline Isoform & $\begin{array}{l}\text { Major } \\
\text { localization }\end{array}$ & Key features & Substrate examples \\
\hline HDAC1, HDAC2 & Nucleus & $\begin{array}{l}\text { Exist in vivo as } \\
\text { NuRD, } \\
\text { CoREST, } \\
\text { and } 3 \text { MiDAC } \\
\text { complexes }\end{array}$ & $\begin{array}{l}\text { Histones, } \\
\text { transcriptional } \\
\text { regulators }\end{array}$ \\
\hline HDAC3 & Nucleus & $\begin{array}{l}\text { Complexation with } \\
\text { NCoR/SMRT } \\
\text { needed for catalysis }\end{array}$ & $\begin{array}{l}\text { Histones, } \\
\text { transcriptional } \\
\text { regulators }\end{array}$ \\
\hline HDAC6 & Cytoplasm & $\begin{array}{l}\text { Ubiquitin and } \\
\text { microtubule binding } \\
\text { domains, two } \\
\text { catalytic domains }\end{array}$ & $\begin{array}{l}\text { Tubulin, cortactin } \\
\text { Hsp90, Tau }\end{array}$ \\
\hline \multicolumn{4}{|c|}{ In vitro longer chain Acyl-Lys peptide hydrolases } \\
\hline HDAC8 & Nucleus & $\begin{array}{l}\text { Moderate AcLys } \\
\text { hydrolysis with } \\
\text { extended sequence }\end{array}$ & $\begin{array}{ll}\text { Histones, } & \text { p53 } \\
\text { SMC3, } & \\
\text { longer } & \text { chair }\end{array}$ \\
\hline
\end{tabular}




\begin{tabular}{|l|l|l|l|}
\hline & \multicolumn{2}{|l|}{$\begin{array}{l}\text { recognition, superior } \\
\text { for } \mathrm{C}_{8}, \mathrm{C}_{12}, \mathrm{C}_{14} \\
\text { acyllysine }\end{array}$} & acyllysine residues \\
\hline HDAC11 & Nucleus & $\begin{array}{l}\text { Preference for } \mathrm{C}_{12}, \\
\mathrm{C}_{14} \text { acyllysine }\end{array}$ & $\begin{array}{l}\text { longer chain } \\
\text { acyllysine residues }\end{array}$ \\
\hline In vitro Ac-polyamine hydrolase & Cytoplasm & $\begin{array}{l}\text { Narrow substrate } \\
\text { channel with } \\
\text { glutamate } \\
\text { HDAC10 }\end{array}$ & $\begin{array}{l}\text { Acetylpolyamines } \\
\text { gatekeeper }\end{array}$ \\
\hline $\begin{array}{l}\text { In vitro trifluoroAc-Lys peptide hydrolases } \\
\text { HDAC7, HDAC9 }\end{array}$ & $\begin{array}{l}\text { Nucleus } \\
\text { cytoplasm }\end{array}$ & $\begin{array}{l}\text { Tissue-specific, } \\
\text { MEF2 binding } \\
\text { domain }\end{array}$ & $\begin{array}{l}\text { None? } \\
\text { substrates } \\
\text { HDAC3 }\end{array}$ \\
\hline
\end{tabular}

Table 2. The eleven human HDAC isoforms summarized according to substrate preference, localization, and key features. 


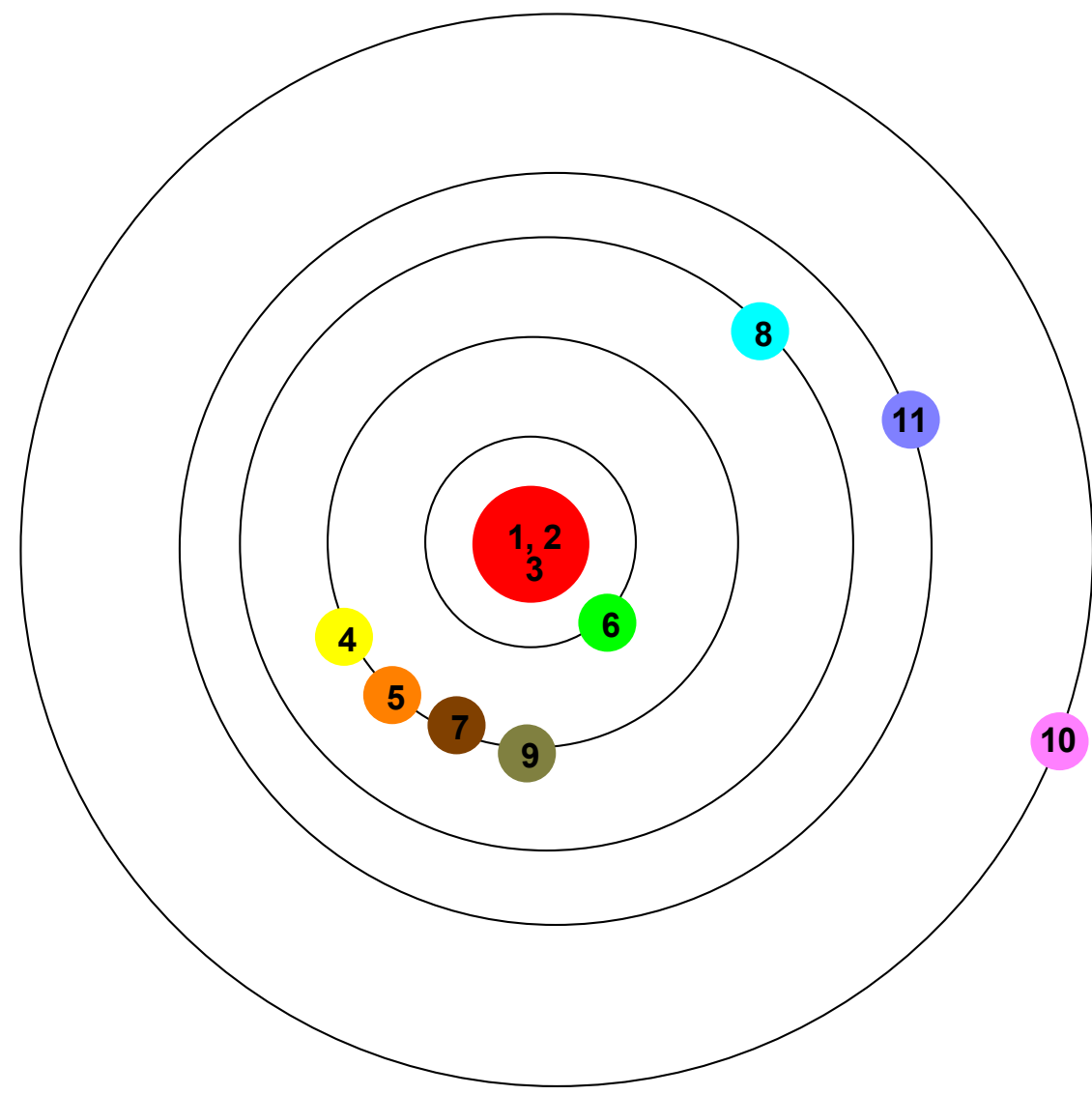

Figure 3. A 'solar system' of human HDACs: at the core are HDAC1, HDAC2 and HDAC3 which exist in multiprotein complexes in the nucleus. These isoforms deacetylate histones and transcriptional regulators, and homologues are ubiquitous across life forms. Next is HDAC6, responsible for the deacetylation of cytoplasmic proteins, followed by an 'asteroid belt' of the pseudoenzymes HDAC4, HDAC5, HDAC7 and HDAC9 with poor catalytic activity. The 'outer planets' HDAC8 and HDAC11 preferentially hydrolyze non-acetyl acyllysine substrates while the distant HDAC10 is a polyamine deacetylase. 


\section{Profiling HDAC inhibition}

The in vitro profiling of HDAC inhibitors in cell-free enzymatic assays invariably involves the monitoring of product formation using acetyllysine derivatives or peptides based on the $\mathrm{N}$-terminal histone tail sequence that contain an acetyllysine residue. ${ }^{32}$ Assay kits often employ peptides with an AcLys-AMC (aminomethylcoumarin) residue at the Cterminus which undergoes acetyllysine hydrolysis by HDACs (Figure 4). The resulting C-terminal lysine is recognized by the exopeptidase trypsin, which cleaves the backbone amide to release free aminomethylcoumarin that fluoresces at a longer wavelength than the substrate. Although less amenable to high-throughput screening, direct detection of product formation by chromatographic separation or mass spectrometry without the need for trypsin cleavage are among the alternative formats. ${ }^{33}$ In the past, crude cell extracts were used as the source of HDACs, and these mainly contained the nuclear isoforms in an unknown ratio. Nowadays, using recombinant HDAC proteins, the detailed profiling of compounds to determine their subtype selectivity against all eleven isoforms can be accomplished. 


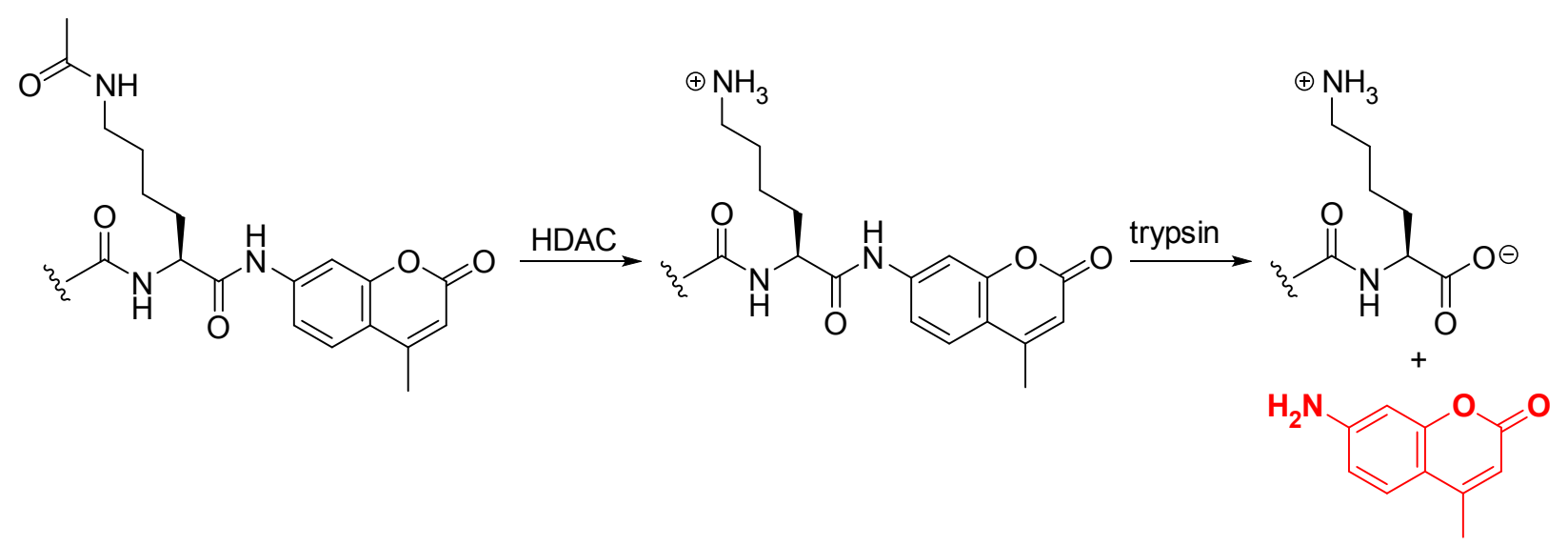

Figure 4. A fluorescence-based assay for measuring HDAC activity based upon product cleavage by trypsin to release aminomethylcoumarin.

Due to differences in protein stability and substrate preference, running HDAC assays against individual isoforms is actually complicated in practice. With regards to the protein, there are options involving full-length enzyme or catalytic domain only, or the addition of binding partners to more closely approximate the cellular environment. Purity, with the possibility of residual contamination by other isoforms, and batch to batch variation are further issues. Simple acetyllysine containing substrates undergo efficient hydrolysis by recombinant HDAC1, HDAC2 and HDAC6 in the fluorescent assay, as well as HDAC3 when co-expressed with NCoR. ${ }^{34,35}$ Although such assays are operationally convenient, it should be kept in mind that the true substrates are proteins 
(or multimeric complexes thereof) rather than acetyllysine derivatives or peptides.

Beyond these isoforms, further tinkering is needed for the other HDACs which have

lower catalytic activity for acetyllysine hydrolysis. By switching to more labile (but artificial) trifluoroacetyllysyl substrates in lieu of acetyllysine derivatives, or using mutated enzymes with higher turnover, the inhibition can be quantitatively measured. However, these assays may not accurately reflect the in vivo functions of the enzyme. For example, HDAC11 preferentially acts upon non-acetyl lysine PTMs and a recent assay employing a longer acyllysine substrate showed significant differences compared to the traditional trifluoroacetyllysine-based method. ${ }^{36}$ Similarly, the current HDAC10 kits are based on peptides rather than more meaningful acetylpolyamine substrates. As a result of all these complexities, care should be exercised in the interpretation of literature $\mathrm{HDAC} \mathrm{IC}_{50}$ or $\mathrm{K}_{\mathrm{i}}$ values taken at different times or from different laboratories, and the experimental procedures consulted for the exact assay method employed and the data obtained for reference standards. 
In cell-based studies, HDAC inhibitors are usually profiled by their growth inhibition of human cancer cell lines, with readouts in other cell types used for non-cancer therapeutic indications. Evidence of HDAC target engagement is commonly demonstrated by western blotting of the substrate proteins such as histones for nuclear HDACs, p53 for HDAC1 and tubulin for HDAC6, to show a dose-dependent elevation of acetylation levels. Cellular thermal shift assays (CETSA) are a version that allow for the quantification of ligand binding in intact cells. ${ }^{37}$ The NanoBRET technology based on competitive binding between inhibitor and a fluorescent tracer is an alternative approach that enables the measurement of target engagement and drug reisdence time in cells. ${ }^{38}$ In addition, downstream effects as a result of HDAC inhibition can be measured, ranging from phenotypic changes such as cell differentiation to altered protein expression levels such as induction of the p21 (CIP1/WAF1) cyclin-dependent kinase inhibitor.

\section{Natural product HDAC inhibitors}


To inhibit a HDAC, the logical starting point is to mimic the tetrahedral oxyanion enzyme intermediate (Figure 2B) and design a molecule that coordinates to the active site zinc cation with a slender hydrophobic linker to fit the substrate binding channel. In addition, it is helpful to anchor the molecule at the other end with a cap that can potentially engage in additional binding interactions with the rim of the enzyme. In fact, this simple model for a HDAC pharmacophore composed of three elements - zinc binding group, linker and cap - is sufficiently powerful to account for the vast majority of HDAC inhibitors and is widely used since it was proposed by Jung in $1997 .{ }^{39}$

As the medicinal chemist par excellence, nature has successfully used the three-point model for the design of nanomolar HDAC inhibitors with a variety of zinc binding groups, linkers and caps. As mentioned in the introduction, the Streptomyces metabolite trichostatin A (1, Figure 5) was the first potent HDAC inhibitor to be identified, by Yoshida thirty years ago. ${ }^{40}$ Trichostatin A perfectly illustrates the HDAC pharmacophore: the hydroxamic acid functions as a bidentate zinc chelator, as later confirmed through X-ray crystallography of trichostatin A-HDAC complexes, while the 
diene is a rigid linker that sits in the substrate channel and terminates with a substituted phenyl ring as the cap. The cap's tertiary amine substituent, protruding out of the enzyme surface, presumably aids in drug solvation by the aqueous environment. Psammaplin A (2) isolated from a marine sponge is a symmetrical prodrug, undergoing disulfide reduction to the active molecule which conforms to the three-point pharmacophore with the thiol as a monodentate zinc binding group. ${ }^{41}$ Since thiols have poor bioavailability, the disulfide protection ensures higher stability and cell permeability prior to metabolic activation. A masked thiol prodrug features once again in the depsipeptide family of HDAC inhibitors, either as a reducible disulfide in the bacterial natural products romidepsin (FK228, 3) and spiruchostatin A (4) or as a hydrolytically labile thioester in largazole (5) of cyanobacterial origin. ${ }^{42}$ Upon metabolism, the free thiol common to all three natural products becomes the zinc binding group, as observed in the X-ray structure of largazole with HDAC8. 


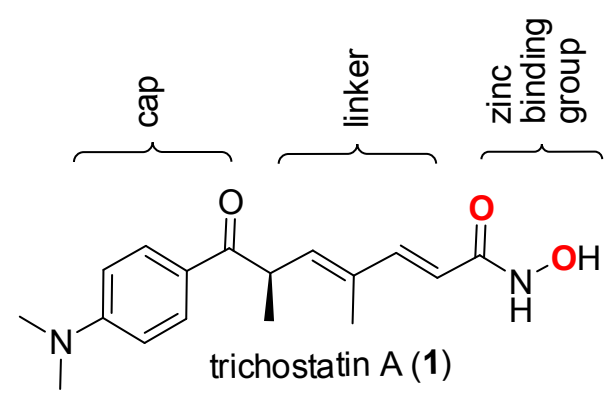<smiles>O=C(NCCSSCCNC(=O)/C(Cc1ccc(O)c(Br)c1)=N/O)/C(Cc1ccc(O)c(Br)c1)=N/O</smiles>

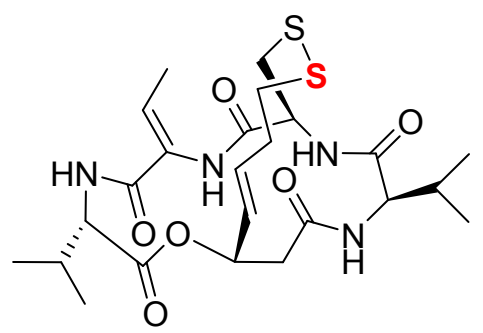

romidepsin (3)

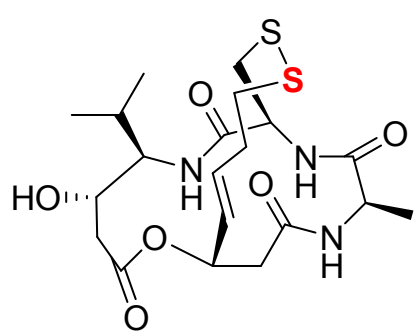
spiruchostatin A (4)<smiles>CCCCCCCC(=O)SCC/C=C/C(CC(=O)NCc1nc(C2=N[C@](C)(C(=O)NC(C(C)C)C(C)C)C(=O)O2)cs1)OC(C)(C)C</smiles>

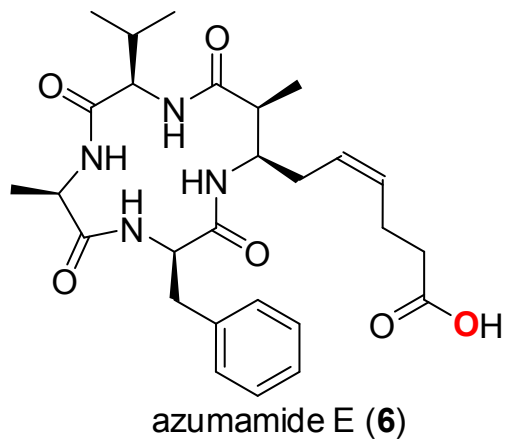

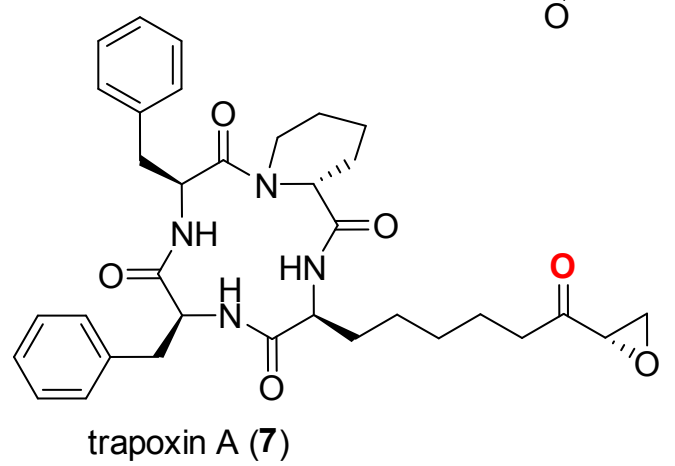

Figure 5. Examples of potent natural product HDAC inhibitors, with zinc binding atoms indicated in red.

While trichostatin A with its simple aromatic cap is a nonselective HDAC inhibitor, both romidepsin and largazole contain larger macrocyclic caps that contribute to their enzyme affinity as well as enable isoform discrimination. ${ }^{43}$ The importance of 
augmenting zinc and substrate channel binding with additional interactions is illustrated by the marine sponge natural product azumamide $E(6)$. Synthetic carboxylic acids have fared poorly as HDAC inhibitors despite their successful use as zinc binding groups against other metalloenzymes. Although the short chain butyric, phenylbutyric and valproic acid have been explored as HDAC inhibitors in the clinic, their sole redeeming factor is the existence of prior human safety and pharmacokinetic data. The actual inhibition of HDACs by these carboxylic acids is weak, verging upon the high micromolar level, and they will not be discussed further. Azumamide $E$, on the other hand, achieves submicromolar potency with selectivity for HDAC1 over HDAC6 and the macrocyclic scaffold presumably makes a significant contribution to these aspects. Interestingly, a synthetic analogue with the carboxylic acid replaced by a bidentate hydroxamic acid is even more active as a HDAC inhibitor. ${ }^{44}$ Trapoxin A (7), one of a family of fungal cyclic tetrapeptide HDAC inhibitors, is another interesting example as ketones are normally inefficient ligands for zinc. The X-ray structure of 7 with HDAC8 indicates the ketone is a substrate mimic, reacting with the active site water to form a tetrahedral gem-diolate which then functions as a bidentate zinc binding group. ${ }^{45}$ 
Although medicinal chemists work on many epigenetic targets for drug discovery, HDACs are apparently the only one that nature has taken seriously and the only one against which highly active secondary metabolites have been discovered. This emphasis probably reflects the producing microbial or marine organism's need for chemical defense against competing species or predators. In this regard, the rapid toxicity arising from HDAC inhibition is evolutionarily more helpful compared to the slower consequences of the disruption of DNA or histone methylation. A further question is which HDAC should be inhibited, with the core HDAC1/HDAC2 isoforms being prime candidates due to their direct impact upon gene transcription and the existence of homologues in virtually all species. Indeed, it is unlikely to be a coincidence that all the natural products in Figure 5 strongly inhibit HDAC1/HDAC2 with nanomolar $I C_{50}$ values, and except for the nonselective trichostatin $A$, are less active against the cytoplasmic HDAC6. Turner has suggested that evolutionary exposure to natural product and environmental HDAC inhibitors may have forced organisms to develop resistance mechanisms, and these same pathways are now subverted by tumor cells to their advantage upon chemotherapy with such agents. ${ }^{46}$ 


\section{Clinical candidate and approved HDAC inhibitors}

In a tour de force of chemical biology, Breslow started with DMSO as a lead for cell differentiation and eventually progressed to a more active series of hydroxamic acids culminating in suberoylanilide hydroxamic acid (SAHA). ${ }^{47}$ Later acquired by Merck, SAHA now known as vorinostat (8, Figure 6) became the first HDAC inhibitor to receive FDA approval, in 2006 for the treatment of cutaneous T-cell lymphoma. In parallel, the depsipeptide natural product romidepsin (3) was also discovered on the basis of phenotypic activity before its molecular target was identified. Romidepsin advanced to clinical development by Gloucester Pharmaceuticals before receiving FDA approval in 2009, for cutaneous T-cell lymphoma as well. Another natural depsipeptide, spiruchostatin A (OBP-801, 4) is under investigation in Phase 1 clinical trials for the treatment of solid tumors. ${ }^{48}$ Meanwhile, the elucidation of the mechanism of action of trichostatin A led to tremendous medicinal chemistry interest in hydroxamic acids as HDAC inhibitors and they remain the most popular choice of zinc binding group against 
this target. Subsequent to vorinostat, six other clinical candidates tefinostat (9), ${ }^{49}$ CG200745 (10), ${ }^{50}$ ricolinostat (11), ${ }^{51}$ citarinostat (12), ${ }^{52}$ CUDC-101 (13) ${ }^{53}$ and tinostamustine $(14)^{54}$ have appeared that feature similar aliphatic hydroxamic acids with linear methylene chains. The X-ray structure of the vorinostat-HDAC8 complex (Figure 7) illustrates the typical bidentate coordination observed with hydroxamic acids within the HDAC active site..$^{55}$<smiles>C#Cc1cccc(Nc2ncnc3cc(OCCCCCC(=O)NO)c(OCCCCC(=O)NO)cc23)c1</smiles><smiles>C#Cc1cccc(Nc2ncnc3cc(OCCCCCC(=O)NO)c(OCCCCC(=O)NO)cc23)c1</smiles><smiles>C#Cc1cccc(Nc2ncnc3cc(OCCCCCC(=O)NO)c(OCCCCC(=O)NO)cc23)c1</smiles>

Figure 6. Clinical candidate HDAC inhibitors with aliphatic hydroxamic acids. 


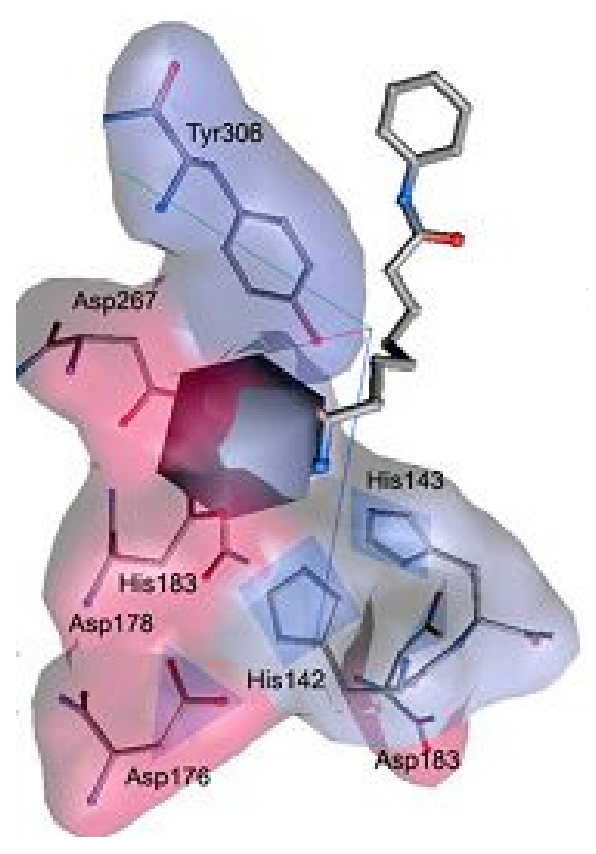

Figure 7. The binding interactions in the vorinostat-HDAC8 X-ray structure. The zinc cation is displayed as a centroid with the coordinating Asp and His residues in pink. The His and Tyr residues involved in water activation and substrate binding respectively are indicated in blue. Reprinted with permission from ref. 55 .

\begin{abstract}
A second family of HDAC inhibitors, inspired by trichostatin A, contains a more rigid alkenyl hydroxamic acid. In 2014, belinostat (15, Figure 8) originating from Prolifix and now marketed by Onxeo/Spectrum, became the third HDAC inhibitor to be approved for T-cell lymphoma after vorinostat and romidepsin. ${ }^{56} \mathrm{~A}$ year later, Novartis's panobinostat (16) was approved for the treatment of relapsed or refractory multiple myeloma by both
\end{abstract}


the FDA and the EMA. ${ }^{57}$ Two other alkenyl hydroxamic acids resminostat $(17)^{58}$ and pracinostat $(18)^{59}$ are in clinical trials. A newer series of compounds contains an even more rigid phenylhydroxamic acid: givinostat (19, Figure 9), ${ }^{60}$ abexinostat (20), ${ }^{61}$ AR-42 (21) ${ }^{62}$ and bisthianostat (22). ${ }^{63} \mathrm{~A}$ more polar pyrimidinyl heteroaromatic hydroxamic acid was employed in quisinostat (23), ${ }^{64}$ nanatinostat (24) ${ }^{65}$ and fimepinostat (25). ${ }^{66}$<smiles>O=C(/C=C/c1cccc(S(=O)(=O)Nc2ccccc2)c1)NO</smiles><smiles>Cc1[nH]c2ccccc2c1CCNCc1ccc(/C=C/C(=O)NO)cc1</smiles><smiles>CN(C)Cc1ccc(S(=O)(=O)n2ccc(/C=C/C(=O)NO)c2)cc1</smiles><smiles>CCCCc1nc2cc(/C=C/C(=O)NO)ccc2n1CCN(CC)CC</smiles>

Figure 8. Clinical candidate HDAC inhibitors with alkenyl hydroxamic acids. 


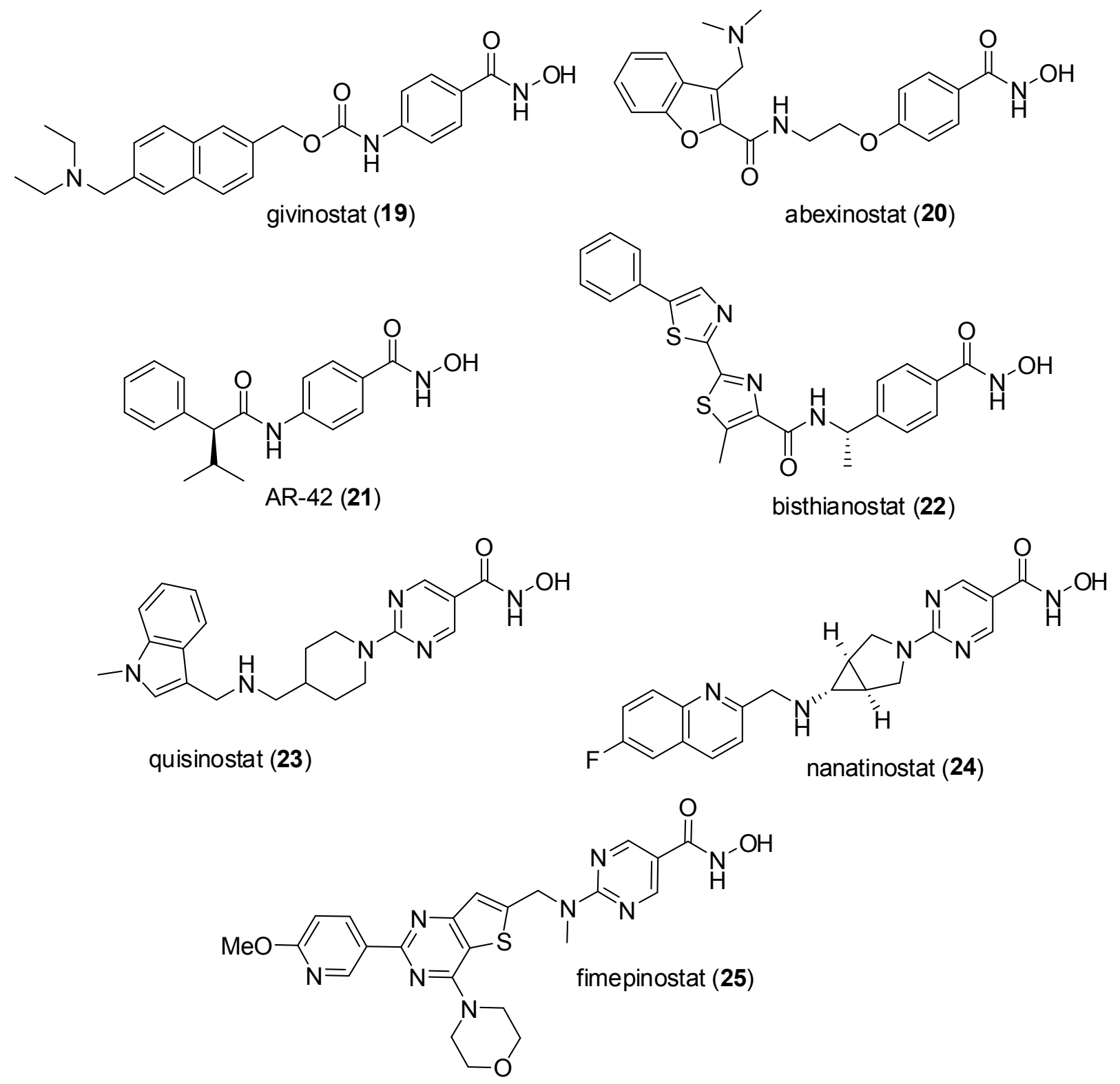

Figure 9. Clinical candidate HDAC inhibitors with aromatic hydroxamic acids. 
Pharmacodynamic data against individual HDAC isoforms is available for the approved drugs and the majority of clinical candidates (Table 3 ). Romidepsin has the typical profile of natural product HDAC inhibitors, with a high activity against the nuclear isoforms HDAC1-3.67 There is selectivity, as the natural product is sparing against HDAC8 and HDAC6 although the non-acetyllysine hydrolyzing HDAC10 and HDAC11 are also strongly inhibited. Compared to romidepsin, the forerunner of the hydroxamic acids, vorinostat, has a saturated aliphatic linker and a phenyl cap. With its relatively simple and unconstrained structure, vorinostat would not be predicted to be selective (nor was it intended to be, since the subtleties of isoform function were unknown at the time), and in biochemical enzyme assays it inhibits both the nuclear and cytoplasmic HDACs indiscriminately at submicromolar levels. Although the later hydroxamic acids show an extensive diversity in the architecture of their linker and cap regions, they share a common pharmacological profile insofar that all potently inhibit HDAC1-3 just like vorinostat or romidepsin.

\begin{tabular}{|l|l|l|l|l|l|l|l|l|l|l|l|}
\hline & \multicolumn{1}{|l|}{ HDAC isoform $\mathrm{IC}_{50}, \mathrm{nM}$} \\
\hline Cpd. & 1 & 2 & 3 & 8 & 4 & 5 & 7 & 9 & 6 & 10 & 11 \\
\hline
\end{tabular}




\begin{tabular}{|c|c|c|c|c|c|c|c|c|c|c|c|}
\hline $\begin{array}{l}\text { romidepsin } \\
\text { (3) }\end{array}$ & 1 & 1 & 1 & $\begin{array}{l}>100 \\
0\end{array}$ & 647 & $\begin{array}{l}>100 \\
0\end{array}$ & $\begin{array}{l}>100 \\
0\end{array}$ & $\begin{array}{l}>100 \\
0\end{array}$ & $\begin{array}{l}22 \\
6\end{array}$ & 1 & 0.3 \\
\hline $\begin{array}{l}\text { vorinostat } \\
(8)^{a}\end{array}$ & 60 & 42 & 36 & 173 & 20 & 36 & 129 & 49 & 29 & 60 & 31 \\
\hline $\begin{array}{l}\text { ricolinostat } \\
\text { (11) }\end{array}$ & 58 & 48 & 51 & 100 & $>1000$ & $>1000$ & $>1000$ & $>1000$ & 5 & - & $>1000$ \\
\hline $\begin{array}{l}\text { citarinostat } \\
\text { (12) }\end{array}$ & 35 & 45 & 46 & 137 & $>1000$ & $>1000$ & $>1000$ & $>1000$ & 3 & - & - \\
\hline $\begin{array}{l}\text { belinostat } \\
(15)^{a}\end{array}$ & 26 & 22 & 19 & 22 & 15 & 25 & 51 & 24 & 10 & 59 & 27 \\
\hline $\begin{array}{l}\text { panobinostat } \\
(16)^{a}\end{array}$ & 3 & 2 & 2 & 22 & 1 & 1 & 2 & 1 & 1 & 31 & 4 \\
\hline $\begin{array}{l}\text { pracinostat } \\
(\mathbf{1 8})^{a}\end{array}$ & 28 & 27 & 19 & 48 & 16 & 21 & 104 & 24 & 247 & 23 & 24 \\
\hline givinostat (19) & 133 & 293 & 136 & 837 & $>1000$ & 532 & 524 & 512 & 312 & 331 & 287 \\
\hline $\begin{array}{l}\text { abexinostat } \\
(\mathbf{2 0})\end{array}$ & 21 & 63 & 148 & 370 & 60 & 48 & 350 & 168 & 12 & 52 & 14 \\
\hline $\begin{array}{l}\text { bisthianostat } \\
\text { (22) }\end{array}$ & 4 & 13 & 6 & 17 & $>1000$ & $>1000$ & $>1000$ & $>1000$ & 2 & 2 & 78 \\
\hline $\begin{array}{l}\text { quisinostat } \\
(\mathbf{2 3})\end{array}$ & 0.1 & 0.3 & 5 & 4 & 0.6 & 4 & 119 & 32 & 77 & 0.5 & 0.4 \\
\hline $\begin{array}{l}\text { fimepinostat } \\
\text { (25) }\end{array}$ & 2 & 5 & 2 & 191 & 409 & 674 & 426 & 554 & 27 & 3 & 5 \\
\hline
\end{tabular}

Table 3. $I C_{50}$ values of clinical candidate and approved thiol and hydroxamic acid HDAC inhibitors. ${ }^{a}$ For these compounds, $\mathrm{K}_{\mathrm{i}}$ values are given, from a side-by-side comparison in ref. 59. Data for other compounds compiled from refs. 51, 52, 60, 61, 63, 64 and 66. 
Besides the hydroxamic acids, ortho-aminoanilides (or benzamides) are a second class

of synthetic HDAC inhibitors that have yielded clinical candidates. X-ray crystallography

of enzyme-inhibitor complexes shows bidentate coordination of the carbonyl oxygen

and aniline nitrogen with the active site zinc cation. Nevertheless, ortho-aminoanilides

would be expected to be weaker metal binders than hydroxamic acids, and this is

reflected in their typical micromolar $\mathrm{IC}_{50}$ values in standard assay conditions compared

to the nanomolar potency of the latter. However, the ortho-aminoanilides exhibit unusual

kinetics, being tight-binding inhibitors with slow-on/slow-off rates that benefit from pre-

incubation and equilibration compared to the fast-on/fast-off behavior observed with

hydroxamic acids. For example, with pre-incubation, an ortho-aminoanilide had $\mathrm{K}_{\mathrm{i}}$

values of 148 and $5 \mathrm{nM}$ respectively against HDAC1 and HDAC3, compared to 5 and 8

$\mathrm{nM}$ respectively for vorinostat (whose activity was unchanged upon pre-incubation). ${ }^{68}$

Pfizer's tacedinaline (26, Figure 10$)^{69}$ was an early clinical candidate with a simpler cap

compared to entinostat $(27)^{70}$ and mocetinostat (28). ${ }^{71}$ Tucidinostat (29) from Shenzen

Chipscreen Biosciences received approval from the CFDA in 2015 for the treatment of

peripheral T-cell lymphoma and marks the first example of a 'Made in China' drug 
where the entire drug discovery process was carried out there. ${ }^{72}$ Domatinostat $(30)^{73}$ and CXD101 $(31)^{74}$ are additional ortho-aminoanilides in clinical trials.

The available literature data on ortho-aminoanilides (Table 4) indicates they are similar as a class, inhibiting HDAC1-3 while poorly active against HDAC6 and HDAC8. The larger dimensions of the ortho-aminoanilide compared to a thiol or hydroxamic acid zinc binding group can be accommodated by the lateral cavity present in HDAC1-3 but absent in HDAC6. Although HDAC8 contains the lateral cavity, the substitution of a tryptophan residue for a leucine present in HDAC1-3 leads to a shallower channel that does not bind to the ortho-aminoanilide. To some extent, the ortho-aminoanilides are similar in their activity profile to romidepsin and related depsipeptide natural products in that they predominantly inhibit HDAC1-3. 


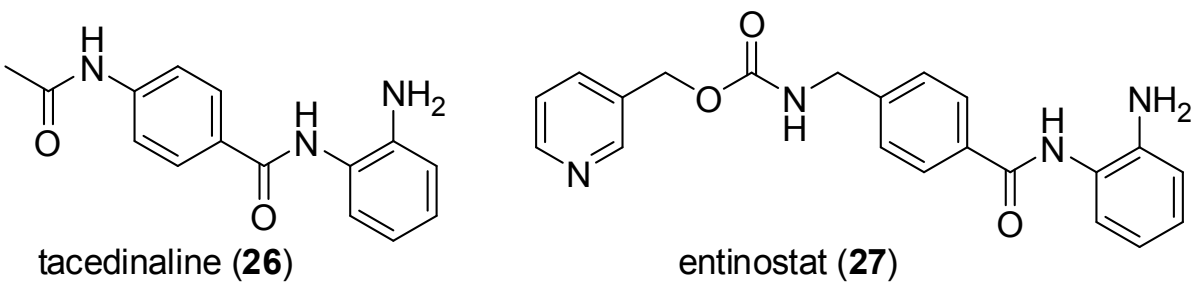<smiles>CCOC(=O)OCCO</smiles>

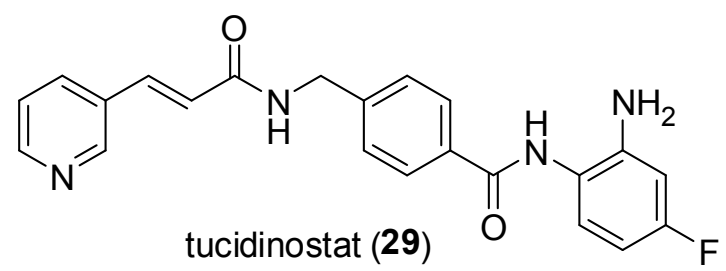<smiles></smiles><smiles>Cc1cn(C)nc1CN1CCC(c2ccc(C(=O)Nc3ccccc3N)cc2)CC1</smiles>

Figure 10. Clinical candidate ortho-aminoanilide HDAC inhibitors.

\begin{tabular}{|l|l|l|l|l|l|l|l|l|l|l|l|}
\hline & \multicolumn{10}{|l|}{ HDAC isoform $\mathrm{IC}_{50}, \mu \mathrm{M}$} \\
\hline Cpd. & $\mathbf{1}$ & $\mathbf{2}$ & $\mathbf{3}$ & $\mathbf{8}$ & $\mathbf{4}$ & $\mathbf{5}$ & $\mathbf{7}$ & $\mathbf{9}$ & $\mathbf{6}$ & $\mathbf{1 0}$ & $\mathbf{1 1}$ \\
\hline tacedinaline & 0. & 0. & 1. & $>1$ & - & - & - & - & - & - & - \\
$(\mathbf{2 6})$ & 9 & 9 & 2 & 0 & & & & & & & \\
\hline entinostat (27) & 0. & 1. & 2. & $>1$ & $>1$ & - & $>1$ & 0.5 & $>1$ & - & - \\
& 2 & 2 & 3 & 0 & 0 & & 0 & & 0 & & \\
\hline mocetinostat & 0. & 0. & 1. & $>1$ & $>1$ & $>1$ & $>1$ & - & $>1$ & - & 0. \\
$(28)$ & 2 & 3 & 7 & 0 & 0 & 0 & 0 & & 0 & & 6 \\
\hline tucidinostat & 0. & 0. & 0. & 0.7 & $>1$ & $>1$ & $>1$ & $>1$ & $>1$ & 0.1 & 0. \\
$(29)$ & 1 & 2 & 1 & & 0 & 0 & 0 & 0 & 0 & & 4 \\
\hline domatinostat & 1. & 1. & 0. & $>1$ & $>1$ & $>1$ & $>1$ & $>1$ & $>1$ & $>1$ & 9. \\
(30) & 2 & 1 & 6 & 0 & 0 & 0 & 0 & 0 & 0 & 0 & 7 \\
\hline
\end{tabular}




\begin{tabular}{|l|l|l|l|l|l|l|l|l|l|l|l|}
\hline CXD101 (31) & 0. & 0. & 0. & - & - & - & - & - & - & - & - \\
& 1 & 6 & 6 & & & & & & & & \\
\hline
\end{tabular}

Table 4. $I_{50}$ values of clinical candidate and approved ortho-aminoanilide HDAC inhibitors compiled from refs. 69-74. Note that values are in $\mu \mathrm{M}$, unlike the $\mathrm{nM}$ in Table 3 and assay conditions may not have involved enzyme pre-incubation.

In addition to the compounds discussed above, there are HDAC inhibitors in Phase 1 clinical trials with undisclosed structures: CKD-504 and CKD-506 (Chong Kung Dan Pharmaceutical Corp.), CS3003 (CStone Pharmaceuticals), HG146 (HitGen), KA2507 (Karus Therapeutics) and OKI-179 (OnKure). The majority are reported to be HDAC6 selective inhibitors, while OKI-179 is a synthetic analogue of largazole (5).

\title{
HDAC inhibitors as cytotoxic agents
}

\author{
After the DNMTs, HDACs were the next epigenetic target to receive scrutiny for drug \\ discovery and this rapidly accelerated with the early discovery of compounds that \\ displayed potent antiproliferative activity in human cancer cell lines that was
}


recapitulated in tumor xenograft animal models. At the same time, the simplicity and flexibility of the HDAC pharmacophore provided medicinal chemists with the freedom to operate and design and optimize independent lead series. Since the first-in-human experiments with vorinostat in 2000, HDAC inhibitors have been investigated in nearly a thousand clinical trials, primarily in oncology but numerous other indications as well. It is fair to say the accumulated clinical experience from the last two decades is disappointing as it did not fulfill the promise of the earlier data from in vitro and in vivo models. Efficacy with an acceptable margin of safety and tolerability has mainly been observed in certain hematological cancers. ${ }^{75,76}$ To date, we have four approvals for Tcell lymphoma, one for multiple myeloma and one for combination therapy against breast cancer, and the HDAC inhibitors are not first-line therapy against any of these indications.

What HDAC inhibitors actually do in cells is an extremely complicated question. Microarray experiments indicate that $<10 \%$ of the genome undergoes significantly altered expression upon treatment with a HDAC inhibitor. ${ }^{77}$ In a cancer cell, these 
perturbations appear to disrupt their metastable state and drive the cell towards nonproliferative fates involving a combination of differentiation, immunomodulation, chromatin instability, reduced DNA damage repair, reactive oxygen species production, cell cycle arrest, apoptosis, autophagy, and the reduction of angiogenesis and cell migration. ${ }^{78}$ These effects are most strongly felt in hematological cancers, perhaps due to the fact that the tumor is derived in a complex process of hematopoiesis from stem cells. Epigenetic programming plays a heavy role in this transformation, and the blood cell lineages appear to be more plastic and susceptible to reprogramming compared to more terminally differentiated cancer types. The particular success in the treatment of Tcell lymphoma is strongly linked to immunomodulation, as HDAC inhibitors cause a reduction in the 'cytokine storm' characteristic of this disorder. ${ }^{79}$ Meanwhile, it has proven challenging to find a therapeutic window that allows the higher dosing needed against more aggressive cancers without compromising patient tolerability. ${ }^{80}$ Resistance to HDAC inhibitors is a further issue,$^{81}$ mainly arising via compensating changes in HAT/HDAC expression levels, the induction of p21 (CIP1/WAF1) and thioredoxin, and drug efflux by $A B C$ transporters. 
The first clinical candidates vorinostat and romidepsin have limited oral bioavailability and their trials required intravenous administration. Romidepsin, with its complex structure, was considered intractable for analogue generation although this would eventually change through the design of efficient total synthesis routes by academic groups. ${ }^{82}$ While vorinostat is a much simpler molecule and an oral formulation was later developed, it suffers from extensive metabolism through hydroxamic acid glucuronidation and oxidative cleavage of the aliphatic methylene chain. For fast followers, the main challenge was to improve target affinity and the pharmacokinetic liabilities and both aspects were successfully addressed in second generation HDAC inhibitors. However, the primary focus was cancer, in which the cytotoxic activity is largely driven by the inhibition of HDAC1-3. Thus, medicinal chemistry lead optimization consciously or subconsciously selected for compounds with high activity against these nuclear isoforms. In the clinic, both the older and the newer compounds exhibit a similar pattern of dose limiting toxicities and adverse events dominated by fatigue, diarrhea, bone marrow toxicity, thrombocytopenia and in some cases cardiac abnormalities. Since these are observed regardless of the nature of the inhibitor, they are likely to be 
on-target effects due to systemic HDAC inhibition rather than compound specific idiosyncrasies. The pleiotropic nature of the cellular response to HDAC inhibition is indicative of a global disruption of gene expression, which leads to the following conclusions:

\section{The clinical effects are driven by HDAC1, HDAC2 and HDAC3 inhibition}

The inhibition of these isoforms increases the acetylation of histones and other nuclear proteins, leading to gene activation through increased accessibility of DNA by RNA pol II and the promotion of protein-protein interactions between bromodomain containing proteins and acetyllysine residues. Our current portfolio of clinical candidates (Tables 3 and 4) is unanimously identical in its high activity against HDAC1-3 and we believe this is the reason why compounds are not particularly differentiated from one another in their biological effects. 


\section{The inhibition of isoforms in addition to HDAC1-3 by current candidates is likely to be \\ undesirable}

The clinical compounds primarily vary in their selectivity between the nuclear isoforms

HDAC1-3 and the cytoplasmic HDAC6. Some inhibit both the nuclear and cytoplasmic enzymes strongly (e.g. vorinostat and fast followers) while others are either selective for HDAC1-3 (e.g. romidepsin, ortho-aminoanilides) or HDAC6 (e.g. ricolinostat). However, these differences have not translated into major shifts in therapeutic application or dramatic clinical benefit for one compound over another. Meanwhile, a lack of activity observed in enzyme assays against HDAC4, HDAC5, HDAC7 and HDAC9 is a misleading measure of selectivity, as a compound may still be capable of binding to the active sites and thereby abrogate their non-enzymatic role in protein scaffolding. As for HDAC8, HDAC10 and HDAC11, the traditional assays indicate differing levels of inhibition that may again be of questionable relevance given their preference for nonacetyllysine substrates. Although there are fine distinctions in biochemical in vitro selectivity between the clinical inhibitors in Tables 3 and 4, this may conceal a broader 
in vivo spectrum of activity against the majority of isoforms. While the inhibition of isoforms other than HDAC1-3 may be beneficial, in nonselective compounds any advantage that accrues is likely to be swamped out by the side effects arising from HDAC1-3 inhibition. The history of medicinal chemistry suggests that improved target selectivity usually leads to a superior safety profile, and this is likely to hold true for HDACs as well.

\title{
3. The clinical compounds are cytotoxic agents
}

\begin{abstract}
Although HDAC inhibitors are a modern chapter in drug discovery, their phenotypic effects are widespread and not restricted to a particular cellular pathway or compartment. Their activity profile as drugs, at least in its present manifestation, is reminiscent of classical cytotoxic agents rather than a targeted therapy. In their account of the discovery of vorinostat (SAHA), ${ }^{47}$ Breslow and Marks made these prescient comments: 'Even if some increase or decrease in transcription of particular genes is helpful in the anticancer effects of SAHA, as has been proven to be the case, a continuing long-term modulation induced by a drug that is slowly released from the
\end{abstract}


receptor pocket-and indeed might bind reasonably strongly to other sites-could cause undesirable effects. SAHA has hit the happy medium. It is potent enough to be useful and tolerated in patients. If the dosing is intermittent, such as not to maintain a continuous 'therapeutic' level of SAHA, it can be released from the binding site periodically so as to allow the deacetylation activities in cells. This is a general consideration, which could well be true of many other medicinal compounds. Thus, it is probably a mistake for medicinal chemists to set out first to find the most potent compound they can achieve in a series and then to look at any question of toxicity, as is often done. As with SAHA, in other series there will be examples in which the medium potency compound has enough efficacy to be a useful drug but not so much as to cause unacceptable side effects.'

\section{Clinical performance of HDAC inhibitors}

\section{Monotherapy}

Aside from the approvals in hematological cancers, HDAC inhibitors are under exploration in single agent Phase 2/3 clinical trials for other oncology applications as 
well as non-cancer indications (Table 5). Among these examples, tefinostat is designed to have selective toxicity in liver cancer. Hepatocytes express carboxylesterase- 1 that hydrolyzes the tefinostat ester to a pharmacologically active carboxylic acid which is retained due to its ionized nature, whereas in other cells efflux of the neutral drug limits exposure. Panobinostat, aside from its approval in multiple myeloma, is under investigation as an immunomodulator for graft-versus-host diseases following allogeneic hematopoietic stem cell transplantation. ${ }^{83}$ Outside oncology, vorinostat is in early studies for the treatment of epilepsy ${ }^{84}$ and Cushing's disease. ${ }^{85}$ Meanwhile, Italfarmaco is pursuing the development of givinostat for Duchenne and Becker muscular dystrophy, ${ }^{86}$ while Regenacy is targeting ricolinostat for diabetic neuropathic pain. ${ }^{87}$ Early indications from multiple myeloma clinical trials are encouraging regarding the tolerability of ricolinostat, 10-fold selective for HDAC6 over HDAC1-3, compared to inhibitors with lower selectivity. ${ }^{88}$

\begin{tabular}{|l|l|l|l|}
\hline Cpd. & Organization & Indication & Status \\
\hline
\end{tabular}




\begin{tabular}{|c|c|c|c|}
\hline romidepsin & $\begin{array}{l}\text { Bristol } \\
\text { Squibb }\end{array}$ & $\begin{array}{l}\text { cutaneous T-cell lymphoma } \\
\text { peripheral T-cell lymphoma } \\
\text { HIV, +3BNC117 }\end{array}$ & $\begin{array}{l}\text { FDA approved } \\
\text { FDA approved } \\
\text { Phase 2, \#03041012 }\end{array}$ \\
\hline vorinostat & Merck & $\begin{array}{l}\text { cutaneous T-cell lymphoma } \\
\text { epilepsy } \\
\text { Cushing's disease } \\
\text { breast cancer, } \\
\text { pembrolizumab, tamoxifen }\end{array}$ & $\begin{array}{l}\text { FDA approved } \\
\text { Phase 2, \#03894826 } \\
\text { Phase 2, \#04339751 } \\
\text { Phase 2, \#04190056 }\end{array}$ \\
\hline tefinostat & GlaxoSmithKline & hepatocellular carcinoma & $\begin{array}{ll}\text { Phase } & 1 / 2, \\
\# 02759601\end{array}$ \\
\hline ricolinostat & Regenacy & diabetic neuropathic pain & Phase 2, \#03176472 \\
\hline belinostat & Onxeo, Spectrum & peripheral T-cell lymphoma & FDA approved \\
\hline panobinostat & Novartis & $\begin{array}{l}\text { multiple myeloma } \\
\text { graft-versus-host disease } \\
\text { myelodysplastic syndrome, } \\
+ \text { azacitidine }\end{array}$ & $\begin{array}{l}\text { FDA, EMA approved } \\
\text { Phase 3, \#04326764 } \\
\text { Phase 2, \#03151304 }\end{array}$ \\
\hline pracinostat & Helsinn, Menarini & $\begin{array}{l}\text { acute myeloid leukemia, + } \\
\text { azacitidine } \\
\text { myelodysplastic syndrome, } \\
+ \text { azacitidine }\end{array}$ & $\begin{array}{l}\text { Phase 3, \#03151408 } \\
\text { Phase 2, \#03151304 }\end{array}$ \\
\hline givinostat & Italfarmaco & $\begin{array}{l}\text { Duchenne } \\
\text { dystrophy }\end{array}$ & $\begin{array}{l}\text { Phase } \\
\# 03373968\end{array}$ \\
\hline
\end{tabular}




\begin{tabular}{|c|c|c|c|}
\hline & & $\begin{array}{l}\text { polycythemia vera, } \\
\text { +hydroxyurea }\end{array}$ & Phase 2, \#00928707 \\
\hline abexinostat & Xynomics & $\begin{array}{l}\text { follicular lymphoma } \\
\text { renal carcinoma, + } \\
\text { pazopanib }\end{array}$ & $\begin{array}{l}\text { Phase 2, \#03934567 } \\
\text { Phase 3, \#03592472 }\end{array}$ \\
\hline entinostat & Syndax & $\begin{array}{l}\text { breast cancer, } \\
\text { exemestane } \\
\text { renal carcinoma, + IL-2 }\end{array}$ & $\begin{array}{l}\text { Phase 3, \#02115282 } \\
\text { and \#03538171 } \\
\text { Phase 2, \#03501381 }\end{array}$ \\
\hline tucidinostat & Chipscreen & $\begin{array}{l}\text { peripheral T-cell lymphoma } \\
\text { B-cell lymphoma } \\
\text { breast cancer, + } \\
\text { exemestane } \\
\text { soft-tissue sarcoma, + } \\
\text { toripalimab }\end{array}$ & $\begin{array}{l}\text { CFDA approved } \\
\text { Phase 3, \#04231448 } \\
\text { NMPA approved } \\
\text { Phase 2, \#04025931 }\end{array}$ \\
\hline domatinostat & $4 S C$ & GI cancers, +avelumab & Phase 2, \#03812796 \\
\hline
\end{tabular}

Table 5. Drug approvals and examples of Phase $2 / 3$ trials conducted with HDAC inhibitors. For combination trials, the other drugs involved are indicated with ' + '. The clinical trial is identified by the ClinicalTrials.gov NCT number.

\section{Combination therapy}


The development of resistance is a major obstacle to cancer chemotherapy, and one of the contributing factors is the stem cell-like tumor phenotype that fosters epigenetic reprogramming in response to the drug. This suggests that combination with a HDAC inhibitor could be valuable in sensitizing cancer cells to the treatment, and many clinical trials have investigated this hypothesis. ${ }^{89,90}$ Combination therapy of HDAC inhibitors with cytotoxic agents has not shown significant promise, and this further supports our conclusion that nonselective HDAC inhibitors themselves behave as cytotoxic agents. Meanwhile, the approval of panobinostat for multiple myeloma has led to multiple trials with first-line therapies against this indication such as bortezomib and lenalidomide. ${ }^{91}$ Numerous studies have focused on the potential synergy between kinase and HDAC inhibitors, and a Phase 3 trial is investigating the combination of abexinostat and pazopanib. ${ }^{92}$

Promising results were observed in the treatment of postmenopausal breast cancer using the combination of the aromatase inhibitor exemestane and the orthoaminoanilide HDAC inhibitor entinostat. ${ }^{93} \mathrm{~A}$ larger Phase 3 trial in China with a similar 
combination of exemestane and tucidinostat reported positive results that led to the 2019 NMPA approval of this combination for the treatment of breast cancer. ${ }^{94}$ This landmark event represents the first approval of a HDAC inhibitor for an indication outside hematological cancers.

Since both HDACs and DNMTs are transcriptional repressors, combined epigenetic therapy against these two targets is an attractive proposition. Pracinostat is in late stage trials in combination with the DNMT inhibitor azacitidine for the treatment of myelodysplastic syndrome and newly diagnosed acute myeloid leukemia. ${ }^{95,96}$ At an earlier stage, biologic antibodies, including immunotherapy agents, ${ }^{97}$ are being explored in combination trials with various HDAC inhibitors. Among the non-oncologic indications, the ability of HDAC inhibitors to reactivate latent reservoirs of the HIV virus to undergo replication appears to be the most promising for combination therapy. The potency of romidepsin in inhibiting the nuclear HDAC1-3 isoforms suggests it is a good candidate for viral transcriptional activation, and Phase 2 trials with the neutralizing antibody 3BNC117 are underway. ${ }^{98}$ 


\section{Dual mechanism agents}

An interesting approach to leveraging HDAC inhibitors is to take advantage of their simple three-point binding model. Since the cap region is not involved in critical contacts with the active site, it is possible to introduce an independent second pharmacophore here to give dual mechanism of action agents that achieve the equivalent of combination therapy within a single entity. ${ }^{99,100}$ The US company Curis has pioneered this strategy, and their first clinical candidate CUDC-101 is a hybrid of vorinostat and erlotinib with a nanomolar activity profile against both HDACs and receptor tyrosine kinases. ${ }^{101}$ A second Curis candidate fimepinostat is a hybrid of pyrimidinyl HDAC inhibitors and the PI3K inhibitor pictilisib, with nanomolar $\mathrm{IC}_{50}$ values against all four PI3K isoforms in addition to its HDAC inhibition. Fimepinostat has received FDA Fast Track status for the treatment of relapsed or refractory diffuse large B-cell lymphoma. ${ }^{102}$ It was shown to be similarly potent as romidepsin in the reversal of HIV-1 latency, without a negative effect on T cell proliferation. ${ }^{103}$ Mundipharma's tinostamustine is a more recent dual mechanism of action agent related to the DNA alkylating agent 
bendamustine, and combines this activity with HDAC inhibition. Serendipitously, the HDAC inhibitor domatinostat was recently found to have a second target as it potently inhibits tubulin polymerization. ${ }^{104}$ Larger late stage trials are needed before the efficacy and tolerability of these four multitargeting drugs can be evaluated in a clinical setting.

\section{Atypical HDAC inhibitors}

Not all HDAC inhibitors fully adhere to the classical zinc binding group-linker-cap model and some outliers illustrate the possibilities for such non-conformist compounds. Intriguingly, Olsen's romidepsin analogue 32 (Figure 11) has the thiol zinc binding group removed. ${ }^{105}$ While the compound is two orders of magnitude weaker in HDAC inhibition than romidepsin, it still possesses a respectable level of activity. Since zinc binding groups generally come with associated pharmacokinetic issues, this example suggests that it is possible to avoid them altogether if sufficient binding by other means is possible. Meanwhile, in the HDAC8 bound X-ray structure of Novartis's phenylalanine derivative 33, the two aromatic rings sit within the hydrophobic substrate channel and 
the internal cavity (Figure 12), meaning that this inhibitor has no cap. ${ }^{106}$ The X-ray structure shows coordination between the zinc cation and the $\alpha$-aminoamide, a rare motif for a zinc binding group. As the internal cavity is absent in HDAC6, 33 is inactive against this isoform and moreover shows selectively for HDAC8 over HDAC1 and HDAC2. The cyclopentenyl hydroxamic acid 34 is an even more minimal 'capless' HDAC inhibitor with some selectivity for HDAC6. ${ }^{107}$

Two other unusual HDAC inhibitors are 35 and 36 . The benzoylhydrazide 35 is a typical example of this class with reported selectivity for the nuclear isoforms HDAC1-3.108 Although X-ray crystallographic evidence of the binding mode is unavailable, docking studies suggest zinc coordination is not involved and the compound has unusual faston/slow-off kinetics. On the other hand, the vorinostat analogue 36 highlights that the linker is not just a space filling moiety. By switching from the suberoyl linker to its perfluorinated variant, the activity of the approved drug is virtually lost against human HDACs. However, 36 gains in potency against two bacterial HDAC-like enzymes PA3774 and PA0321 from the pathogen Pseudomonas aeruginosa. ${ }^{109}$ 
<smiles>CCCCNNC(=O)c1ccc(Br)cc1</smiles>

35

$$
\begin{array}{ll}
\text { HDAC1500 nM } & \text { HDAC8 } 2 \mu \mathrm{M} \\
\text { HDAC2 } 100 \mathrm{nM} & \text { HDAC69 } \mu \mathrm{M} \\
\text { HDAC3 } 60 \mathrm{nM} & \text { HDAC10 } 15 \mu \mathrm{M} \\
& \text { HDAC1145 } \mathrm{M} \\
& \text { HDAC4,5,79>100 } \mu \mathrm{M}
\end{array}
$$

HDAC8 90 nM<smiles>NCCc1cc(Cl)cc(Cl)c1</smiles>

33<smiles>O=C(NO)C1=CCCC1</smiles>

34
HDAC2 $2 \mu \mathrm{M}$ HDAC8 $1 \mu \mathrm{M}$ HDAC4 $22 \mu \mathrm{M}$ HDAC5 $18 \mu \mathrm{M}$ HDAC7 $13 \mu \mathrm{M}$ HDAC9 $>30 \mu \mathrm{M}$<smiles>COc1cccc2c1c(O)c(C(=O)N(C)c1ccc(C(F)(F)F)cc1)c(=O)n2C</smiles>

HDAC8 $11 \mathrm{nM}$ HDAC5 $110 \mathrm{nM}$ HDAC7 220 nM

HDAC1 $4 \mu \mathrm{M}$ HDAC2 $32 \mu \mathrm{M}$ HDAC3 $>50 \mu \mathrm{M}$ HDAC6 $7 \mu \mathrm{M}$ HDAC4 $9 \mu \mathrm{M}$

Figure 11. Some examples of unusual HDAC inhibitors. In this and subsequent figures, $\mathrm{IC}_{50}$ values (or in some instances $\mathrm{K}_{\mathrm{i}}$ ) against individual isoforms are given, with values below $1 \mu \mathrm{M}$ highlighted in red. 


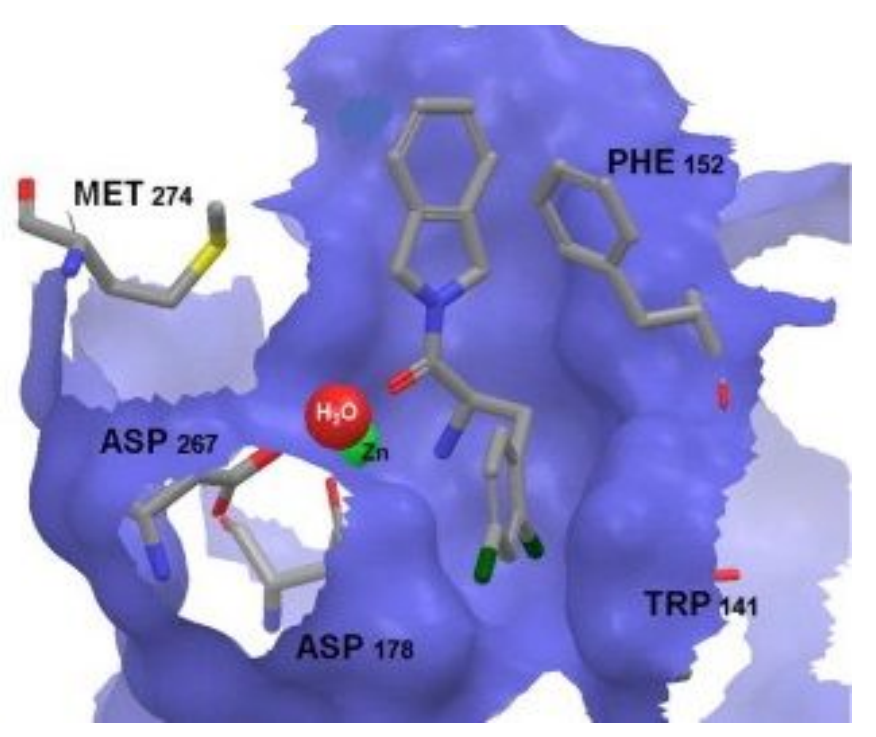

Figure 12. X-ray structure of the 33-HDAC8 complex showing active site interactions. Reprinted with permission from ref. 106.

The heterocycle 37 , despite its compact nature and apparent lack of a linker or zinc binding group, was reported to selectively inhibit HDAC8. Further investigation revealed that $\mathbf{3 7}$ is an electrophilic thiol-reactive species that leads to covalent modification of the Cys28, Cys153, Cys244, Cys314 and Cys352 residues within HDAC8. ${ }^{110}$ Both mixed disulfide and thiocyanate adducts were identified, and enzyme inhibition was predicted to be predominantly due to reaction with the Cys 153 residue within the substrate binding channel of this isoform. Perhaps the romidepsin analogue 32 has a similar mechanism of action involving allosteric modification of Cys residues by conjugate 
addition to the dehydroalanine residue, as this would explain why a similar largazole analogue lacking the unsaturated alkene was devoid of activity.

Naturally, allosteric modulators need not adhere to the standard model for HDAC active site binding. However, there are few examples of small molecules reported to bind with high affinity to HDACs outside the active site. Tasquinimod (38) is an antagonist of the calcium-binding protein S100A9 in Phase 3 clinical trials for castration-resistant prostate cancer. It was also shown to bind HDAC4 with a $\mathrm{K}_{d}$ of $10-30 \mathrm{nM}$, and homology modeling suggests allosteric binding that locks HDAC4 in an inactive conformation that is unable to interact with HDAC3.111 In endothelial cells, the administration of tasquinimod induced the same phenotype of reduced vascular inflammation as HDAC4 silencing, suggesting that the interaction between HDAC4 and tasquinimod does have a functional consequence. ${ }^{112}$

\section{Isoform selectivity}


At the preclinical stage, the most exciting development in HDAC inhibitor discovery is the identification of compounds with an enhanced isoform selectivity profile compared to those in clinical development. At the same time, it is worth asking what selectivity actually means. The enzymatic activity of HDAC1, HDAC2, HDAC3 and HDAC6 can be reliably tracked with acetyllysine containing peptides and provides meaningful data on inhibitor selectivity between these isoforms, keeping in mind that in vivo kinetics while bound to other proteins and acting upon protein substrates will be different. For all other HDAC isoforms, in vitro selectivity as measured by commercial assays is of varying physiological relevance and needs to be backed up by independent demonstration of cellular target engagement through orthogonal detection methods. Despite these caveats, highly selective compounds are now available that are valuable tools for understanding the optimum specificity for cancer and neurodegenerative disorders, two of the most important targets for HDAC inhibitors. ${ }^{113,114}$ In addition, selective inhibitors are likely to be crucial for extending HDAC inhibition therapy to chronic diseases that require wider safety profiles such as inflammation, ${ }^{115} \mathrm{~T}$-cell regulation, ${ }^{116}$ obesity, ${ }^{117}$ fibrosis, ${ }^{118}$ and alcohol use disorder. ${ }^{119}$ 
There are several patterns of isoform selectivity that appear particularly promising. Firstly, targeting transcriptional regulation would benefit from the selective inhibition of the nuclear enzymes HDAC1, HDAC2 and HDAC3 (or a subset of these three) with minimal activity against other isoforms. Conversely, selective cytoplasmic HDAC6 inhibition will have its own therapeutic applications if unaccompanied by interference with nuclear isoforms. Next, there is the opportunity to focus on the turnover of nonacetyllysine PTMs or polyamine acetylation through the selective inhibition of HDAC8, HDAC11 or HDAC10. Finally, the active site occupancy of HDAC4, HDAC5, HDAC7 or HDAC9 (without necessarily affecting catalysis) might be sufficient for pharmacological activity and eliminate their ability to bind acetyllysine containing proteins. Moreover, more complex composite patterns of selectivity can be envisioned that combine one or more of the above options without reaching the unwanted inhibition of all eleven enzymes to a substantial degree.

HDAC1 and HDAC2 
Selective inhibitors of these nuclear isoforms would be particularly useful against indications such as cancer and viral replication in which the deacetylation of histone and transcriptional regulators plays a vital role. Although the clinical compounds adequately inhibit HDAC1 and HDAC2, they are also active against some or all of the other isoforms at physiologically relevant concentrations (Tables 3 and 4) and a cleaner profile could be advantageous. Merck discovered that the addition of a 5-phenyl or 5thienyl substituent to ortho-aminoanilide HDAC inhibitors, as exemplified by 39 and $\mathbf{4 0}$ (Figure 13), ${ }^{120,121}$ or by Acetylon's ACY-957 (41), conferred high HDAC1/HDAC2 selectivity. The aryl group of the biphenyl moiety occupies the internal cavity, and in these two isoforms there is a Ser107 residue while HDAC3 contains a bulkier Tyr residue that limits access. Compound 39 outperformed nonselective HDAC inhibitors in vitro and in vivo against B-cell acute lymphoblastic leukemia, but not other B-cellderived malignancies, suggesting the selective inhibition of HDAC1/HDAC2 is sufficient for this condition. ${ }^{122}$ As a single agent and in combination with the DNMT inhibitor azacitidine, 41 had promising results against acute myeloid leukemia, including activity against primary patient derived cells and in vivo xenograft models. ${ }^{123}$ The PROTAC 
approach of recruiting an E3 ubiquitin ligase to foster degradation of a protein of interest has recently been applied to epigenetic targets. ${ }^{124}$ The ortho-aminoanilide 42 incorporates a ligand for the von Hippel-Lindau E3 ligase. ${ }^{125}$ Treatment of HCT116 cells with $10 \mu \mathrm{M}$ of $\mathbf{4 2}$ for 24 hours led to nearly complete degradation of HDAC1 and HDAC2.

HDAC2 is implicated in the negative regulation of memory formation and synaptic plasticity in the brain, with long-term potentiation impaired in HDAC2 overexpressing mice. ${ }^{126}$ Treatment with vorinostat ameliorated contextual fear conditioning but had no effect in HDAC2-deficient mice, suggesting non-redundancy between HDAC2 and HDAC1. While the high sequence homology between these two isoforms is an obstacle to the development of inhibitors that discriminate between the two, there are examples of ortho-aminoanilides that achieve a level of kinetic selectivity. Although the Broad Institute's BRD4884 (43) inhibits HDAC1 more strongly, it has a residence time half-life of 20 minutes with HDAC1 compared to 143 minutes with HDAC2. ${ }^{127}$ In the BRD4884- 
HDAC2 X-ray structure (Figure 14), there is a bridging water molecule between the pyran oxygen and the enzyme that provides additional stabilization to the complex.

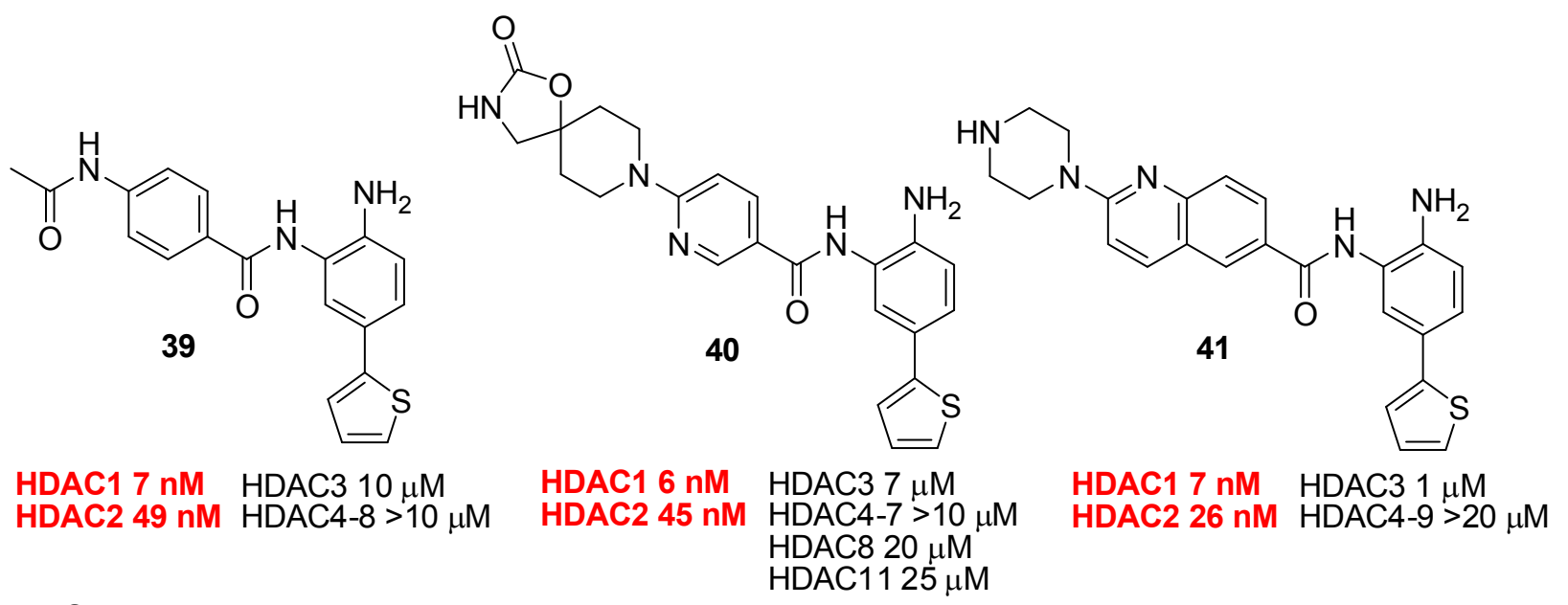

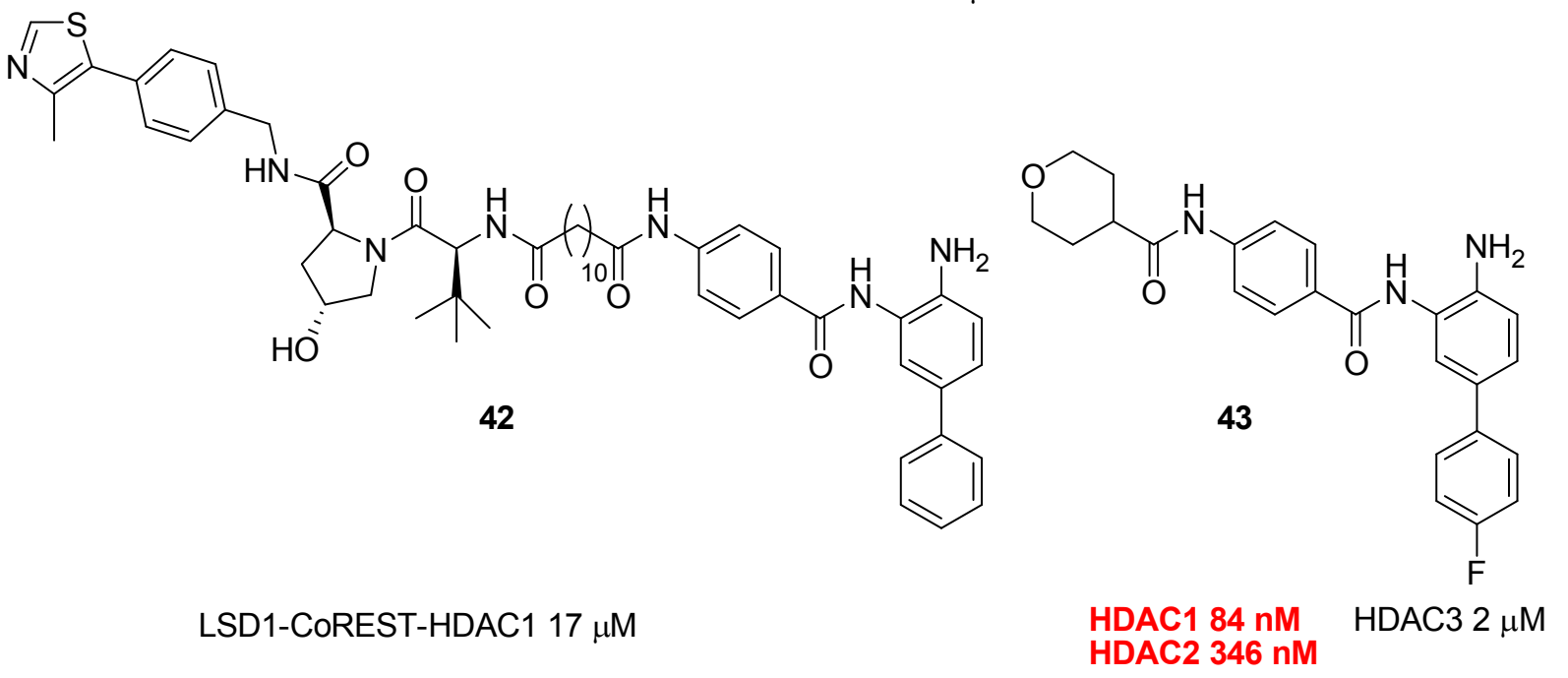

Figure 13. Examples of biaryl ortho-aminoanilide selective HDAC1/HDAC2 inhibitors. 


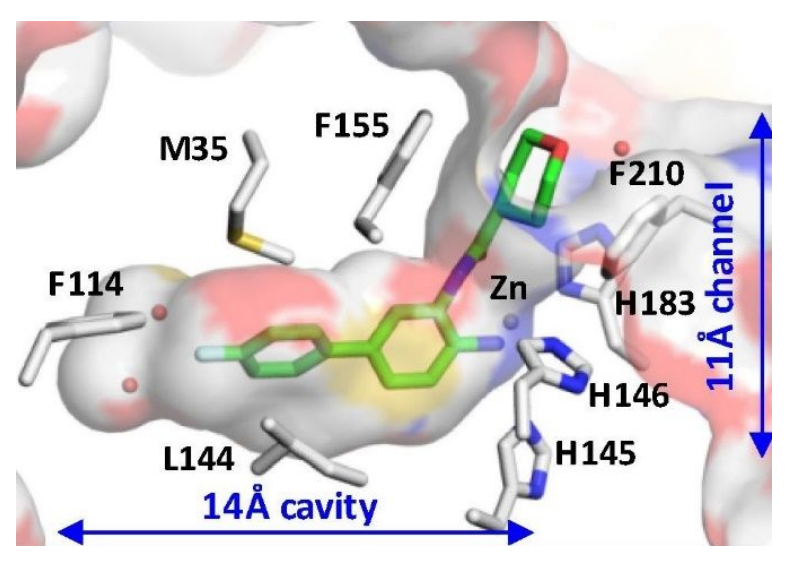

Figure 14. The X-ray structure of 43-HDAC2 is typical of ortho-aminoanilides. Bidentate coordination is observed with the zinc cation, while the addition of a 5-aryl substituent enables occupancy of the lateral internal $14 \AA$ cavity. Reprinted with permission from ref. 127.

\section{$H D A C 3$}

HDAC3 exists in multiprotein complexes that contain NCoR/SMRT which are distinct from the repressor complexes occupied by HDAC1/HDAC2. Furthermore, the selective inhibition of HDAC3 offers the ability to indirectly modulate the tissue-specific HDAC4/HDAC5/HDAC7/HDAC9, since they recruit acetyllysine containing substrates for hydrolysis by HDAC3. The design of selective HDAC3 inhibitors has recently been 
comprehensively reviewed. ${ }^{128}$ The 4 -fluoro derivative (44, Figure 15$)$ of the clinical candidate tacedinaline has a markedly HDAC3 selective profile compared to the latter attributed to both steric and electronic effects. ${ }^{129}$ The more extended cap in RGFP996 (45) from Repligen results in even higher selectivity for HDAC3 over other isoforms. More recently, the amide bearing HDAC3 selective inhibitor 46 has been reported, ${ }^{130}$ which will be useful in teasing out any compound class specific properties of the orthoaminoanilides 44 and 45.

The availability of HDAC3 selective probes has proven to be illuminating in a number of in vivo disease models. In CNS applications, 45 has promoted the extinction of drugseeking behavior, ${ }^{131}$ induced memory enhancement, ${ }^{132}$ reduced cognitive decline in Huntington's and Alzheimer's disease,$^{133,134}$ and was protective in a stroke model. ${ }^{135}$ Furthermore, 45 activated brown and beige fat suggesting potential cardiovascular applications arising through the involvement of HDAC3 with the transcriptional coactivator PRDM16. ${ }^{136}$ Meanwhile, 44 was shown to reactivate HIV-1 replication from resting CD4+ T cells isolated from antiretroviral-treated, aviremic HIV+ patients, ${ }^{137}$ and 
to suppress pancreatic islet inflammation and $\beta$-cell apoptosis in non-obese diabetic mice. ${ }^{138}$<smiles>CC(=O)Nc1ccc(C(=O)Nc2ccc(F)cc2N)cc1</smiles>

44

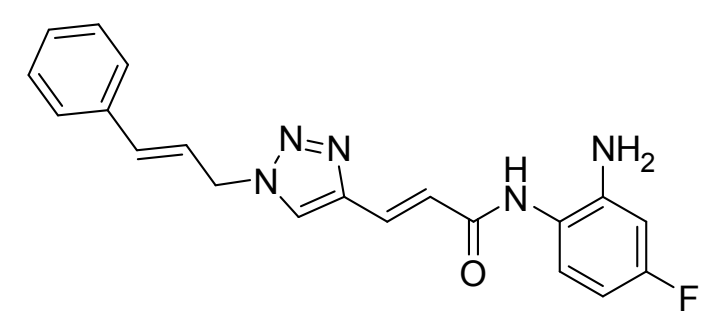

45

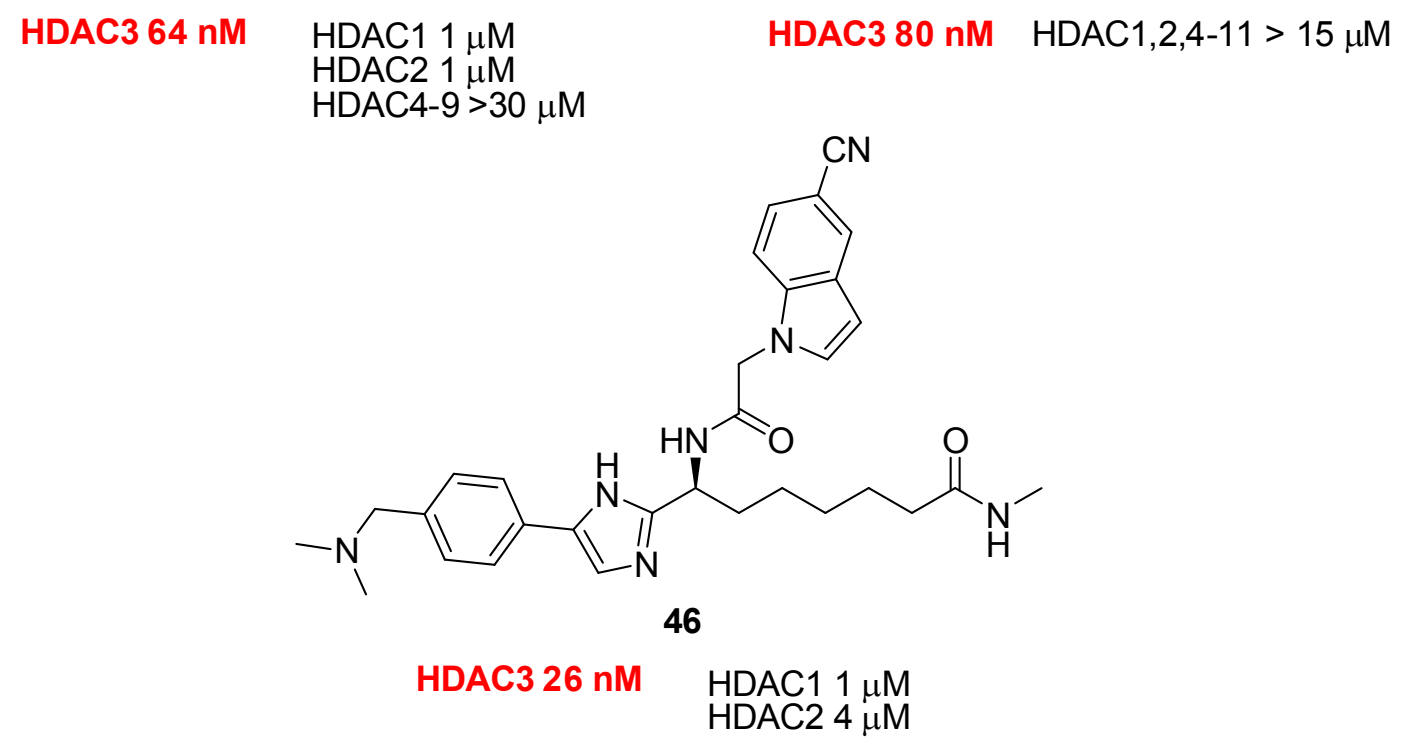

Figure 15. Examples of selective HDAC3 inhibitors.

\section{HDAC6}

The inhibition of HDAC1-3 is critical for achieving a truly epigenetic effect involving transcriptional regulation in the nucleus. On the other hand, orthogonal inhibition of the 
major cytoplasmic isoform HDAC6 is potentially valuable against a host of human diseases. HDAC6 knockout mice are viable and fertile, and although abnormalities were reported in dopaminergic signaling, ${ }^{139}$ this is in stark contrast with the lethality or clearly defective phenotypes observed with other isoforms. This suggests that a highly selective HDAC6 inhibitor would be well tolerated and avoids the on-target side effects of more promiscuous compounds. The substrate channel in HDAC6's second catalytic domain (CD2) is wider and shallower compared to HDAC1-3, favoring compounds with shorter linkers and larger, extended caps. However, because of similarities in the active sites between HDAC6 and HDAC8, discriminating between these two isoforms is more challenging. Kozikowski has pioneered the development of HDAC6-selective arylhydroxamic acid inhibitors such as tubastatin A (47, Figure 16) which is widely employed as a tool compound. ${ }^{140}$ Kozikowski's SW-100 (48) and Liou's MPT0G211 (49) are examples of more recent brain-penetrant inhibitors with a superior HDAC6/HDAC8 selectivity profile compared to tubastatin A. ${ }^{141,142}$ Instead of a phenyl linker, Acetylon's ACY-1083 (50) contains a pyrimidinyl ring and is reported to be $>250-$ fold selective for HDAC6 over other isoforms. ${ }^{143}$ 
A PROTAC example with a nonselective hydroxamic acid HDAC iunhibitor linked to a cereblon ligand nevertheless led to the selective degradation of HDAC6. ${ }^{144}$ Subsequently, the group reported 51 in which the HDAC6 selective scaffold of nexturastat $A$ was affixed to the cereblon ligand pomalidomide. ${ }^{145}$ In MM1S cells, 51 had a $\mathrm{DC}_{50}$ of $1.6 \mathrm{nM}$ for the selective degradation of HDAC6.<smiles>CN1CCc2c(c3ccccc3n2Cc2ccc(C(=O)NO)cc2)C1</smiles>

47

HDAC6 4 nM HDAC8 755 nM HDAC7 306 nM HDAC9 739 nM

HDAC1 $8 \mu \mathrm{M}$ HDAC2 $19 \mu \mathrm{M}$ HDAC3 $8 \mu \mathrm{M}$ HDAC4 $3 \mu \mathrm{M}$ HDAC5 $1 \mu \mathrm{M}$ HDAC10 $25 \mu \mathrm{M}$ HDAC11 $16 \mu \mathrm{M}$

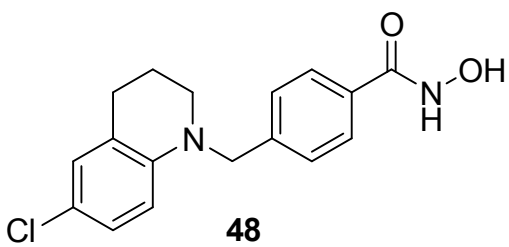

HDAC6 2 nM

HDAC1 $5 \mu \mathrm{M}$ HDAC2 $33 \mu \mathrm{M}$ HDAC3 $30 \mu \mathrm{M}$ HDAC8 $4 \mu \mathrm{M}$ HDAC4 $11 \mu \mathrm{M}$ HDAC5 $4 \mu \mathrm{M}$ HDAC7 $5 \mu \mathrm{M}$ HDAC9 $4 \mu \mathrm{M}$ HDAC10 $26 \mu \mathrm{M}$ HDAC $116 \mu \mathrm{M}$<smiles>O=C(NO)c1ccc(CNc2cccc3cccnc23)cc1</smiles>

HDAC6 0.3 nM HDAC1 $10 \mu \mathrm{M}$ HDAC7 709 nM HDAC2 $13 \mu \mathrm{M}$ HDAC11 376 nM HDAC3 $8 \mu \mathrm{M}$ HDAC8 $1 \mu \mathrm{M}$ HDAC4 $4 \mu \mathrm{M}$ HDAC5 $3 \mu \mathrm{M}$ HDAC9 $2 \mu \mathrm{M}$ HDAC10 $10 \mu \mathrm{M}$<smiles>O=C(NO)c1cnc(C2(c3ccccc3)CCC(F)(F)CC2)nc1</smiles>

HDAC6 3 nM

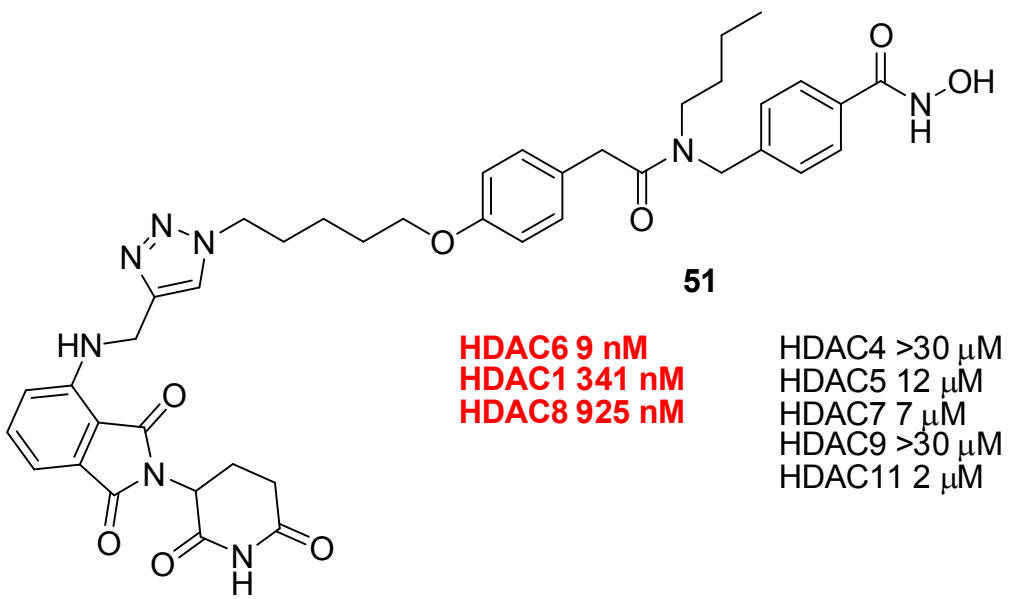


Figure 16. Examples of selective HDAC6 inhibitors. See also the HDAC10 discussion on tubastatin (47) and analogues.

X-ray crystallographic studies with HDAC6 selective arylhydroxamic acids indicate mono-coordination within the shallower active site compared to the more common bidentate zinc coordination observed against other isoforms. ${ }^{146}$ Meanwhile, the aryl group engages in $\pi-\pi$ interactions with the substrate channel while the cap extends into the solvent exposed enzyme rim, as illustrated by the binding of $\mathbf{5 0}$ to HDAC6 (Figure 17). Recent studies (see below), suggest that tubastatin and related compounds with a basic amine in the linker or cap region are also capable of inhibiting the acetylspermidine hydrolysis activity of HDAC10. 


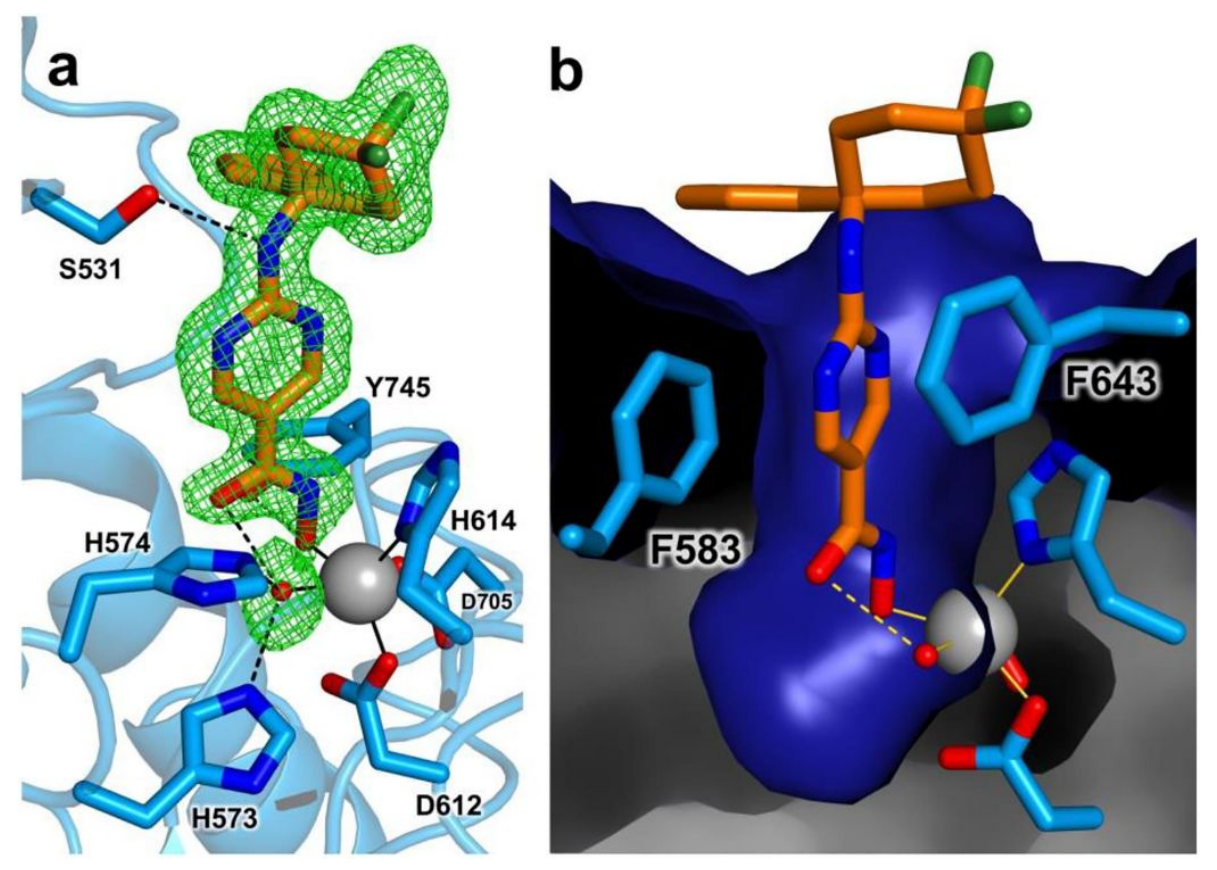

Figure 17. a) Simulated annealing omit map of the 50-HDAC6 (catalytic domain 2) binding. The hydroxamic acid engages in mono-coordinate interactions with the zinc cation while the carbonyl group hydrogen bonds the active site water involved in amide hydrolysis. The linker makes an additional hydrogen bond with Ser531. b) Cut-away view of the active site surface highlighting the zinc coordination polyhedron and the aromatic interactions between the inhibitor and the substrate binding channel. Reprinted with permission from ref. 146 .

The inhibition of HDAC6 has been extensively studied in cell-based and in vivo disease models, although some examples involved compounds with lower selectivity profiles than 47-51 and phenotypic effects may be due to residual effects against other HDAC isoforms. Robust data has been obtained in animal models for cancer and 


\begin{abstract}
neurodegenerative disorders, with early stage clinical trials ongoing for the treatment of hematological malignancies, solid tumors and Huntington's disease, as well as Regenacy's planned Phase 2 trial with ricolinostat for diabetic neuropathic pain. ${ }^{147,148}$ In addition, earlier preclinical studies are promising against a number of other indications. ${ }^{149}$
\end{abstract}

\title{
HDAC8
}

The challenge with HDAC8 inhibition is to avoid hitting the other nuclear isoforms HDAC1-3 as well as the cytoplasmic HDAC6. ${ }^{150}$ With regards to the latter, ortho- or meta-substituted aromatic linkers are helpful, compared to the para-substitution typical in HDAC6 selective inhibitors. Pharmacyclic's PCl-34051 (52, Figure 18) was the first to exhibit high selectivity for HDAC8 and is the most widely used tool compound for this isoform. ${ }^{151}$ Newer examples include Huang's cinnamoyl terphenylhydroxamic acid WK216 (53) and Beeler's phenylalanine derived hydroxamic acid $54 .{ }^{152,153}$ In animal models, selective HDAC8 inhibitors have shown promise in neuroblastoma ${ }^{154}$ as well as different 
inflammatory settings such as hypertensive inflammation, ${ }^{155}$ neuroinflammation ${ }^{156}$ and airway inflammation. ${ }^{157}$ Recently, $\mathbf{5 2}$ was shown to resensitize melanoma tumor xenograft cells to inhibition by the tyrosine kinase inhibitor erlotinib. ${ }^{158}$<smiles>COc1ccc(Cn2ccc3ccc(C(=O)NO)cc32)cc1</smiles>

52<smiles>COc1ccc(/C=C/C(=O)NO)c(-c2ccc(-c3ccccc3)cc2)c1</smiles>

53<smiles>O=C(NO)[C@H](Cc1ccccc1)n1nnc(-c2ccccc2)c1C#CC1CC1</smiles>

54

HDAC8 56 nM HDAC1 $8 \mu \mathrm{M}$ HDAC2 $>20 \mu \mathrm{M}$ HDAC3 >20 $\mu \mathrm{M}$ HDAC6 $20 \mu \mathrm{M}$ HDAC4 $>20 \mu \mathrm{M}$ HDAC10 $>20 \mu \mathrm{M}$ HDAC11 $>20 \mu \mathrm{M}$

HDAC8 27 nM HDAC1 $3 \mu \mathrm{M}$ HDAC2 $>20 \mu \mathrm{M}$ HDAC3 $3 \mu \mathrm{M}$ HDAC6 $>20 \mu \mathrm{M}$ HDAC4 $>20 \mu \mathrm{M}$ HDAC10 $>20 \mu \mathrm{M}$ HDAC11 $>20 \mu \mathrm{M}$

Figure 18. Examples of selective HDAC8 inhibitors.

\section{HDAC11}

The first selective HDAC11 inhibitor FT895 (55, Figure 19) was recently reported by

FORMA, and modeling suggests that the pyrazine ring extends into the internal cavity adjacent to the zinc cation. ${ }^{159}$ While fluorescent acetyllysine peptide substrates were 
used in FORMA's enzymatic assays, Lin employed a potentially more relevant myristoyllysine peptide with HPLC monitoring to discover acylhydrazide inhibitor $56{ }^{160}$ In this assay, 55 and 56 were of similar potency in inhibiting demyristoylation. Presumably, $\mathbf{5 6}$ binds to HDAC11 with the alkyl chain occupying the internal cavity. With the availability of such probes, in vivo investigations will become possible to validate the importance of HDAC11 as a therapeutic target.<smiles>CC1(C)c2cccc(C(=O)NO)c2CN1c1cnc(C(F)(F)F)cn1</smiles>

55<smiles>CCCCCCCCCCCCCCCCNNC(=O)c1cccs1</smiles>

56

HDAC11 3 nM HDAC1-7,9,10>10 $\mu \mathrm{M}$ HDAC8 $6 \mu \mathrm{M}$

HDAC11 830 nM HDAC1-7,9,10 >10 $\mu \mathrm{M}$ HDAC8 $6 \mu \mathrm{M}$

Figure 19. Examples of selective HDAC11 inhibitors.

HDAC10

\begin{abstract}
The profiling of approved and clinical candidate HDAC inhibitors indicates that many strongly inhibit HDAC10 in assay kits employing trifluoroacetyllysine substrates.
\end{abstract}


Although we now know that HDAC10 is a small molecule polyamine deacetylase, the assay results indicate that many HDAC inhibitors are capable of entering and occupying the substrate channel. Recently, instead of the conventional monitoring of product formation, Miller employed a FRET ligand displacement assay. In this assay, the HDAC6 selective inhibitor tubastatin A (47) actually bound more strongly to HDAC10 than HDAC6. ${ }^{161}$ Since tubastatin A was much more effective than other HDAC inhibitors tested, it is likely that the molecule's amine forms a favorable electrostatic interaction with the glutamate gatekeeper residue unique to HDAC10. From a library of tubastatin $A$ analogues, compounds 57 and 58 (Figure 20) were slightly more potent in HDAC10 binding, perhaps due to a greater rotational flexibility to accommodate interaction with the glutamate. Furher improvements will be needed to ensure HDAC6/HDAC10 selectivity with these tubastatin A based compounds. 
<smiles>CN1CCc2c(c3ccccc3n2Cc2ccc(C(=O)NO)cc2)C1</smiles>

HDAC10 13 nM
HDAC1 $1 \mu \mathrm{M}$ HDAC2 $13 \mu \mathrm{M}$ HDAC3 $2 \mu \mathrm{M}$ HDAC8 $1 \mu \mathrm{M}$<smiles>CN(C)Cc1cn(Cc2ccc(C(=O)NO)cc2)c2ccccc12</smiles>

57<smiles>O=C(NO)c1ccc(Cn2cc(CN3CCCC3)c3ccccc32)cc1</smiles>

HDAC10 $5 \mathrm{nM} \quad \mathrm{HDAC} 11 \mu \mathrm{M}$ HDAC3 $631 \mathrm{nM}$ HDAC2 $6 \mu \mathrm{M}$ HDAC8 398 nM

HDAC10 4 nM HDAC1 $794 \mathrm{nM}$ HDAC3 $398 \mathrm{nM}$ HDAC8 $316 \mathrm{nM}$

HDAC2 $6 \mu \mathrm{M}$<smiles>NCCCNCCCCCC(=O)NO</smiles>

HDAC10 120 nM

Figure 20. Tubastatin A (47), analogues 57 and 58, and the spermidine hydroxamic acid 59. Note that $I_{50}$ values for 47,57 and 58 correspond to a FRET displacement assay for HDAC10 and enzymatic assays for other isoforms. The value for 59 comes from an assay monitoring $\mathrm{N}$-acetylputrescine hydrolysis.

Christianson examined a number of spermidine derivatives as potential inhibitors, using an enzymatic assay based on $\mathrm{N}$-acetylputrescine hydrolysis. The hydroxamic acid $\mathbf{5 9}$ is a submicromolar HDAC10 inhibitor, and the X-ray structure (Figure 21) of 59 omplexed to Danio rerio (zebrafish) HDAC10 has provided useful information on the binding interactions. The hydroxamic acid engages in bidentate coordination with the zinc cation, while the methylene chain features a bifurcated hydrogen bond between the secondary amine $\mathrm{NH}$ proton and the gatekeeper glutamate residue..$^{162}$ 


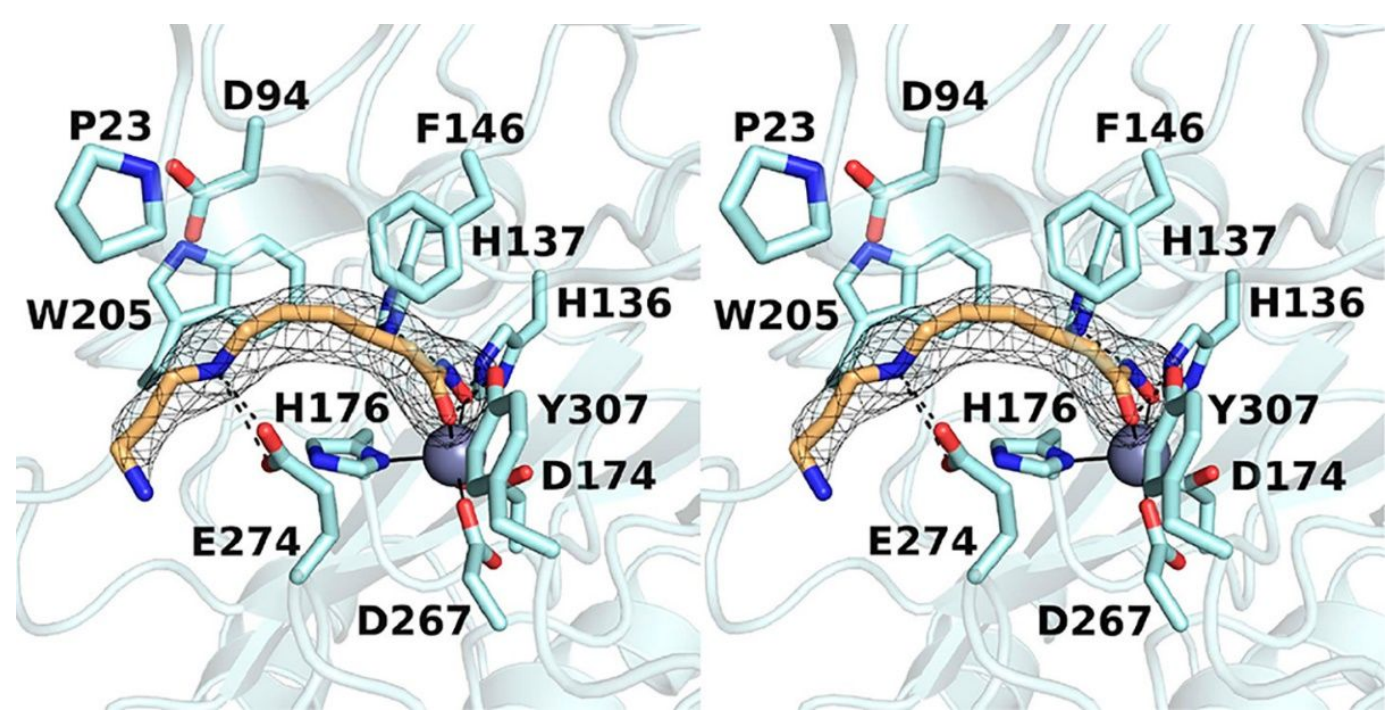

Figure 21. Polder omit map of 59 bound to the active site of HDAC10. The hydroxamic acid is coordinated as a bidentate ligand to the zinc cation, while the $\mathrm{NH}$ proton engages in hydrogen bonding with the Glu274 gatekeeper residue. Reprinted from ref. 162.

\section{HDAC4/HDAC5/HDAC7/HDAC9}

Since these isoforms have low catalytic activity, assays have employed mutant enzymes or reactive trifluoroacetyllysine substrates. While the physiological relevance of such data is questionable, it does give an idea of active site occupancy. The highly selective inhibitor TMP269 (60, Figure 21) was reported by Tempero and contains an 
unusual oxadiazole zinc binding group. ${ }^{163}$ The X-ray structure of 60 bound to HDAC7 revealed a U-shaped conformation with interactions between a fluorine and the oxadiazole oxygen with the zinc, at relatively long distances of $2.7 \AA$ and $3.0 \AA$ respectively compared to the $\sim 2 \AA$ observed with hydroxamic acids. Thus, the binding involves weak electrostatic interactions with zinc rather than direct coordination. Because these HDACs have an active site tyrosine (Figure 2) replaced by the smaller histidine, the more roomy substrate binding channel is able to accommodate the bulky trifluoromethyloxadiazole unlike the other isoforms, leading to high selectivity. In mouse models, 60 demonstrated protective activity against pulmonary arterial hypertension and cerebral ischemia/reperfusion injury. ${ }^{164,165}$ The structurally related analogue TMP195 reduced mycobacterial infection in a zebrafish embryo model for tuberculosis. ${ }^{166}$

The CHDI Foundation reported a more conventional hydroxamic acid inhibitor 61 but with an unusual chiral cyclopropane scaffold. ${ }^{167}$ The first generation compound lacking the cyclopropyl fluorine substituent had poorer pharmacokinetic properties due to glucuronidation. An X-ray structure of des-fluoro-61 with HDAC4 (Figure 22) indicates 
bidentate coordination of the hydroxamic acid with the phenyl ring in a lower pocket engaged in $\pi$-stacking interactions. More recently, $\mathrm{CHDI}$ have disclosed the aromatic hydroxamic acid CHDI-390576 (62) with good plasma, muscle and brain exposure in vivo upon oral administration in mice. ${ }^{168}$<smiles>O=C(NCC1(c2nc(-c3ccccc3)cs2)CCOCC1)c1cccc(-c2noc(C(F)(F)F)n2)c1</smiles>

60

\begin{abstract}
HDAC4 $126 \mathrm{nM}$ HDAC5 $80 \mathrm{nM}$ HDAC7 $36 \mathrm{nM}$ HDAC9 19 nM
\end{abstract}<smiles>O=C(NO)[C@]1(F)[C@H](c2ccccc2)[C@H]1c1ccc(-c2ncc(F)cn2)cc1</smiles>

61

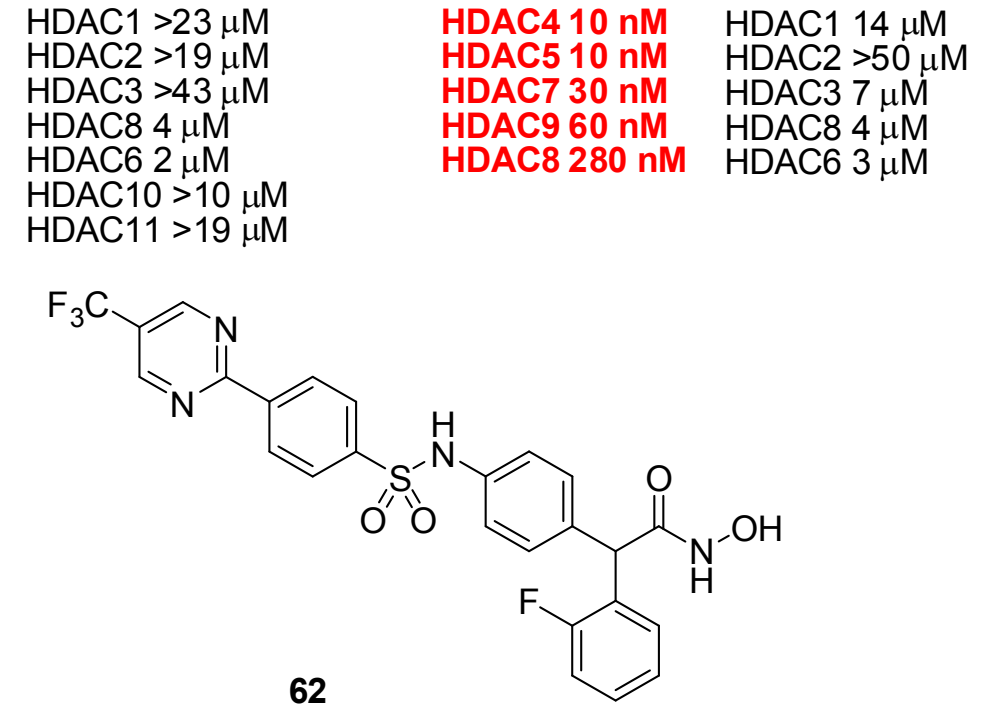

HDAC4 54 nM HDAC5 $60 \mathrm{nM}$ HDAC7 $31 \mathrm{nM}$ HDAC9 50 nM

HDAC1 $40 \mu \mathrm{M}$ HDAC2 $>50 \mu \mathrm{M}$ HDAC3 $26 \mu \mathrm{M}$ HDAC8 $9 \mu \mathrm{M}$ HDAC6 $6 \mu \mathrm{M}$

Figure 21. Examples of selective HDAC4/HDAC5/HDAC7/HDAC9 inhibitors. 


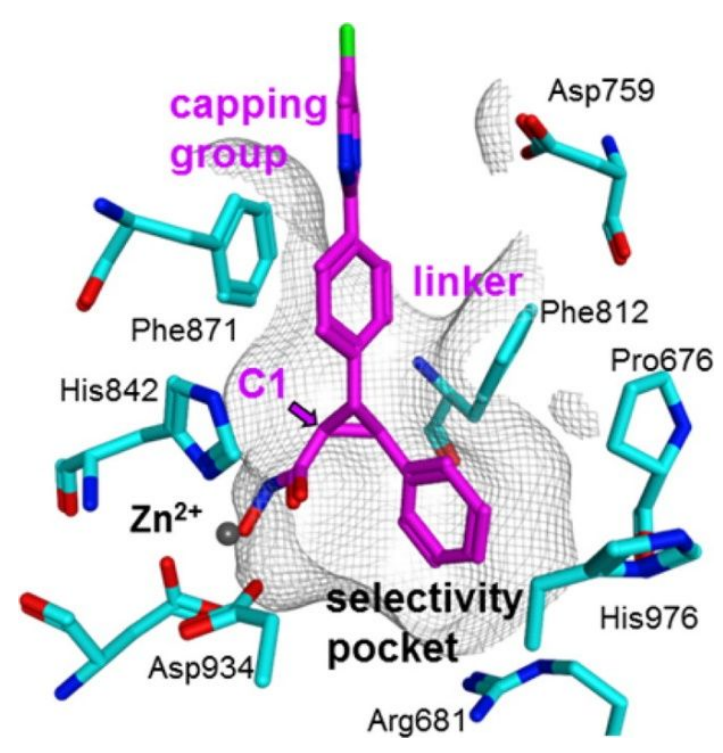

Figure 22. The binding interactions of des-fluoro-61 (with $\mathrm{H}$ instead of $\mathrm{F}$ at $\mathrm{C} 1$ ) within the HDAC4 active site, showing the occupancy of the selectivity pocket by the phenyl ring. Reprinted from ref. 167.

\section{Summary}

The timeline from bench to bedside was remarkably speedy for HDACs. The clinical trials of a HDAC inhibitor began in 2000 , only four years after the first mammalian HDAC was characterized. In the last twenty years, over 30 HDAC inhibitors have entered clinical development with five regulatory approvals. Nevertheless, these medicinal chemistry successes have occurred despite the biological complexity of the target. Although there are only eleven human HDACs, this small number carries out a 
set of at least five cellular functions: nuclear lysine deacetylation (HDAC1/2/3), cytoplasmic lysine deacetylation (HDAC6), fatty acid deacylation (HDAC8/11), polyamine deacylation (HDAC10) and acetyllysine recognition (HDAC4/5/7/9). We believe that selectivity will be the key to unlock the full therapeutic value of HDAC inhibitors, and a toolkit of compounds is now available (Table 6) that will fuel future discoveries in HDAC biology and drug discovery.

\begin{tabular}{|l|l|l|l|}
\hline Isoform & Compound class & Examples & $\begin{array}{l}\text { Selectivity } \\
\text { challenge }\end{array}$ \\
\hline HDAC1/2 & 5-aryl-ortho-aminoanilides & $39-43$ & HDAC1 vs 2 \\
\hline HDAC3 & 4-fluoro-ortho-aminoanilides & 44,45 & HDAC1/2 \\
\hline HDAC6 & para-arylhydroxamic acids & $47-51$ & HDAC8/10 \\
\hline HDAC8 & ortho/meta-arylhydroxamic acids & $\mathbf{5 2 - 5 4}$ & HDAC6 \\
\hline HDAC11 & ortho/meta-arylhydroxamic acids & $\mathbf{5 5}$ & HDAC8 \\
\hline HDAC10 & basic hydroxamic acids & $47,57-59$ & HDAC6 \\
\hline HDAC4/5/7/9 & $\begin{array}{l}\text { oxadiazoles, a-branched hydroxamic } \\
\text { acids }\end{array}$ & $60-62$ & HDAC4 vs 5 vs 7 vs \\
\hline
\end{tabular}

Table 6. Summary of the major isoform selective HDAC inhibitors, and the selectivity issues faced within each class. 


\begin{abstract}
While the next 30 years are too distant for accurate predictions, we anticipate that major advances will already occur within the next decade along many fronts including the following:
\end{abstract}

- Target validation to identify the ideal HDAC inhibitor profile for specific therapeutic indications.

- Unconventional approaches to HDAC drug discovery e.g. dual mechanism agents, PROTACs, covalent inhibitors, non-active site modulators.

- Personalized medicine and patient stratification strategies, which are rare at the present time for HDAC inhibitor therapy.

- Clinical optimization of HDAC dosing regimens, particularly the timing of administration for combination therapies. 


\title{
AUTHOR INFORMATION
}

\begin{abstract}
A. Ganesan*
*School of Pharmacy, University of East Anglia, Norwich NR4 7TJ, United Kingdom
\end{abstract}

\section{Author Contributions}

The manuscript was written through contributions of all authors. All authors have given approval to the final version of the manuscript.

\section{ABBREVIATIONS}

ABC, ATP-binding cassette; Abl, Abelson murine leukemia viral oncogene homolog; ARID, AT-rich interactive domain-containing protein; ATM, ataxia-telangiectasia mutated; BAX, BCL2 associated $X$ protein; BRD, bromodomain; CAF, chromatin assembly factor; CFDA, China Food and Drug Administration; CIP, cyclin-dependent kinase inhibitory protein; CoREST, co-repressor for element-1-silencing transcription factor; $\mathrm{DC}_{50}$, half maximal concentration of protein degradation; DNMT, DNA methyltransferase; E2F, E2 promoter binding factor; EMA, European Medicines Agency; ERR, estrogen-related receptor; FDA, Food and Drug Administration; FOXP, forkhead 
box P; FRET, fluorescence resonance energy transfer; GR, glucocorticoid receptor; GRP, glucose-regulated protein; HAT, histone acetyltransferase; HDAC, histone deacetylase; HIF, hypoxia-inducing factor; Hos, Histone deacetylase-A one similar; Hsp, heat shock protein; Ku, lupus Ku autoantigen protein; LSD, lysine-specific demethylase; MEF, myocyte enhancer factor; MiDAC, mitotic deacetylase complex; MIER, mesoderm induction early response; NCoR, nuclear receptor corepressor; NCT, national clinical trial; NES, nuclear export sequence; NLS, nuclear localization sequence; NMPA, National Medical Products Administration; NuRD, nucleosome remodeling and deacetylation; PCAF, P300/CBP-associated factor (KAT2B); PRDM, PR domain containing; PROTAC, proteolysis targeting chimera; PTM, post-translational modification; SMC, structural maintenance of chromosome; SMRT, silencing mediator of retinoic and thyroid receptors; Sin, SWI-independent; STAT, signal transducer and activator of transcription; WAF, wild-type activating fragment.

\section{Biographical Sketch}


Terence C. Ho obtained his first class Master's degree in Pharmacy (MPharm) from the University of East Anglia (UK) in 2017. During the course, he undertook a final year project under Professor Mark Searcey on peptide stapling of peptide chains to inhibit the p53-MDM2 protein-protein interaction for applications in oncology. In 2018, he started studying Medicine (MBBS) at the University of East Anglia and is currently in his second year.

Alex H. Y. Chan received his first class Master's degree of Pharmacy (MPharm) from the University of East Anglia (UK) in 2017. He won the Andrew Thompson Prize for the best Medicinal Chemistry research project on the design and synthesis of triazole-based HDAC inhibitors for Schistosomiasis therapy under the supervision of Professor Ganesan. Currently he is a second year doctoral student in Chemistry at the University of Cambridge (UK) under the supervision of Dr. Finian Leeper working on the design, synthesis and biological evaluation of thiamine pyrophosphate dependent enzyme inhibitors for malarial treatment. His research interests lie in discovering small molecules as selective drugs to combat infectious diseases. 
Ganesan (one name only) was born in Malaysia and obtained his undergraduate degree in Chemistry from the neighboring National University of Singapore. After graduate studies at the University of California-Berkeley and postdoctoral research at Harvard University, he returned to Singapore to work at the Centre for Natural Product Research. Subsequently, he was Principal Investigator at Singapore's Institute of Molecular and Cell Biology and Reader at the University of Southampton's Department of Chemistry before taking up his present position. Ganesan's interests are in drug discovery, natural products and epigenetics. He was a chair of the European COST networks TD0905 Epigenetics: From Bench to Bedside and CM1406 Epigenetic Chemical Biology. He is a co-founder of Karus Therapeutics and sits on the IUPAC Drug Discovery and Development and the RSC Bioorganic and Medicinal Chemistry Sector committees.

\section{References}


${ }^{1}$ Azevedo, C.; Saiardi, A. Why Always Lysine? The Ongoing Tale of One of the Most Modified Amino Acids. Adv. Biol. Regul. 2016, 60, 144-150.

2 Xu, H.; Zhou, J.; Lin, S.; Deng, W.; Zhang, Y.; Xue, Y. PLMD: An Updated Data Resource of Protein Lysine Modifications. J. Genet. Genomics 2017, 44, 243-250.

3 Ganesan, A. Epigenetic Drug Discovery: A Success Story for Cofactor Interference. Philos. Trans. R. Soc. Lond., B, Biol. Sci. 2018, 373, 20170069.

${ }^{4}$ Miller, T. A.; Witter, D. J.; Belvedere, S. Histone Deacetylase Inhibitors. J. Med. Chem. 2003, 46, 5097-5116.

${ }^{5}$ Paris, M.; Porcelloni, M.; Binaschi, M.; Fattori, D. Histone Deacetylase Inhibitors: From Bench to Clinic. J. Med. Chem. 2008, 51, 1505-1529.

${ }^{6}$ Narita, T.; Weinert, B. T.; Choudhary, C. Functions and Mechanisms of Non-Histone Protein Acetylation. Nat. Rev. Mol. Cell Biol. 2019, 20, 156-174.

7 Cochran, A. G.; Conery, A. R.; Sims, R. J. Bromodomains: A New Target Class for Drug Development. Nat. Rev. Drug Discov. 2019, 18, 609-628.

8 Barnes, C. E.; English, D. M.; Cowley, S. M. Acetylation \& Co: An Expanding Repertoire of Histone Acylations Regulates Chromatin and Transcription. Essays Biochem. 2019, 63, 97-107.

9 Yoshida, M.; Kudo, N.; Kosono, S.; Ito, A. Chemical and Structural Biology of Protein Lysine Deacetylases. Proc. Jpn. Acad., Ser. B, Phys. Biol. Sci. 2017, 93, 297-321.

10 Jiang, Y.; Liu, J.; Chen, D.; Yan, L.; Zheng, W. Sirtuin Inhibition: Strategies, Inhibitors, and Therapeutic Potential. Trends Pharmacol. Sci. 2017, 38, 459-472.

11 Ganesan, A. Targeting the Zinc-Dependent Histone Deacetylases (HDACs) for Drug Discovery. In Topics in Medicinal Chemistry 33. Epigenetic Chemistry, Mai, A., Ed.; Springer: Cham, 2020; pp 1-28.

12 Porter, N. J.; Christianson, D. W. Structure, Mechanism, and Inhibition of the ZincDependent Histone Deacetylases. Curr. Opin. Struct. Biol. 2019, 59, 9-18. 
13 Kelly, R. D. W.; Cowley, S. M. The Physiological Roles of Histone Deacetylase (HDAC) 1 and 2: Complex Co-Stars with Multiple Leading Parts. Biochem. Soc. Trans. 2013, 41, 741-749.

14 Emmett, M. J.; Lazar, M. A. Integrative Regulation of Physiology by Histone Deacetylase 3. Nat. Rev. Mol. Cell Biol. 2019, 20, 102-115.

${ }^{15}$ Li, T.; Zhang, C.; Hassan, S.; Liu, X.; Song, F.; Chen, K.; Zhang, W.; Yang, J. Histone Deacetylase 6 in Cancer. J. Hematol. Oncol. 2018, 11, 111.

${ }^{16}$ Kutil, Z.; Skultetyova, L.; Rauh, D.; Meleshin, M.; Snajdr, I.; Novakova, Z.; Mikesova, J.; Pavlicek, J.; Hadzima, M.; Baranova, P.; Havlinova, B.; Majer, P.; Schutkowski, M.; Barinka, C. The Unraveling of Substrate Specificity of Histone Deacetylase 6 Domains Using Acetylome Peptide Microarrays and Peptide Libraries. FASEB J. 2019, 33, 40354045 .

17 Osko, J. D.; Christianson, D. W. Structural Basis of Catalysis and Inhibition of HDAC6 CD1, the Enigmatic Catalytic Domain of Histone Deacetylase 6. Biochemistry 2019, 58, 4912-4924.

${ }^{18}$ Chakrabarti, A.; Oehme, I.; Witt, O.; Oliveira, G.; Sippl, W.; Romier, C.; Pierce, R. J.; Jung, M. HDAC8: A Multifaceted Target for Therapeutic Interventions. Trends Pharmacol. Sci. 2015, 36, 481-492.

19 Castañeda, C. A.; Wolfson, N. A.; Leng, K. R.; Kuo, Y.-M.; Andrews, A. J.; Fierke, C. A. HDAC8 Substrate Selectivity Is Determined by Long- and Short-Range Interactions Leading to Enhanced Reactivity for Full-Length Histone Substrates Compared with Peptides. J. Biol. Chem. 2017, 292, 21568-21577.

${ }^{20}$ Aramsangtienchai, P.; Spiegelman, N. A.; He, B.; Miller, S. P.; Dai, L.; Zhao, Y.; Lin, H. HDAC8 Catalyzes the Hydrolysis of Long Chain Fatty Acyl Lysine. ACS Chem. Biol. 2016, 11, 2685-2692.

21 Yanginlar, C.; Logie, C. HDAC11 Is a Regulator of Diverse Immune Functions. Biochim. Biophys. Acta Gene Regul. Mech. 2018, 1861, 54-59. 
22 Kutil, Z.; Novakova, Z.; Meleshin, M.; Mikesova, J.; Schutkowski, M.; Barinka, C. Histone Deacetylase 11 Is a Fatty-Acid Deacylase. ACS Chem. Biol. 2018, 13, 685693.

23 Moreno-Yruela, C.; Galleano, I.; Madsen, A. S.; Olsen, C. A. Histone Deacetylase 11 Is an $\varepsilon-N$-Myristoyllysine Hydrolase. Cell Chem. Biol. 2018, 25, 849-856.

${ }^{24}$ Asfaha, Y.; Schrenk, C.; Alves Avelar, L. A.; Hamacher, A.; Pflieger, M.; Kassack, M. U.; Kurz, T. Recent Advances in Class Ila Histone Deacetylases Research. Bioorg. Med. Chem. 2019, 27, 115087.

25 Matthews, B. M. Structural basis of the action of thermolysin and related zinc peptidases. Acc. Chem. Res. 1988, 21, 333-340.

26 Koeneke, E.; Witt, O.; Oehme, I. HDAC Family Members Intertwined in the Regulation of Autophagy: A Druggable Vulnerability in Aggressive Tumor Entities. Cells 2015, 4, 135-168.

27 Hai, Y.; Shinsky, S. A.; Porter, N. J.; Christianson, D. W. Histone Deacetylase 10 Structure and Molecular Function as a Polyamine Deacetylase. Nat. Commun. 2017, 8, 15368.

28 Shinsky, S. A.; Christianson, D. W. Polyamine Deacetylase Structure and Catalysis: Prokaryotic Acetylpolyamine Amidohydrolase and Eukaryotic HDAC10. Biochemistry 2018, 57, 3105-3114.

29 Kuchler, K.; Jenull, S.; Shivarathri, R.; Chauhan, N. Fungal KATs/KDACs: A New Highway to Better Antifungal Drugs? PLoS Pathog. 2016, 12, e1005938.

30 Pfaller, M. A.; Rhomberg, P. R.; Messer, S. A.; Castanheira, M. In Vitro Activity of a Hos2 Deacetylase Inhibitor, MGCD290, in Combination with Echinocandins against Echinocandin-Resistant Candida Species. Diagn. Microbiol. Infect. Dis. 2015, 81, 259263.

31 Fioravanti, R.; Mautone, N.; Rovere, A.; Rotili, D.; Mai, A. Targeting Histone Acetylation/Deacetylation in Parasites: An Update (2017-2020). Curr. Opin. Chem. Biol. 2020, (in press). doi: 10.1016/j.cbpa.2020.05.008 
32 Heltweg, B.; Trapp, J.; Jung, M. In Vitro Assays for the Determination of Histone Deacetylase Activity. Methods 2005, 36, 332-337.

33 Liao, D. Profiling Technologies for the Identification and Characterization of SmallMolecule Histone Deacetylase Inhibitors. Drug Discovery Today: Technol. 2015, 18, 24 28.

34 Bradner, J. E.; West, N.; Grachan, M. L.; Greenberg, E. F.; Haggarty, S. J.; Warnow, T.; Mazitschek, R. Chemical Phylogenetics of Histone Deacetylases. Nat. Chem. Biol. 2010, 6, 238-243.

35 Madsen, A. S.; Olsen, C. A. Profiling of Substrates for Zinc-Dependent Lysine Deacylase Enzymes: HDAC3 Exhibits Decrotonylase Activity in Vitro. Angew. Chem. Int. Ed. Engl. 2012, 51, 9083-9087.

36 Kutil, Z.; Mikešová, J.; Zessin, M.; Meleshin, M.; Nováková, Z.; Alquicer, G.; Kozikowski, A.; Sippl, W.; Bařinka, C.; Schutkowski, M. Continuous Activity Assay for HDAC11 Enabling Reevaluation of HDAC Inhibitors. ACS Omega 2019, 4, 1989519904.

${ }^{37} \mathrm{Hau}$, M.; Zenk, F.; Ganesan, A.; lovino, N.; Jung, M. Cellular Analysis of the Action of Epigenetic Drugs and Probes. Epigenetics 2017, 12, 308-322.

38 Robers, M. B.; Dart, M. L.; Woodroofe, C. C.; Zimprich, C. A.; Kirkland, T. A.; Machleidt, T.; Kupcho, K. R.; Levin, S.; Hartnett, J. R.; Zimmerman, K.; Niles, A. L.; Ohana, R. F.; Daniels, D. L.; Slater, M.; Wood, M. G.; Cong, M.; Cheng, Y.-Q.; Wood, K. V. Target Engagement and Drug Residence Time Can Be Observed in Living Cells with BRET. Nat. Commun. 2015, 6, 10091.

39 Jung, M.; Hoffmann, K.; Brosch, G.; Loidl, P. Analogues of Trichostatin A and Trapoxin B as Histone Deacetylase Inhibitors. Bioorg. Med. Chem. Lett. 1997, 7, 16551658.

40 Yoshida, M.; Kijima, M.; Akita, M.; Beppu, T. Potent and Specific Inhibition of Mammalian Histone Deacetylase Both in Vivo and in Vitro by Trichostatin A. J. Biol. Chem. 1990, 265, 17174-17179. 
41 Jing, Q.; Hu, X.; Ma, Y.; Mu, J.; Liu, W.; Xu, F.; Li, Z.; Bai, J.; Hua, H.; Li, D. MarineDerived Natural Lead Compound Disulfide-Linked Dimer Psammaplin A: Biological Activity and Structural Modification. Marine Drugs 2019, 17, 384.

42 Ganesan, A. Romidepsin and the Zinc-binding Thiol Family of Natural Product HDAC Inhibitors. In Successful Drug Discovery, Vol 2, Fischer, J.; Childers, W. E., Eds.; WileyVCH: Weinheim, 2016; pp 13-20.

43 Ganesan, A. Macrocyclic Inhibitors of Zinc-dependent Histone Deacetylases (HDACs). In Macrocycles in Drug Discovery, Levin, J., Ed.; RSC: Cambridge, 2015; pp 109-140.

${ }^{44}$ Wen, S.; Carey, K. L.; Nakao, Y.; Fusetani, N.; Packham, G.; Ganesan, A. Total Synthesis of Azumamide $A$ and Azumamide E, Evaluation as Histone Deacetylase Inhibitors, and Design of a More Potent Analogue. Org. Lett. 2007, 9, 1105-1108.

45 Porter, N. J.; Christianson, D. W. ACS Chem. Biol. 2017, 12, 2281-2286.

46 Halsall, J. A.; Turner, B. M. Histone Deacetylase Inhibitors for Cancer Therapy: An Evolutionarily Ancient Resistance Response May Explain Their Limited Success. BioEssays 2016, 38, 1102-1110.

47 Marks, P. A.; Breslow, R. Dimethyl Sulfoxide to Vorinostat: Development of This Histone Deacetylase Inhibitor as an Anticancer Drug. Nat. Biotechnol. 2007, 25, 84-90. 48 Ono, H.; Sowa, Y.; Horinaka, M.; lizumi, Y.; Watanabe, M.; Morita, M.; Nishimoto, E.; Taguchi, T.; Sakai, T. The Histone Deacetylase Inhibitor OBP-801 and Eribulin Synergistically Inhibit the Growth of Triple-Negative Breast Cancer Cells with the Suppression of Survivin, Bcl-XL, and the MAPK Pathway. Breast Cancer Res. Treat. 2018, 171, 43-52.

49 Ossenkoppele, G. J.; Lowenberg, B.; Zachee, P.; Vey, N.; Breems, D.; Loosdrecht, A. A. V. de; Davidson, A. H.; Wells, G.; Needham, L.; Bawden, L.; Toal, M.; Hooftman, L.; Debnam, P. M. A Phase I First-in-Human Study with Tefinostat - a Monocyte/Macrophage Targeted Histone Deacetylase Inhibitor - in Patients with Advanced Haematological Malignancies. Br. J. Haematol. 2013, 162, 191-201. 
50 Jung, D. E.; Park, S. B.; Kim, K.; Kim, C.; Song, S. Y. CG200745, an HDAC Inhibitor, Induces Anti-Tumour Effects in Cholangiocarcinoma Cell Lines via miRNAs Targeting the Hippo Pathway. Sci. Rep. 2017, 7, 10921.

51 Santo, L.; Hideshima, T.; Kung, A. L.; Tseng, J.-C.; Tamang, D.; Yang, M.; Jarpe, M.; van Duzer, J. H.; Mazitschek, R.; Ogier, W. C.; Cirstea, D.; Rodig, S.; Eda, H.; Scullen, T.; Canavese, M.; Bradner, J.; Anderson, K. C.; Jones, S. S.; Raje, N. Preclinical Activity, Pharmacodynamic, and Pharmacokinetic Properties of a Selective HDAC6 Inhibitor, ACY-1215, in Combination with Bortezomib in Multiple Myeloma. Blood 2012, 119, 2579-2589.

52 Huang, P.; Almeciga-Pinto, I.; Jarpe, M.; van Duzer, J. H.; Mazitschek, R.; Yang, M.; Jones, S. S.; Quayle, S. N. Selective HDAC Inhibition by ACY-241 Enhances the Activity of Paclitaxel in Solid Tumor Models. Oncotarget 2017, 8, 2694-2707.

${ }^{53}$ Cai, X.; Zhai, H.-X.; Wang, J.; Forrester, J.; Qu, H.; Yin, L.; Lai, C.-J.; Bao, R.; Qian, C. Discovery of 7-(4-(3-Ethynylphenylamino)-7-methoxyquinazolin-6-yloxy)- $N$ hydroxyheptanamide (CUDC-101) as a Potent Multi-Acting HDAC, EGFR, and HER2 Inhibitor for the Treatment of Cancer. J. Med. Chem. 2010, 53, 2000-2009.

54 Mehrling, T.; Chen, Y. The Alkylating-HDAC Inhibition Fusion Principle: Taking Chemotherapy to the Next Level with the First in Class Molecule EDO-S101. Anticancer Agents Med. Chem. 2016, 16, 20-28.

55 Bertrand, P. Inside HDAC with HDAC Inhibitors. Eur. J. Med. Chem. 2010, 45, 20952116.

56 Finn, P. W.; Loza, E.; Carstensen, E. The Discovery and Development of Belinostat. In Successful Drug Discovery, Vol 2, Fischer, J.; Childers, W. E., Eds.; Wiley-VCH: Weinheim, 2016; pp 31-58.

57 Atadja, P.; Perez, L. Discovery and Development of Farydak (NVP-LBH589, Panobinostat) as an Anticancer Drug. In Successful Drug Discovery, Vol 2, Fischer, J.; Childers, W. E., Eds.; Wiley-VCH: Weinheim, 2016; pp 59-88. 
58 Mandl-Weber, S.; Meinel, F. G.; Jankowsky, R.; Oduncu, F.; Schmidmaier, R.; Baumann, P. The Novel Inhibitor of Histone Deacetylase Resminostat (RAS2410) Inhibits Proliferation and Induces Apoptosis in Multiple Myeloma (MM) Cells. Br. J. Haematol. 2010, 149, 518-528.

59 Wang, H.; Yu, N.; Chen, D.; Lee, K. C. L.; Lye, P. L.; Chang, J. W. W.; Deng, W.; Ng, M. C. Y.; Lu, T.; Khoo, M. L.; Poulsen, A.; Sangthongpitag, K.; Wu, X.; Hu, C.; Goh, K. C.; Wang, X.; Fang, L.; Goh, K. L.; Khng, H. H.; Goh, S. K.; Yeo, P.; Liu, X.; Bonday, Z.; Wood, J. M.; Dymock, B. W.; Kantharaj, E.; Sun, E. T. Discovery of (2E)-3-\{2-Butyl-1-[2(diethylamino)ethyl]-1H-benzimidazol-5-yl\}-N-hydroxyacrylamide (SB939), an Orally Active Histone Deacetylase Inhibitor with a Superior Preclinical Profile. J. Med. Chem. 2011, 54, 4694-4720.

60 Matalon, S.; Palmer, B. E.; Nold, M. F.; Furlan, A.; Kassu, A.; Fossati, G.; Mascagni, P.; Dinarello, C. A. The Histone Deacetylase Inhibitor ITF2357 Decreases Surface CXCR4 and CCR5 Expression on CD4(+) T-Cells and Monocytes and Is Superior to Valproic Acid for Latent HIV-1 Expression in Vitro. J. Acquir. Immune Defic. Syndr. 2010, 54, 1-9.

61 Buggy, J. J.; Cao, Z. A.; Bass, K. E.; Verner, E.; Balasubramanian, S.; Liu, L.; Schultz, B. E.; Young, P. R.; Dalrymple, S. A. CRA-024781: A Novel Synthetic Inhibitor of Histone Deacetylase Enzymes with Antitumor Activity in Vitro and in Vivo. Mol. Cancer Ther. 2006, 5, 1309-1317.

62 Lu, Q.; Wang, D.-S.; Chen, C.-S.; Hu, Y.-D.; Chen, C.-S. Structure-Based Optimization of Phenylbutyrate-Derived Histone Deacetylase Inhibitors. J. Med. Chem. 2005, 48, 5530-5535.

${ }^{63}$ Zhang, S.-W.; Gong, C.-J.; Su, M.-B.; Chen, F.; He, T.; Zhang, Y.-M.; Shen, Q.-Q.; Su, Y.; Ding, J.; Li, J.; Chen, Y.; Nan, F.-J. Synthesis and in Vitro and in Vivo Biological Evaluation of Tissue-Specific Bisthiazole Histone Deacetylase (HDAC) Inhibitors. J. Med. Chem. 2020, 63, 804-815. 
${ }^{64}$ Arts, J.; King, P.; Mariën, A.; Floren, W.; Beliën, A.; Janssen, L.; Pilatte, I.; Roux, B.; Decrane, L.; Gilissen, R.; Hickson, I.; Vreys, V.; Cox, E.; Bol, K.; Talloen, W.; Goris, I.; Andries, L.; Du Jardin, M.; Janicot, M.; Page, M.; van Emelen, K.; Angibaud, P. JNJ26481585, a Novel "Second-Generation" Oral Histone Deacetylase Inhibitor, Shows Broad-Spectrum Preclinical Antitumoral Activity. Clin. Cancer Res. 2009, 15, 68416851.

65 Moffat, D.; Patel, S.; Day, F.; Belfield, A.; Donald, A.; Rowlands, M.; Wibawa, J.; Brotherton, D.; Stimson, L.; Clark, V.; Owen, J.; Bawden, L.; Box, G.; Bone, E.; Mortenson, P.; Hardcastle, A.; van Meurs, S.; Eccles, S.; Raynaud, F.; Aherne, W. Discovery of 2-(6-\{[(6-Fluoroquinolin-2-yl)methyl]amino\}bicyclo[3.1.0]hex-3-yl)- $N$ hydroxypyrimidine-5-carboxamide (CHR-3996), a Class I Selective Orally Active Histone Deacetylase Inhibitor. J. Med. Chem. 2010, 53, 8663-8678.

66 Qian, C.; Lai, C.-J.; Bao, R.; Wang, D.-G.; Wang, J.; Xu, G.-X.; Atoyan, R.; Qu, H.; Yin, L.; Samson, M.; Zifcak, B.; Ma, A. W. S.; DellaRocca, S.; Borek, M.; Zhai, H.-X.; Cai, X.; Voi, M. Cancer Network Disruption by a Single Molecule Inhibitor Targeting Both Histone Deacetylase Activity and Phosphatidylinositol 3-Kinase Signaling. Clin. Cancer Res. 2012, 18, 4104-4113.

67 Hong, J.; Luesch, H. Largazole: From Discovery to Broad-Spectrum Therapy. Nat. Prod. Rep. 2012, 29, 449-456.

68 Chou, C. J.; Herman, D.; Gottesfeld, J. M. Pimelic Diphenylamide 106 is a Slow, Tight-binding Inhibitor of Class I Histone Deacetylases. J. Biol. Chem. 2008, 283, 35402-35409.

${ }^{69}$ Moradei, O. M.; Mallais, T. C.; Frechette, S.; Paquin, I.; Tessier, P. E.; Leit, S. M.; Fournel, M.; Bonfils, C.; Trachy-Bourget, M.-C.; Liu, J.; Yan, T. P.; Lu, A.-H.; Rahil, J.; Wang, J.; Lefebvre, S.; Li, Z.; Vaisburg, A. F.; Besterman, J. M. Novel Aminophenyl Benzamide-Type Histone Deacetylase Inhibitors with Enhanced Potency and Selectivity. J. Med. Chem. 2007, 50, 5543-5546. 
70 Khan, N.; Jeffers, M.; Kumar, S.; Hackett, C.; Boldog, F.; Khramtsov, N.; Qian, X.; Mills, E.; Berghs, S. C.; Carey, N.; Finn, P. W.; Collins, L. S.; Tumber, A.; Ritchie, J. W.; Jensen, P. B.; Lichenstein, H. S.; Sehested, M. Determination of the Class and Isoform Selectivity of Small-Molecule Histone Deacetylase Inhibitors. Biochem. J. 2008, 409, 581-589.

${ }^{71}$ Fournel, M.; Bonfils, C.; Hou, Y.; Yan, P. T.; Trachy-Bourget, M.-C.; Kalita, A.; Liu, J.; Lu, A.-H.; Zhou, N. Z.; Robert, M.-F.; Gillespie, J.; Wang, J. J.; Ste-Croix, H.; Rahil, J.; Lefebvre, S.; Moradei, O.; Delorme, D.; Macleod, A. R.; Besterman, J. M.; Li, Z. MGCD0103, a Novel Isotype-Selective Histone Deacetylase Inhibitor, Has Broad Spectrum Antitumor Activity in Vitro and in Vivo. Mol. Cancer Ther. 2008, 7, 759-768.

72 Lu, X.; Ning, Z.; Li, Z.; Cao, H.; Wang, X. Development of Chidamide for Peripheral TCell Lymphoma, the First Orphan Drug Approved in China. Intractable Rare Dis. Res. 2016, 5, 185-191.

73 Bretz, A. C.; Parnitzke, U.; Kronthaler, K.; Dreker, T.; Bartz, R.; Hermann, F.; Ammendola, A.; Wulff, T.; Hamm, S. Domatinostat Favors the Immunotherapy Response by Modulating the Tumor Immune Microenvironment (TIME). J. Immunother. Cancer 2019, 7, 294.

${ }^{74}$ Eyre, T. A.; Collins, G. P.; Gupta, A.; Coupe, N.; Sheikh, S.; Whittaker, J.; Wang, L. M.; Campo, L.; Soilleux, E.; Tysoe, F.; Cousins, R.; La Thangue, N.; Folkes, L. K.; Stratford, M. R. L.; Kerr, D.; Middleton, M. R. A Phase 1 Study to Assess the Safety, Tolerability, and Pharmacokinetics of CXD101 in Patients with Advanced Cancer. Cancer 2019, 125, 99-108.

75 Seval, G. C.; Beksac, M. A Comparative Safety Review of Histone Deacetylase Inhibitors for the Treatment of Myeloma. Expert Opin. Drug Saf. 2019, 18, 563-571.

76 Duvic, M.; Dimopoulos, M. The Safety Profile of Vorinostat (Suberoylanilide Hydroxamic Acid) in Hematologic Malignancies: A Review of Clinical Studies. Cancer Treatment Rev. 2016, 43, 58-66. 
$77 \mathrm{Li}$, W.; Sun, Z. Mechanism of Action for HDAC Inhibitors-Insights from Omics Approaches. Int. J. Mol. Sci. 2019, 20, 1616.

78 Eckschlager, T.; Plch, J.; Stiborova, M.; Hrabeta, J. Histone Deacetylase Inhibitors as Anticancer Drugs. Int. J. Mol. Sci. 2017, 18, 1414.

79 Duvic, M. Histone Deacetylase Inhibitors for Cutaneous T-Cell Lymphoma. Dermatol. Clin. 2015, 33, 757-764.

80 Shah, R.R. Safety and Tolerability of Histone Deacetylase (HDAC) Inhibitors in Oncology. Drug Saf. 2019, 42, 235-245.

81 Flower, A.; Abla, O. Resistance to Histone Deacetylase Inhibitors in the Treatment of Lymphoma. In Resistance to Targeted Therapies in Lymphomas; Xavier, A. C., Cairo, M. S., Eds.; Resistance to Targeted Anti-Cancer Therapeutics; Springer: Cham, 2019; pp 87-110.

82 Yurek-George, A.; Cecil, A. R. L.; Mo, A. H. K.; Wen, S.; Rogers, H.; Habens, F.; Maeda, S.; Yoshida, M.; Packham, G.; Ganesan, A. The First Biologically Active Synthetic Analogues of FK228, the Depsipeptide Histone Deacetylase Inhibitor. J. Med. Chem. 2007, 50, 5720-5726.

${ }^{83}$ Zhang, Q.; Dai, Y.; Cai, Z.; Mou, L. HDAC Inhibitors: Novel Immunosuppressants for Allo- and Xeno- Transplantation. ChemistrySelect 2018, 3, 176-187.

84 Citraro, R.; Leo, A.; Santoro, M.; D'agostino, G.; Constanti, A.; Russo, E. Role of Histone Deacetylases (HDACs) in Epilepsy and Epileptogenesis. Curr. Pharm. Des. 2017, 23, 5546-5562.

${ }^{85} \mathrm{Lu}$, J.; Chatain, G. P.; Bugarini, A.; Wang, X.; Maric, D.; Walbridge, S.; Zhuang, Z.; Chittiboina, P. Histone Deacetylase Inhibitor SAHA Is a Promising Treatment of Cushing Disease. J. Clin. Endocrinol. Metab. 2017, 102, 2825-2835.

${ }^{86}$ Sandoná, M.; Consalvi, S.; Tucciarone, L.; Puri, P. L.; Saccone, V. HDAC Inhibitors for Muscular Dystrophies: Progress and Prospects. Expert Opin. Orphan Drugs 2016, 4, $125-127$. 
87 Wang, X.; Shen, X.; Xu, Y.; Xu, S.; Xia, F.; Zhu, B.; Liu, Y.; Wang, W.; Wu, H.; Wang, F. The Etiological Changes of Acetylation in Peripheral Nerve Injury-Induced Neuropathic Hypersensitivity. Mol. Pain 2018, 14, 1744806918798408.

88 Vogl, D. T.; Raje, N.; Jagannath, S.; Richardson, P.; Hari, P.; Orlowski, R.; Supko, J. G.; Tamang, D.; Yang, M.; Jones, S. S.; Wheeler, C.; Markelewicz, R. J.; Lonial, S. Ricolinostat, the First Selective Histone Deacetylase 6 Inhibitor, in Combination with Bortezomib and Dexamethasone for Relapsed or Refractory Multiple Myeloma. Clin. Cancer Res. 2017, 23, 3307-3315.

89 Suraweera, A.; O'Byrne, K. J.; Richard, D. J. Combination Therapy With Histone Deacetylase Inhibitors (HDACi) for the Treatment of Cancer: Achieving the Full Therapeutic Potential of HDACi. Front. Oncol. 2018, 8, 92.

90 Morel, D.; Jeffery, D.; Aspeslagh, S.; Almouzni, G.; Postel-Vinay, S. Combining Epigenetic Drugs with Other Therapies for Solid Tumours - Past Lessons and Future Promise. Nat. Rev. Clin. Oncol. 2020, 17, 91-107.

91 Abramson, H. N. The Multiple Myeloma Drug Pipeline-2018: A Review of Small Molecules and Their Therapeutic Targets. Clin. Lymphoma, Myeloma Leuk. 2018, 18, 611-627.

92 Aggarwal, R.; Thomas, S.; Pawlowska, N.; Bartelink, I.; Grabowsky, J.; Jahan, T.; Cripps, A.; Harb, A.; Leng, J.; Reinert, A.; Mastroserio, I.; Truong, T.-G.; Ryan, C. J.; Munster, P. N. Inhibiting Histone Deacetylase as a Means to Reverse Resistance to Angiogenesis Inhibitors: Phase I Study of Abexinostat Plus Pazopanib in Advanced Solid Tumor Malignancies. J. Clin. Oncol. 2017, 35, 1231-1239.

93 Yardley, D. A.; Ismail-Khan, R. R.; Melichar, B.; Lichinitser, M.; Munster, P. N.; Klein, P. M.; Cruickshank, S.; Miller, K. D.; Lee, M. J.; Trepel, J. B. Randomized Phase II, Double-Blind, Placebo-Controlled Study of Exemestane with or without Entinostat in Postmenopausal Women with Locally Recurrent or Metastatic Estrogen ReceptorPositive Breast Cancer Progressing on Treatment with a Nonsteroidal Aromatase Inhibitor. J. Clin. Oncol. 2013, 31, 2128-2135. 
94 Jiang, Z.; Li, W.; Hu, X.; Zhang, Q.; Sun, T.; Cui, S.; Wang, S.; Ouyang, Q.; Yin, Y.; Geng, C.; Tong, Z.; Cheng, Y.; Pan, Y.; Sun, Y.; Wang, H.; Ouyang, T.; Gu, K.; Feng, J.; Wang, X.; Wang, S.; Liu, T.; Gao, J.; Cristofanilli, M.; Ning, Z.; Lu, X. Tucidinostat plus Exemestane for Postmenopausal Patients with Advanced, Hormone ReceptorPositive Breast Cancer (ACE): A Randomised, Double-Blind, Placebo-Controlled, Phase 3 Trial. Lancet Oncol. 2019, 20, 806-815.

${ }^{95}$ Abaza, Y. M.; Kadia, T. M.; Jabbour, E. J.; Konopleva, M. Y.; Borthakur, G.; Ferrajoli, A.; Estrov, Z.; Wierda, W. G.; Alfonso, A.; Chong, T. H.; Chuah, C.; Koh, L.-P.; Goh, B.C.; Chang, J. E.; Durkes, D. E.; Foudray, M. C.; Kantarjian, H. M.; Dong, X. Q.; GarciaManero, G. Phase 1 Dose Escalation Multicenter Trial of Pracinostat Alone and in Combination with Azacitidine in Patients with Advanced Hematologic Malignancies. Cancer 2017, 123, 4851-4859.

96 Garcia-Manero, G.; Abaza, Y.; Takahashi, K.; Medeiros, B. C.; Arellano, M.; Khaled, S. K.; Patnaik, M.; Odenike, O.; Sayar, H.; Tummala, M.; Patel, P.; Maness-Harris, L.; Stuart, R.; Traer, E.; Karamlou, K.; Yacoub, A.; Ghalie, R.; Giorgino, R.; Atallah, E. Pracinostat plus Azacitidine in Older Patients with Newly Diagnosed Acute Myeloid Leukemia: Results of a Phase 2 Study. Blood Adv. 2019, 3, 508-518.

${ }^{97}$ Banik, D.; Moufarrij, S.; Villagra, A. Immunoepigenetics Combination Therapies: An Overview of the Role of HDACs in Cancer Immunotherapy. Int. J. Mol. Sci. 2019, 20, 2241.

98 Rosás-Umbert, M.; Ruiz-Riol, M.; Fernández, M. A.; Marszalek, M.; Coll, P.; Manzardo, C.; Cedeño, S.; Miró, J. M.; Clotet, B.; Hanke, T.; Moltó, J.; Mothe, B.; Brander, C.; BCN02 study group. In Vivo Effects of Romidepsin on T-Cell Activation, Apoptosis and Function in the BCN02 HIV-1 Kick\&Kill Clinical Trial. Front. Immunol. 2020, 11, 418.

${ }^{99}$ Ganesan, A. Multitarget Drugs: An Epigenetic Epiphany. ChemMedChem 2016, 11, $1227-1241$. 
100 de Lera, A. R.; Ganesan, A. Two-hit Wonders: The Expanding Universe of Multitargeting Epigenetic Agents. Curr. Opin. Chem. Biol. 2020, (in press). doi: 10.1016/j.cbpa.2020.05.009

101 Galloway, T. J.; Wirth, L. J.; Colevas, A. D.; Gilbert, J.; Bauman, J. E.; Saba, N. F.; Raben, D.; Mehra, R.; Ma, A. W.; Atoyan, R.; Wang, J.; Burtness, B.; Jimeno, A. A Phase I Study of CUDC-101, a Multitarget Inhibitor of HDACs, EGFR, and HER2, in Combination with Chemoradiation in Patients with Head and Neck Squamous Cell Carcinoma. Clin. Cancer Res. 2015, 21, 1566-1573.

102 Oki, Y.; Kelly, K. R.; Flinn, I.; Patel, M. R.; Gharavi, R.; Ma, A.; Parker, J.; Hafeez, A.; Tuck, D.; Younes, A. CUDC-907 in Relapsed/Refractory Diffuse Large B-Cell Lymphoma, Including Patients with MYC-Alterations: Results from an Expanded Phase I Trial. Haematologica 2017, 102, 1923-1930.

${ }^{103}$ Gunst, J. D.; Kjær, K.; Olesen, R.; Rasmussen, T. A.; Østergaard, L.; Denton, P. W.; Søgaard, O. S.; Tolstrup, M. Fimepinostat, a Novel Dual Inhibitor of HDAC and PI3K, Effectively Reverses HIV-1 Latency Ex Vivo without T Cell Activation. J. Virus Erad. 2019, 5, 133-137.

104 Wobser, M.; Weber, A.; Glunz, A.; Tauch, S.; Seitz, K.; Butelmann, T.; Hesbacher, S.; Goebeler, M.; Bartz, R.; Kohlhof, H.; Schrama, D.; Houben, R. Elucidating the Mechanism of Action of Domatinostat (4SC-202) in Cutaneous T Cell Lymphoma Cells. J. Hematol. Oncol. 2019, 12, 30.

105 Kitir, B.; Maolanon, A. R.; Ohm, R. G.; Colaço, A. R.; Fristrup, P.; Madsen, A. S.; Olsen, C. A. Chemical Editing of Macrocyclic Natural Products and Kinetic Profiling Reveal Slow, Tight-Binding Histone Deacetylase Inhibitors with Picomolar Affinities. Biochemistry 2017, 56, 5134-5146.

106 Whitehead, L.; Dobler, M. R.; Radetich, B.; Zhu, Y.; Atadja, P. W.; Claiborne, T.; Grob, J. E.; McRiner, A.; Pancost, M. R.; Patnaik, A.; Shao, W.; Shultz, M.; Tichkule, R.; Tommasi, R. A.; Vash, B.; Wang, P.; Stams, T. Human HDAC Isoform Selectivity 
Achieved via Exploitation of the Acetate Release Channel with Structurally Unique Small Molecule Inhibitors. Bioorg. Med. Chem. 2011, 19, 4626-4634.

107 Wagner, F. F.; Olson, D. E.; Gale, J. P.; Kaya, T.; Weïwer, M.; Aidoud, N.; Thomas, M.; Davoine, E. L.; Lemercier, B. C.; Zhang, Y.-L.; Holson, E. B. Potent and Selective Inhibition of Histone Deacetylase 6 (HDAC6) Does Not Require a Surface-Binding Motif. J. Med. Chem. 2013, 56, 1772-1776.

108 Wang, Y.; Stowe, R. L.; Pinello, C. E.; Tian, G.; Madoux, F.; Li, D.; Zhao, L. Y.; Li, J.L.; Wang, Y.; Wang, Y.; Ma, H.; Hodder, P.; Roush, W. R.; Liao, D. Identification of Histone Deacetylase Inhibitors with Benzoylhydrazide Scaffold That Selectively Inhibit Class I Histone Deacetylases. Chem. Biol.(Oxford, U. K.) 2015, 22, 273-284.

109 Meyners, C.; Wolff, B.; Kleinschek, A.; Krämer, A.; Meyer-Almes, F.-J. Perfluorinated Hydroxamic Acids Are Potent and Selective Inhibitors of HDAC-like Enzymes from Pseudomonas aeruginosa. Bioorg. Med. Chem. Lett. 2017, 27, 1508-1512.

110 Muth, M.; Jänsch, N.; Kopranovic, A.; Krämer, A.; Wössner, N.; Jung, M.; Kirschhöfer, F.; Brenner-Weiß, G.; Meyer-Almes, F.-J. Covalent Inhibition of Histone Deacetylase 8 by 3,4-Dihydro-2H-Pyrimido[1,2-c][1,3]Benzothiazin-6-Imine. Biochim. Biophys. Acta Gen. Subj. 2019, 1863, 577-585.

111 Isaacs, J. T.; Antony, L.; Dalrymple, S. L.; Brennen, W. N.; Gerber, S.; Hammers, H.; Wissing, M.; Kachhap, S.; Luo, J.; Xing, L.; Björk, P.; Olsson, A.; Björk, A.; Leanderson, T. Tasquinimod Is an Allosteric Modulator of HDAC4 Survival Signaling within the Compromised Cancer Microenvironment. Cancer Res. 2013, 73, 1386-1399.

112 Yang, D.; Xiao, C.; Long, F.; Su, Z.; Jia, W.; Qin, M.; Huang, M.; Wu, W.; Suguro, R.; Liu, X.; Zhu, Y. HDAC4 Regulates Vascular Inflammation via Activation of Autophagy. Cardiovasc. Res. 2018, 114, 1016-1028.

113 Zhao, C.; Dong, H.; Xu, Q.; Zhang, Y. Histone Deacetylase (HDAC) Inhibitors in Cancer: A Patent Review (2017-Present). Expert Opin. Ther. Pat. 2020, 30, 263-274. 
114 Shukla, S.; Tekwani, B. L. Histone Deacetylases Inhibitors in Neurodegenerative Diseases, Neuroprotection and Neuronal Differentiation. Front. Pharmacol. 2020, 11, 537.

115 Zwinderman, M. R. H.; de Weerd, S.; Dekker, F. J. Targeting HDAC Complexes in Asthma and COPD. Epigenomes 2019, 3, 19.

116 Ellmeier, W.; Seiser, C. Histone Deacetylase Function in CD4+ T Cells. Nat. Rev. Immunol. 2018, 18, 617-634.

117 Nijhawan, P.; Behl, T.; Khullar, G.; Pal, G.; Kandhwal, M.; Goyal, A. HDAC in Obesity: A Critical Insight. Obesity Med. 2020, 18, 100212.

118 Lyu, X.; Hu, M.; Peng, J.; Zhang, X.; Sanders, Y. Y. HDAC Inhibitors as Antifibrotic Drugs in Cardiac and Pulmonary Fibrosis. Ther. Adv. Chronic Dis. 2019, 10, 2040622319862697.

119 Bourguet, E.; Ozdarska, K.; Moroy, G.; Jeanblanc, J.; Naassila, M. Class I HDAC Inhibitors: Potential New Epigenetic Therapeutics for Alcohol Use Disorder (AUD). J. Med. Chem. 2018, 61, 1745-1766.

120 Methot, J. L.; Chakravarty, P. K.; Chenard, M.; Close, J.; Cruz, J. C.; Dahlberg, W. K.; Fleming, J.; Hamblett, C. L.; Hamill, J. E.; Harrington, P.; Harsch, A.; Heidebrecht, R.; Hughes, B.; Jung, J.; Kenific, C. M.; Kral, A. M.; Meinke, P. T.; Middleton, R. E.; Ozerova, N.; Sloman, D. L.; Stanton, M. G.; Szewczak, A. A.; Tyagarajan, S.; Witter, D. J.; Secrist, J. P.; Miller, T. A. Exploration of the Internal Cavity of Histone Deacetylase (HDAC) with Selective HDAC1/HDAC2 Inhibitors (SHI-1:2). Bioorg. Med. Chem. Lett. 2008, 18, 973-978.

121 Methot, J. L.; Hoffman, D. M.; Witter, D. J.; Stanton, M. G.; Harrington, P.; Hamblett, C.; Siliphaivanh, P.; Wilson, K.; Hubbs, J.; Heidebrecht, R.; Kral, A. M.; Ozerova, N.; Fleming, J. C.; Wang, H.; Szewczak, A. A.; Middleton, R. E.; Hughes, B.; Cruz, J. C.; Haines, B. B.; Chenard, M.; Kenific, C. M.; Harsch, A.; Secrist, J. P.; Miller, T. A. Delayed and Prolonged Histone Hyperacetylation with a Selective HDAC1/HDAC2 Inhibitor. ACS Med. Chem. Lett. 2014, 5, 340-345. 
122 Stubbs, M. C.; Kim, W.; Bariteau, M.; Davis, T.; Vempati, S.; Minehart, J.; Witkin, M.; Qi, J.; Krivtsov, A. V.; Bradner, J. E.; Kung, A. L.; Armstrong, S. A. Selective Inhibition of HDAC1 and HDAC2 as a Potential Therapeutic Option for B-ALL. Clin. Cancer Res. 2015, 21, 2348-2358.

${ }^{123}$ Min, C.; Moore, N.; Shearstone, J. R.; Quayle, S. N.; Huang, P.; van Duzer, J. H.; Jarpe, M. B.; Jones, S. S.; Yang, M. Selective Inhibitors of Histone Deacetylases 1 and 2 Synergize with Azacitidine in Acute Myeloid Leukemia. PLOS ONE 2017, 12, e0169128.

124 Vogelmann, A.; Robaa, D.; Sippl, W.; Jung, M. Proteolysis Targeting Chimeras (PROTACs) for Epigenetics Research. Curr. Opin. Chem. Biol. 2020, 57, 8-16.

125 Smalley, J. P.; Adams, G. E.; Millard, C. J.; Song, Y.; Norris, J. K. S.; Schwabe, J. W. R.; Cowley, S. M.; Hodgkinson, J. T. PROTAC-Mediated Degradation of Class I Histone Deacetylase Enzymes in Corepressor Complexes. Chem. Commun. 2020, 56, 4476-4479.

126 Penney, J.; Tsai, L.-H. Histone Deacetylases in Memory and Cognition. Sci. Signal. 2014, 7, re12.

127 Wagner, F. F.; Weïwer, M.; Steinbacher, S.; Schomburg, A.; Reinemer, P.; Gale, J. P.; Campbell, A. J.; Fisher, S. L.; Zhao, W.-N.; Reis, S. A.; Hennig, K. M.; Thomas, M.; Müller, P.; Jefson, M. R.; Fass, D. M.; Haggarty, S. J.; Zhang, Y.-L.; Holson, E. B. Kinetic and Structural Insights into the Binding of Histone Deacetylase 1 and 2 (HDAC1, 2) Inhibitors. Bioorg. Med. Chem. 2016, 24, 4008-4015.

128 Sarkar, R.; Banerjee, S.; Amin, S. A.; Adhikari, N.; Jha, T. Histone Deacetylase 3 (HDAC3) Inhibitors as Anticancer Agents: A Review. Eur. J. Med. Chem. 2020, 192, 112171.

129 Wagner, F. F.; Lundh, M.; Kaya, T.; McCarren, P.; Zhang, Y.-L.; Chattopadhyay, S.; Gale, J. P.; Galbo, T.; Fisher, S. L.; Meier, B. C.; Vetere, A.; Richardson, S.; Morgan, N. G.; Christensen, D. P.; Gilbert, T. J.; Hooker, J. M.; Leroy, M.; Walpita, D.; MandrupPoulsen, T.; Wagner, B. K.; Holson, E. B. An Isochemogenic Set of Inhibitors To Define 
the Therapeutic Potential of Histone Deacetylases in $\beta$-Cell Protection. ACS Chem. Biol. 2016, 11, 363-374.

130 Bresciani, A.; Ontoria, J. M.; Biancofiore, I.; Cellucci, A.; Ciammaichella, A.; Di Marco, A.; Ferrigno, F.; Francone, A.; Malancona, S.; Monteagudo, E.; Nizi, E.; Pace, P.; Ponzi, S.; Rossetti, I.; Veneziano, M.; Summa, V.; Harper, S. Improved Selective Class I HDAC and Novel Selective HDAC3 Inhibitors: Beyond Hydroxamic Acids and Benzamides. ACS Med. Chem. Lett. 2019, 10, 481-486.

131 Malvaez, M.; McQuown, S. C.; Rogge, G. A.; Astarabadi, M.; Jacques, V.; Carreiro, S.; Rusche, J. R.; Wood, M. A. HDAC3-Selective Inhibitor Enhances Extinction of Cocaine-Seeking Behavior in a Persistent Manner. Proc. Natl. Acad. Sci. U.S.A. 2013, 110, 2647-2652.

132 Bieszczad, K. M.; Bechay, K.; Rusche, J. R.; Jacques, V.; Kudugunti, S.; Miao, W.; Weinberger, N. M.; McGaugh, J. L.; Wood, M. A. Histone Deacetylase Inhibition via RGFP966 Releases the Brakes on Sensory Cortical Plasticity and the Specificity of Memory Formation. J. Neurosci. 2015, 35, 13124-13132.

133 Suelves, N.; Kirkham-McCarthy, L.; Lahue, R. S.; Ginés, S. A Selective Inhibitor of Histone Deacetylase 3 Prevents Cognitive Deficits and Suppresses Striatal CAG Repeat Expansions in Huntington's Disease Mice. Sci. Rep. 2017, 7, 6082.

134 Janczura, K. J.; Volmar, C.-H.; Sartor, G. C.; Rao, S. J.; Ricciardi, N. R.; Lambert, G.; Brothers, S. P.; Wahlestedt, C. Inhibition of HDAC3 Reverses Alzheimer's DiseaseRelated Pathologies in Vitro and in the 3xTg-AD Mouse Model. Proc. Natl. Acad. Sci. U.S.A. 2018, 115, E11148-E11157.

135 Zhang, M.-J.; Zhao, Q.-C.; Xia, M.-X.; Chen, J.; Chen, Y.-T.; Cao, X.; Liu, Y.; Yuan, Z.-Q.; Wang, X.-Y.; Xu, Y. The HDAC3 Inhibitor RGFP966 Ameliorated Ischemic Brain Damage by Downregulating the AIM2 Inflammasome. FASEB J. 2020, 34, 648-662.

136 Liao, J.; Jiang, J.; Jun, H.; Qiao, X.; Emont, M. P.; Kim, D.-I.; Wu, J. HDAC3Selective Inhibition Activates Brown and Beige Fat Through PRDM16. Endocrinology 2018, 159, 2520-2527. 
137 Barton, K. M.; Archin, N. M.; Keedy, K. S.; Espeseth, A. S.; Zhang, Y.; Gale, J.; Wagner, F. F.; Holson, E. B.; Margolis, D. M. Selective HDAC Inhibition for the Disruption of Latent HIV-1 Infection. PLOS ONE 2014, 9, e102684.

138 Dirice, E.; Ng, R. W. S.; Martinez, R.; Hu, J.; Wagner, F. F.; Holson, E. B.; Wagner, B. K.; Kulkarni, R. N. Isoform-Selective Inhibitor of Histone Deacetylase 3 (HDAC3) Limits Pancreatic Islet Infiltration and Protects Female Nonobese Diabetic Mice from Diabetes. J. Biol. Chem. 2017, 292, 17598-17608.

139 Fukada, M.; Nakayama, A.; Mamiya, T.; Yao, T.-P.; Kawaguchi, Y. Dopaminergic Abnormalities in Hdac6-Deficient Mice. Neuropharmacology 2016, 110, 470-479.

140 Butler, K. V.; Kalin, J.; Brochier, C.; Vistoli, G.; Langley, B.; Kozikowski, A. P. Rational Design and Simple Chemistry Yield a Superior, Neuroprotective HDAC6 Inhibitor, Tubastatin A. J. Am. Chem. Soc. 2010, 132, 10842-10846.

141 Kozikowski, A. P.; Shen, S.; Pardo, M.; Tavares, M. T.; Szarics, D.; Benoy, V.; Zimprich, C. A.; Kutil, Z.; Zhang, G.; Bařinka, C.; Robers, M. B.; Van Den Bosch, L.; Eubanks, J. H.; Jope, R. S. Brain Penetrable Histone Deacetylase 6 Inhibitor SW-100 Ameliorates Memory and Learning Impairments in a Mouse Model of Fragile $X$ Syndrome. ACS Chem. Neurosci. 2019, 10, 1679-1695.

142 Lee, H.-Y.; Nepali, K.; Huang, F.-I.; Chang, C.-Y.; Lai, M.-J.; Li, Y.-H.; Huang, H.-L.; Yang, C.-R.; Liou, J.-P. (N-Hydroxycarbonylbenylamino)Quinolines as Selective Histone Deacetylase 6 Inhibitors Suppress Growth of Multiple Myeloma in Vitro and in Vivo. J. Med. Chem. 2018, 61, 905-917.

143 Krukowski, K.; Ma, J.; Golonzhka, O.; Laumet, G. O.; Gutti, T.; van Duzer, J. H.; Mazitschek, R.; Jarpe, M. B.; Heijnen, C. J.; Kavelaars, A. HDAC6 Inhibition Effectively Reverses Chemotherapy-Induced Peripheral Neuropathy. Pain 2017, 158, 1126-1137. 144 Yang, K.; Song, Y.; Xie, H.; Wu, H.; Wu, Y-T.; Leisten, E. D.; Tang, W. Development of the First Small Molecule Histone Deacetylase 6 (HDAC6) Degraders. Bioorg. Med. Chem. Lett. 2018, 28, 2493-2497. 
145 Wu, H.; Yang, K.; Zhang, Z.; Leisten, E. D.; Li, Z.; Xie, H.; Liu, J.; Smith, K. A.; Novakova, Z.; Barinka, C.; Tang, W. Development of Multifunctional Histone Deacetylase 6 Degraders with Potent Antimyeloma Activity. J. Med. Chem. 2019, 62, 7042-7057.

146 Osko, J. D.; Christianson, D. W. Structural Determinants of Affinity and Selectivity in the Binding of Inhibitors to Histone Deacetylase 6. Bioorg. Med. Chem. Lett. 2020, 30, 127023.

147 Li, T.; Zhang, C.; Hassan, S.; Liu, X.; Song, F.; Chen, K.; Zhang, W.; Yang, J. Histone Deacetylase 6 in Cancer. J. Hematol. Oncol. 2018, 11, 111.

148 Shen, S.; Kozikowski, A. P. A Patent Review of Histone Deacetylase 6 Inhibitors in Neurodegenerative Diseases (2014-2019). Expert Opin. Ther. Pat. 2020, 30, 121-136. 149 Brindisi, M.; Saraswati, A. P.; Brogi, S.; Gemma, S.; Butini, S.; Campiani, G. Old but Gold: Tracking the New Guise of Histone Deacetylase 6 (HDAC6) Enzyme as a Biomarker and Therapeutic Target in Rare Diseases. J. Med. Chem. 2020, 63, 23-39. 150 Banerjee, S.; Adhikari, N.; Amin, S. A.; Jha, T. Histone Deacetylase 8 (HDAC8) and Its Inhibitors with Selectivity to Other Isoforms: An Overview. Eur. J. Med. Chem. 2019, 164, 214-240.

151 Balasubramanian, S.; Ramos, J.; Luo, W.; Sirisawad, M.; Verner, E.; Buggy, J. J. A Novel Histone Deacetylase 8 (HDAC8)-Specific Inhibitor PCI-34051 Induces Apoptosis in T-Cell Lymphomas. Leukemia 2008, 22, 1026-1034.

152 Huang, W.-J.; Wang, Y.-C.; Chao, S.-W.; Yang, C.-Y.; Chen, L.-C.; Lin, M.-H.; Hou, W.-C.; Chen, M.-Y.; Lee, T.-L.; Yang, P.; Chang, C.-I. Synthesis and Biological Evaluation of ortho-Aryl $\mathrm{N}$-Hydroxycinnamides as Potent Histone Deacetylase (HDAC) 8 Isoform-Selective Inhibitors. ChemMedChem 2012, 7, 1815-1824.

153 Ingham, O. J.; Paranal, R. M.; Smith, W. B.; Escobar, R. A.; Yueh, H.; Snyder, T.; Porco, J. A.; Bradner, J. E.; Beeler, A. B. Development of a Potent and Selective HDAC8 Inhibitor. ACS Med. Chem. Lett. 2016, 7, 929-932. 
${ }^{154}$ Rettig, I.; Koeneke, E.; Trippel, F.; Mueller, W. C.; Burhenne, J.; Kopp-Schneider, A.; Fabian, J.; Schober, A.; Fernekorn, U.; von Deimling, A.; Deubzer, H. E.; Milde, T.; Witt, O.; Oehme, I. Selective Inhibition of HDAC8 Decreases Neuroblastoma Growth in Vitro and in Vivo and Enhances Retinoic Acid-Mediated Differentiation. Cell Death Dis. 2015, $6, \mathrm{e} 1657$.

155 Kee, H. J.; Ryu, Y.; Seok, Y. M.; Choi, S. Y.; Sun, S.; Kim, G. R.; Jeong, M. H. Selective Inhibition of Histone Deacetylase 8 Improves Vascular Hypertrophy, Relaxation, and Inflammation in Angiotensin II Hypertensive Mice. Clin. Hypertens. 2019, 25, 13.

156 Lin, F.-L.; Yen, J.-L.; Kuo, Y.-C.; Kang, J.-J.; Cheng, Y.-W.; Huang, W.-J.; Hsiao, G. HADC8 Inhibitor WK2-16 Therapeutically Targets Lipopolysaccharide-Induced Mouse Model of Neuroinflammation and Microglial Activation. Int. J. Mol. Sci. 2019, $20,410$.

157 Li, M.-L.; Su, X.-M.; Ren, Y.; Zhao, X.; Kong, L.-F.; Kang, J. HDAC8 Inhibitor Attenuates Airway Responses to Antigen Stimulus through Synchronously Suppressing Galectin-3 Expression and Reducing Macrophage-2 Polarization. Respir. Res. 2020, 21, 62.

158 Emmons, M. F.; Faião-Flores, F.; Sharma, R.; Thapa, R.; Messina, J. L.; Becker, J. C.; Schadendorf, D.; Seto, E.; Sondak, V. K.; Koomen, J. M.; Chen, Y. A.; Lau, E. K.; Wan, L.; Licht, J. D.; Smalley, K. S. M. HDAC8 Regulates a Stress Response Pathway in Melanoma to Mediate Escape from BRAF Inhibitor Therapy. Cancer Res. 2019, 79, 2947-2961.

159 Martin, M. W.; Lee, J. Y.; Lancia, D. R.; Ng, P. Y.; Han, B.; Thomason, J. R.; Lynes, M. S.; Marshall, C. G.; Conti, C.; Collis, A.; Morales, M. A.; Doshi, K.; Rudnitskaya, A.; Yao, L.; Zheng, X. Discovery of Novel $\mathrm{N}$-Hydroxy-2-Arylisoindoline-4-Carboxamides as Potent and Selective Inhibitors of HDAC11. Bioorg. Med. Chem. Lett. 2018, 28, 21432147.

160 Son, S. I.; Cao, J.; Zhu, C.-L.; Miller, S. P.; Lin, H. Activity-Guided Design of HDAC11-Specific Inhibitors. ACS Chem. Biol. 2019, 14, 1393-1397. 
161 Géraldy, M.; Morgen, M.; Sehr, P.; Steimbach, R. R.; Moi, D.; Ridinger, J.; Oehme, I.; Witt, O.; Malz, M.; Nogueira, M. S.; Koch, O.; Gunkel, N.; Miller, A. K. Selective Inhibition of Histone Deacetylase 10: Hydrogen Bonding to the Gatekeeper Residue Is Implicated. J. Med. Chem. 2019, 62, 4426-4443.

162 Herbst-Gervasoni, C. J.; Christianson, D. W. Binding of $N^{\beta}$-Acetylspermidine Analogues to Histone Deacetylase 10 Reveals Molecular Strategies for Blocking Polyamine Deacetylation. Biochemistry 2019, 58, 4957-4969.

163 Lobera, M.; Madauss, K. P.; Pohlhaus, D. T.; Wright, Q. G.; Trocha, M.; Schmidt, D. R.; Baloglu, E.; Trump, R. P.; Head, M. S.; Hofmann, G. A.; Murray-Thompson, M.; Schwartz, B.; Chakravorty, S.; Wu, Z.; Mander, P. K.; Kruidenier, L.; Reid, R. A.; Burkhart, W.; Turunen, B. J.; Rong, J. X.; Wagner, C.; Moyer, M. B.; Wells, C.; Hong, X.; Moore, J. T.; Williams, J. D.; Soler, D.; Ghosh, S.; Nolan, M. A. Selective Class Ila Histone Deacetylase Inhibition via a Nonchelating Zinc-Binding Group. Nat. Chem. Biol. 2013, 9, 319-325.

164 Sofer, A.; Lee, S.; Papangeli, I.; Adachi, T.; Hwangbo, C.; Comhair, S.; DaSilvaJardine, P.; Kim, J.; Schwarz, J. J.; Erzurum, S. C.; Chun, H. J. Therapeutic Engagement of the Histone Deacetylase IIA-Myocyte Enhancer Factor 2 Axis Improves Experimental Pulmonary Hypertension. Am. J. Respir. Crit. Care Med. 2018, 198, 13451348.

165 Su, L.; Liang, D.; Kuang, S.-Y.; Dong, Q.; Han, X.; Wang, Z. Neuroprotective Mechanism of TMP269, a Selective Class IIA Histone Deacetylase Inhibitor, after Cerebral Ischemia/Reperfusion Injury. Neural Regen. Res. 2020, 15, 277-284.

166 Moreira, J. D.; Koch, B. E. V.; van Veen, S.; Walburg, K. V.; Vrieling, F.; Mara Pinto Dabés Guimarães, T.; Meijer, A. H.; Spaink, H. P.; Ottenhoff, T. H. M.; Haks, M. C.; Heemskerk, M. T. Functional Inhibition of Host Histone Deacetylases (HDACs) Enhances in Vitro and in Vivo Anti-Mycobacterial Activity in Human Macrophages and in Zebrafish. Front. Immunol. 2020, 11, 36. 
167 Luckhurst, C. A.; Breccia, P.; Stott, A. J.; Aziz, O.; Birch, H. L.; Bürli, R. W.; Hughes, S. J.; Jarvis, R. E.; Lamers, M.; Leonard, P. M.; Matthews, K. L.; McAllister, G.; Pollack, S.; Saville-Stones, E.; Wishart, G.; Yates, D.; Dominguez, C. Potent, Selective, and CNS-Penetrant Tetrasubstituted Cyclopropane Class Ila Histone Deacetylase (HDAC) Inhibitors. ACS Med. Chem. Lett. 2016, 7, 34-39.

168 Luckhurst, C. A.; Aziz, O.; Beaumont, V.; Bürli, R. W.; Breccia, P.; Maillard, M. C.; Haughan, A. F.; Lamers, M.; Leonard, P.; Matthews, K. L.; Raphy, G.; Stott, A. J.; Munoz-Sanjuan, I.; Thomas, B.; Wall, M.; Wishart, G.; Yates, D.; Dominguez, C. Development and Characterization of a CNS-Penetrant Benzhydryl Hydroxamic Acid Class Ila Histone Deacetylase Inhibitor. Bioorg. Med. Chem. Lett. 2019, 29, 83-88. 
